Illinois State University

ISU ReD: Research and eData

Theses and Dissertations

$12-2-2013$

\title{
Implementing Nclb: A Case Study In Local Urban School Leadership And School Improvement
}

Michael James Chinino

Illinois State University, mchinino@aol.com

Follow this and additional works at: https://ir.library.illinoisstate.edu/etd

Part of the Educational Administration and Supervision Commons

\section{Recommended Citation}

Chinino, Michael James, "Implementing Nclb: A Case Study In Local Urban School Leadership And School Improvement" (2013). Theses and Dissertations. 28.

https://ir.library.illinoisstate.edu/etd/28

This Dissertation is brought to you for free and open access by ISU ReD: Research and eData. It has been accepted for inclusion in Theses and Dissertations by an authorized administrator of ISU ReD: Research and eData. For more information, please contact ISUReD@ilstu.edu. 


\section{IMPLEMENTING NCLB: A CASE STUDY IN LOCAL URBAN SCHOOL LEADERSHIP AND SCHOOL IMPROVEMENT}

\section{Michael J. Chinino}

168 Pages

May 2010

This qualitative study investigated two urban junior high schools that are implementing the mandates of No Child Left Behind. The study addresses the critical issues of building organizational capacity to determine the extent to which two schools utilized five key components of Paul Kimmelman's knowledge framework to support the school improvement process. First, local leaders must collect and analyze both formative and summative student data. Second, a knowledge management system for both formative and summative data must be developed to identify achievement gaps and trends for various student populations. Third, a systematic search must be conducted to identify the best instructional practices that meet the standards of scientific scrutiny. Fourth, district and school leaders must creative learning teams to generate needed local knowledge about student learning results and appropriate instructional strategies to advance curricular goals. Fifth, professional development opportunities are made available to teachers to work individually and collectively on the crucial tasks of knowledge acquisition, management, and implementation.

A comparative study of the two schools examined systematically each of the five core tasks of the knowledge framework. While the two schools are similar in size, 
educational level of staff, and demographic characteristics of the student population, the district and school leaders diverge on crucial organizational strategies to implement NCLB. In one school most of the work of knowledge acquisition and management is directed from the district office and carried out by teachers who work as solo practitioners in their classrooms. In the other school, considerable time and effort has been dedicated to developing teacher teams that are responsible for examining student performance data and developing appropriate instructional strategies to advance student learning The first school continues to face challenges in coordinating knowledge tasks at three levels: district, school, and classroom. The other school has made major changes to develop a more systemic approach to the school improvement process. 


\title{
IMPLEMENTING NCLB: A CASE STUDY IN LOCAL URBAN \\ SCHOOL LEADERSHIP AND SCHOOL IMPROVEMENT
}

MICHAEL J. CHININO

\author{
A Dissertation Submitted in Partial \\ Fulfillment of the Requirements \\ for the Degree of \\ DOCTOR OF EDUCATION \\ Department of Educational Administration and Foundations \\ ILLINOIS STATE UNIVERSITY
}


IMPLEMENTING NCLB: A CASE STUDY IN LOCAL URBAN

SCHOOL LEADERSHIP AND SCHOOL IMPROVEMENT

MICHAEL J. CHININO

DISSERTATION APPROVED:

\begin{tabular}{lc}
\hline Date & Paul Baker, Chair \\
\hline Date & Joseph Pacha \\
\hline Date & Neil Sappington \\
\hline Date & Albert Azinger
\end{tabular}




\section{ACKNOWLEDGMENTS}

To my dissertation advisor, Dr. Paul J. Baker, who trusted in my intellectual capacity. Dr. Baker's continued encouragement and guidance throughout this scholarly writing contributed to my development as an administrator. Preparing the final dissertation was a huge task, but with Dr. Baker's talent, accuracy, and help, the final paper came together with such clarity. I deeply appreciate Dr. Baker's incredible ability to take everything in the roughest of form and make it all work. He is truly a master at what he does. Thank you.

It is a pleasure to acknowledge a group of professors who worked with me, influenced my writing, and contributed to this dissertation. Dr. Al Azinger, Dr. Patricia Klass, Dr. Joseph Pacha, and Dr. Neil Sappington, thank you for reading the original proposal and your invaluable comments on how to improve this dissertation. Thank you all for your vision, your encouragement, your commitment, and your heartfelt actions. Without your support, I could not have done what I was able to do.

To Pat McCarney, for all that you have done to make my life easier. Your enthusiasm in the midst of hundreds of details made this dream come true.

To my deceased parents, Major Eugene R. Chinino and Cpl. Anne E. Chinino, they both left this world peacefully and always knew in their heart that this day would arrive. They gave me the strength and wisdom to be sincere in my work. 
To my deceased brother Sgt. Anthony G. Chinino, who proudly served in the Viet Nam War so others and I could enjoy freedom and follow the American Dream. He was filled with compassion, respect, brotherhood and love: thanks bro.

To my two daughters, Gina Rose and Angela Mary, who taught me many lessons in parenting during the dissertation years.

Finally, to my wife Sheila, who gave me the time and space I needed to follow my passion and complete what must have seemed like an endless task.

M. J. C. 
CONTENTS

Page

ACKNOWLEDGMENTS $\quad$ i

CONTENTS

TABLES vii

FIGURES viii

CHAPTER

I. BACKGROUND AND STATEMENT OF THE PROBLEM

\begin{tabular}{lr} 
Overview & 2 \\
\hline
\end{tabular}

Problem Statement $\quad 9$

$\begin{array}{lr}\text { Implementing No Child Left Behind } & 10\end{array}$

Knowledge to Build Organizational Capacity 10

$\begin{array}{ll}\text { Knowledge Acquisition } & 12\end{array}$

$\begin{array}{ll}\text { Knowledge Management } & 13\end{array}$

$\begin{array}{ll}\text { Knowledge Implementation } & 16\end{array}$

$\begin{array}{lr}\text { Research Questions } & 18\end{array}$

$\begin{array}{ll}\text { Study Design } & 19\end{array}$

Part I-Site Selection $\quad 19$

Part II-Field Work $\quad 21$

Part III-Review Information $\quad 23$

Part IV-Analysis of Data $\quad 23$

$\begin{array}{ll}\text { Definitions of Key Terms } & 24\end{array}$

Assumptions $\quad 25$

Limitations $\quad 26$

$\begin{array}{ll}\text { Significance of the Study } & 27\end{array}$

$\begin{array}{ll}\text { Organization of the Study } & 28\end{array}$

II. REVIEW OF THE RELATED LITERATURE 29

NCLB Brief History $\quad 30$

$\begin{array}{ll}\text { Organizational Capacity } & 33\end{array}$

iii 
$\begin{array}{ll}\text { Knowledge Acquisition } & 37\end{array}$

Knowledge Management $\quad 42$

Knowledge Implementation $\quad 45$

Concluding Remarks $\quad 48$

$\begin{array}{lr}\text { III. METHODOLOGY } & 50\end{array}$

$\begin{array}{lr}\text { Introduction } & 50\end{array}$

Research Design $\quad 51$

Identification of the School District 52

Data Collection $\quad 55$

$\begin{array}{ll}\text { Data Analysis } & 58\end{array}$

Case Study One-Washington Junior High $\quad 58$

Case Study Two-Stevenson Junior High $\quad 59$

$\begin{array}{lr}\text { Limitations } & 59\end{array}$

Summary $\quad 59$

IV. ANALYSIS OF RESULTS 61

$\begin{array}{ll}\text { Introduction } & 61\end{array}$

Case Study: Stevenson Junior High

Case Study: Washington Junior High $\quad 70$

$\begin{array}{ll}\text { Findings } & 78\end{array}$

$\begin{array}{ll}\text { Research Question } 1 & 78\end{array}$

Stevenson Junior High $\quad 80$

Washington Junior High $\quad 84$

$\begin{array}{ll}\text { Research Question 2 } & 87\end{array}$

Stevenson Junior High $\quad 87$

Washington Junior High 992

Research Question 3

Stevenson Junior High 96

Washington Junior High $\quad 100$

$\begin{array}{ll}\text { Research Question } 4 & 103\end{array}$

Stevenson Junior High $\quad 103$

Washington Junior High 107 
Research Question 5

Stevenson Junior High 111

Washington Junior High 115

$\begin{array}{ll}\text { Research Question } 6 & 118\end{array}$

Stevenson Junior High 119

Washington Junior High 123

Holistic Summary of Two Junior High Schools 125

V. CONCLUSIONS, IMPLICATIONS, AND RECOMMENDATIONS 128

$\begin{array}{ll}\text { Overview of the Study } & 128\end{array}$

Statement of the Problem $\quad 128$

Design of the Study 128

Descriptions of the Cases for Study 129

Stevenson Junior High 129

Washington Junior High 130

Summary of Findings and Conclusions 131

$\begin{array}{ll}\text { Research Question } 1 & 132\end{array}$

Stevenson Junior High School 132

Washington Junior High School 133

Conclusion 134

Research Question $2 \quad 135$

Stevenson Junior High School 135

Washington Junior High School 137

$\begin{array}{ll}\text { Conclusion } & 138\end{array}$

$\begin{array}{ll}\text { Research Question } 3 & 138\end{array}$

Stevenson Junior High School 139

Washington Junior High School $\quad 140$

Conclusion $\quad 141$

Research Question $4 \quad 141$

Stevenson Junior High School 141

Washington Junior High School 143

Conclusion 144 
Stevenson Junior High School

Conclusion

$\begin{array}{ll}\text { Research Question } 6 & 146\end{array}$

Stevenson Junior High School

146

Washington Junior High School

147

Conclusion

Emergent Findings

The Kimmelman Knowledge Framework: A Holistic Appraisal from the Field

Consideration for Further Research

152

Implications

153

Recommendations for Policy and Practice

Recommendations for District-level Leadership $\quad 155$

Recommendations for School Leadership $\quad 155$

Recommendations for Classroom Teachers 156

$\begin{array}{ll}\text { Conclusion to Chapter V } & 156\end{array}$

$\begin{array}{ll}\text { REFERENCES } & 160\end{array}$

APPENDIX: Cook County School Districts Sampled 166 


\section{TABLES}

Table Page

1. Illinois Proficiency Goals

2. Consequences of Failure to Make AYP

3. Comparative Distributive Data 21

4. Alignment of Research Questions with Data Collection Strategies 57

5. Profile of Stevenson Junior High School 62

6. Stevenson Junior High's Math and Reading Global Scores 68

7. Stevenson Junior High's Math and Reading Disaggregated Results $2008 \quad 69$

8. Profile of Washington Junior High School 72

9. Washington Junior High's Math and Reading Disaggregated Results $2008 \quad 73$

10. Washington Junior High's Math and Reading Global Scores 75

11. Building Organizational Capacity Through Knowledge Framework 


\section{FIGURES}

Figure

1. Cluster Categories
Page

22 


\section{CHAPTER I}

\section{BACKGROUND AND STATEMENT OF THE PROBLEM}

\section{Paul L. Kimmelman, in Implementing NCLB-Creating Knowledge Framework to}

Support School Improvement (2006), could not be more on target with his writings, nor could he be more timely for today, when he wrote his book. More important, however, this book is intended to help educators realize that standards, accountability and assessment, teacher quality, parental options, and reforming schools were important but ignored issues for a long time before NCLB became a law. Kimmelman goes on to say,

NCLB is intended to improve the achievement of U.S. students by requiring states to write rigorous standards and assessments to measure whether students are meeting those standards. The assessments are required to provide data that are disaggregated by subgroups so that educators can make informed decisions regarding the appropriate actions to take to ensure that all students successfully meet their state's proficiency standards. (p. 22)

Meeting the requirements of NCLB is a monumental task. By building organizational capacity through a knowledge model, Kimmelman provides an effective framework for evidence based on continuous improvement that complies with the fundamental foundation of NCLB.

Building organizational capacity follows a linear process. First, it is essential to acquire the knowledge you need to do the specific school improvement work required by NCLB. Second, you need to manage that knowledge so it does not become so cumbersome that it makes the work too difficult, less likely to be focused, and does not result in success. Third, you must use knowledge implementation - the process of professional development to transfer that knowledge into the actual work of the organization. (p. 32) 


\section{Overview}

The first Elementary and Secondary Education Act of 1965 (ESEA), which was signed into law by Democratic President Lyndon B. Johnson, was intended to help disadvantaged children receive a higher quality education. In addition, the 1994 Elementary and Secondary Education Act then stipulated that states have a single statewide accountability system for Title I and Non-Title I schools. Many states were still working on meeting the requirements of the 1994 law at the time NCLB was passed.

Three days into his first term of office, President George W. Bush fulfilled a major campaign pledge by sending his education reform plan to Congress. H.R.1, the Elementary and Secondary Education Act, involved such change as to warrant a new name, becoming better known as the No Child Left Behind Act (NCLBA). The act was co-sponsored by prominent Democratic Senator Ted Kennedy, enacted by convincing margins of 87-10 in the Senate and 381-41 in the House of Representative, and was signed into law by President Bush on January 8, $2002\left(107^{\text {th }}\right.$ Cong., $1^{\text {st }}$ Session, December 13, 2001). The No Child Left Behind Act (NCLBA) is the current version of the Elementary and Secondary Education Act (ESEA), the fundamental federal law governing K-12 education (Pub. L. No. 107-110).

The No Child Left Behind Act (NCLBA) is the most influential piece of federal education legislation in American history. By setting standards for measuring student performance, ensuring the quality of teachers, and providing options for students in ineffective schools, NCLB seeks to ensure that all American students are proficient in math and reading by 2014 ( $§ 1001,115$ Stat. 1439). But even teachers, policy-makers, and parents are often confused about the law's expansive provisions. 
The newest ESEA, the No Child Left Behind Act, is intended to narrow the achievement gap between disadvantaged children and their peers in U.S. schools, ensuring that all students have access to quality teachers, and adequate funding across school districts.

Six student categories are required for reporting through NCLB $(2002, \S 1111$, ๆ C 5,115 Stat. 1446). Those six categories are:

1. Race/ethnicity

2. Economic disadvantage

3. Disability

4. Limited English proficiency

5. Migrant status

6. Gender

In addition to those student categories, a school district must report the academic performance of all their populations, special education and regular education, and show a 95\% passing rate to show AYP and not be labeled a school in need. A category must meet the minimum subgroup size of 45 students.

According to Public Law 107-110,

Each state plan shall demonstrate, based on academic assessments described in $\{3$, and in accordance with this paragraph, what constitutes adequate yearly progress of the State, and of all public elementary schools, secondary schools, and local educational agencies in the State, toward enabling all public elementary school and secondary school students to meet the State's student academic achievement standards, while working toward the goal of narrowing the achievement gaps in the State, local educational agencies, and schools. (§ B, p. 1446)

As more and more school districts confront the realities of the No Child Left Behind Act (2001), data collected on each student will be available for reporting to the 
federal government. That data should be able to be harnessed into a digital system to create a plan of action, or goals for each student. Kimmelman, a retired superintendent in Illinois, takes a positive view of NCLB, and his writing assumes a "make no excuses" tone. He believes educators should stop expending time and effort debating NCLB and concentrate their efforts on raising student achievement levels.

School leaders need to forge a base of knowledge that school leaders and policymakers can use to answer the challenges of No Child Left Behind. Leadership and learning is about taking skillful action, producing results and mobilizing others, not simply acquiring academic knowledge (Fullan, Bertani, \& Quinn, 2004).

Increases in proficiency rates must occur for a school to make AYP. Progress in student achievement from "below basic" to the "basic level" is not in and of itself sufficient to meet AYP requirements. Accountability systems must establish proficiency goals statewide, based on assessment data from the 2001-02 school year, which progressively increase to reflect $100 \%$ proficiency for all students so that by $2013-2014$ all students meet or exceed the Illinois Learning Standards. The Illinois increments are shown in Table 1.

Table 1

Illinois Proficiency Goals

\begin{tabular}{llllllllllll}
\hline 2003 & 2004 & 2005 & 2006 & 2007 & 2008 & 2009 & 2010 & 2011 & 2012 & 2013 & 2014 \\
\hline $40 \%$ & $40 \%$ & $47.5 \%$ & $47.5 \%$ & $55 \%$ & $62.5 \%$ & $70 \%$ & $77.5 \%$ & $85 \%$ & $92.5 \%$ & $92.5 \%$ & $100 \%$
\end{tabular}

Furthermore, states are required to ensure that the results of academic assessments are available in sufficient time for school districts to review them and for the state to make 
school level determinations of Annual Yearly Progress ( $\$ 1116$, pp. 1479-1498). Schools that fail to make AYP are held to a series of consequences.

For schools across the state, 2008 was a tough year simply because the federal test score standard rose again. For a school to clear the NCLB hurdle, $62.5 \%$ of its students, on average as well as in various racial and academic subgroups, needed to have tested at "proficient" or better in the annual measurable achievement objectives in reading and math (up from 55\% last year). That's a $7.5 \%$ point increase.

Schools do have a "Safe Harbor." Even if a school does not make AYP in the composite or in any of the student demographic groups, it can fulfill its progress requirement by decreasing the proportion of its students who do not meet/exceed standards by $10 \%$ and for high schools by increasing graduation rates and finally for elementary schools by improving writing assessment results.

Table 2

Consequences of Failure to Make AYP

\begin{tabular}{lll}
\hline $\begin{array}{l}\text { Number of years } \\
\text { school misses goals }\end{array}$ & \multicolumn{1}{c}{ School status } & \multicolumn{1}{c}{ NCLBA interventions } \\
\hline First year missed & N/A & None \\
Second year missed & Needs Improvement & Offer School Choice \\
Third year missed & Needs Improvement & Offer School Choice and SES \\
Fourth year missed & Corrective Action & Offer School Choice and SES \\
Fifth year missed & Plan for Restructure & Offer School Choice and SES \\
Sixth year missed & Implement Restructure & Offer School Choice and SES \\
\hline
\end{tabular}


A key goal of NCLB is to focus attention on subgroups (minimum of 45 students) that have traditionally been underserved by school; for a school or district to meet AYP, it must have all its subgroups also meeting the target.

The law is based on four major principles that are intended to provide a framework through which educators, communities and families can improve their schools. These principals are:

1. Accountability for results

2. Local control and flexibility

3. Expanded school choice

4. Effective program that reflect scientifically based research

Accountability is the cornerstone of NCLB. Schools and districts demonstrate adequate yearly progress under NCLB by meeting state targets for the percentage of students scoring proficient on state tests of reading/language arts and mathematics.

NCLB requires states to do more than administer an annual assessment. Some of the main accountability requirements found in NCLB ask states to do the following:

1. Develop and implement academic content and achievement standards.

2. Administer annual assessments align to state standards in reading/language arts and mathematics in grades 3 through 8 and at least once in grades 10-12.

3. Administer annual assessments of English language proficiency to measure and be held accountable for the progress of English language learners in acquiring English.

4. Use the assessments in reading/language arts and mathematics to determine annually how well all students in public elementary and secondary schools are learning and mastering the subject matter reflected in the state's academic content and achievement standards.

5. Create state and district report cards that include student achievement on assessments. (NCLB, $\S 1111, b, 1$ ) 
These five requirements create a complex multifaceted program intended to punish schools if the accountability has not been met. NCLB places specific demands on states and school districts forcing them to hold schools accountable for failing students, requiring them to monitor student progress annually or face consequences, mandating tougher hiring practices for teachers, and, at its core, instituting penalties for schools that failed to improve.

According to The Education Trust (Published Oct. 31, 2007), if a school does not make Adequate Yearly Progress as defined by the federal No Child Left Behind law, the following can happen to Title I schools:

Year 1: There are no consequences for not making AYP for one year.

Year 2: Schools and districts identify areas that need attention and make necessary adjustments, but nothing happens under NCLB.

Year 3: If a school does not make AYP for 2 consecutive years in the same subject, it is identified as in need of improvement. Schools must identify the specific areas that need improvement and work with parents, teachers and outside experts to develop a 2-year plan to raise student achievement. Parents need to be notified and given the option to transfer their children to a higher performing school in the district.

Year 4: If a school fails to make AYP for another consecutive year, then tutoring and other supplemental educational services must be made available to lowincome students at that school.

Year 5: If a school does not make AYP for 4 years, it is identified for corrective action. Children can continue to transfer to other schools or receive tutoring and other services. In addition, the district and school are required to implement at least one of the following corrective actions:

1. Appoint an outside expert to advise the school.

2. Institute a new curriculum, including appropriate professional development.

3. Extend the school year or the school day for the school.

4. Restructure the school's internal organizational structure.

5. Significantly decrease management authority at the school level.

6. Replace the school staff that are relevant to the failure to make AYP. 
Year 6: If the school fails to make AYP for 5 years, the school must continue corrective action and develop an alternate governance plan, which must include one of the following.

1. Reopen the school as a public charter school.

2. Replace all or most of the staff responsible for the lack of progress

3. Enter into a contract with a private company to operate the school.

4. Turn over operation and management of the school to the state.

5. Implement other fundamental reforms approved by the state.

Year 7: If a school does not make AYP for 6 years, the alternate governance plan that was developed the previous year must be implemented.

On paper, this all proceeds in an orderly and familiar top-down sequence, with federal rules outlining what states are to do, states telling districts what to do, and then districts working with their individual schools. State education departments are charged with setting standards, creating tests intervening in faltering districts, and generally supervising in their ongoing effort to follow NCLBA.

The process of urban schools and how to take ownership for the decisions regarding implementing interventions is not simple. There is not a lot of valid research out there yet on various interventions, as Kimmelman points out (2006). But the NCLB law's emphasis on peer reviewed research paves the way for teachers to start doing their own action-research and begin to take part in the shaping of education from the bottom up. Since 2001-2002, the work of public school teachers and administrators in the United States has been shaped by the standards-based accountability (SBA) provisions of the No Child Left Behind Act of 2001. NCLB requires each state to develop content and achievement standards in several subjects, administer tests to measure students' progress toward these standards, develop targets for performance on these tests, and impose a series of interventions on schools and districts that do not meet the targets. Together, the standards, assessments, and consequences constitute a standards-based accountability 
system. Many states had such systems in place before NCLB took effect, but since 20012002, every state in the United States has had to develop and implement an SBA system that meets the requirements of the law, and the provisions have affected every public school and district in the nation (U.S. Department of Education, 2005).

Kimmelman (2006) admits that it was unrealistic for Congress and the U.S. Department of Education to think that, suddenly, every school and state in the country was going to rapidly embrace the notion that every student would make adequate yearly progress regardless of whether it was educationally possible, or that every school district would be able to ensure that all its teachers would be highly qualified by 2006 . Rather than accept the challenge, many educators and their organizations simply chose to put their energy into opposing the provisions of the law.

\section{Problem Statement}

By the end of the $20^{\text {th }}$ century and the early decade of the $21^{\text {st }}$ century, the United States faced an educational crisis. Many public schools were under performing, and federal legislation (the No Child Left Behind act) demanded that all schools be held accountable for the academic achievement of all students. School leaders face the challenge to increase the organizational capacity of their school to reach targeted achievement goals. Many researchers, and reformers advocate new management and leadership strategies that can lead to successful school development.

One formulation of the needed strategies is found in the synthesis of Paul K. Kimmelmanm, who argues that school leaders must create a knowledge framework to support school improvement. This knowledge framework can be broken down into three components. 
The first component is knowledge acquisition. There are two parts to knowledge acquisition. The first involves acquiring data about student learning that can be transferred into useful knowledge. The second is best practice, having the knowledge about available curricular and instructional tools that represent best practices.

The second component is knowledge management and how school leaders manage summative assessment results that are monitored for each student over time. Consideration is also given to managing formative assessment findings that are shared with the students as an ongoing learning opportunity.

The final component is knowledge implementation, which is defined as collaborative professional development. These are activities that require on-going training of teachers while they engage in a variety of school improvement projects

Kimmelmann and other researchers are convinced that school leaders can successfully implement No Child Left Behind if they adopt professional practices identified in the knowledge framework.

This study examines two school districts that are implementing No Child Left Behind. It addresses the critical issues of building organizational capacity that will allow schools to achieve higher levels of school performance. The key components of the knowledge framework are utilized to guide this inquiry.

\section{Implementing No Child Left Behind}

\section{Knowledge to Build Organizational Capacity}

Implementing No Child Left Behind provides the context and rationale for this study. First, this section establishes the connection on how to build Organizational Capacity. Secondly, in implementing NCLB, I will discuss Kimmelman's Knowledge 
Acquisition, Knowledge Management and Knowledge Implementation as the focus of this research. All of these topics are influential and will help sustain implementing No Child Left Behind mandates.

According to Kimmeleman (2006), to build organizational capacity to implement NCLB, the focus needs to be on familiarity, awareness, and understanding of NCLB 's core requirements. He states that organizational capacity follows a linear process:

1. It is essential to acquire the knowledge you need to do the specific school improvement work required by NCLB.

2. Manage that knowledge so it does not become so cumbersome that it makes the work too difficult.

3. Use knowledge implementation-professional development- to transfer that knowledge into the actual work of the organization. The right data and research are necessary to identify the work that needs to be done.

4. The process must be implemented with professional development that is focused, sustained over time, benchmarked to determine progress, led by teachers who are actively involved in the planning and held accountable for results, and guided by research and evidenced-based practices.

The research clearly states that teachers need time to plan together, and yet school schedules and policies provide neither the time nor the training in how to best use that time (Fullan et al., 2006; Elmore, 2000). Improvement needs to be embraced, but initiatives must be based on priorities that stay focused over time. Teachers must be given opportunities to work together on key issues. It is time to concentrate on key issues already in place. It is time to guarantee that staff agrees with the mission/vision at their schools, understand the best practices and implement, and provide time to implement both alone and collaboratively the research and protocols that have already been introduced (Reeves 2002). 
Viewing knowledge to build organizational capacity through Kimmelman's research lens, he says:

To build the organizational capacity of school districts will necessitate breaking the traditional cultural bureaucratic model of school organizations and incorporating more contemporary thinking used in organizations that focus their work around teams. (p. 30)

\section{Knowledge Acquisition}

It is essential to sustain what is working well. Sustaining success can be as difficult as the process of improving. What is needed is a linear process that begins with (a) acquiring and analyzing specific information that identifies deficiencies and what needs to be accomplished, and (b) basing the improvement work on what is learned from credible research on how to implement the process.

Building organizational capacity is about acquiring, managing, and implementing knowledge. Acquiring and analyzing data is the starting point. It is important to collect the right data. Kimmelman recommends a data retreat. A team of teachers and administrators will recognize the importance of collecting, understanding, and using data to inform their NCLB compliance work. State testing under NCLB sets an important context for this work, and, obviously, the sanctions associated with not meeting the AYP goals of the law provide an incentive to carefully review the data. Kimmelman developed an 8-step organized retreat:

1. Developing leadership teams, setting the context, and organizing the retreat.

2. Collecting and organizing the data

3. Analyzing data patterns

4. Posing hypotheses

5. Developing improvement goals

6. Designing specific strategies

7. Defining evaluation criteria

8. Making the commitment 
How is knowledge acquired and what instructional practices are being used regarding student learning? According to Kimmelman,

Analyzing data and using credible research will enable you to make informed decisions about how to improve those aspects of your organizational performance that are deficient. Without that knowledge, the process of improving those deficiencies is unlikely to be very substantial. A case can also be made for using that knowledge to sustain and improve those aspects of the organization that are doing as well or better than expected. It is important to keep in mind that while working on the deficiencies, it is also essential to sustain what is working well. Sustaining success can be as difficult as the process of improving. (pp. 35-36)

As was stated earlier about basing the improvement work on what is learned from

credible research, Kimmelman addresses nationally normed testing, i.e., ISAT as:

Nationally normed testing can be used as a benchmark on how students in one school district are doing in comparison to their peers throughout the country, state, or even in their own school district, it often fails to provide the necessary information regarding the specific deficiencies that need to be improved. (p. 38)

Kimmelman goes on to say:

Once you have the data and have identified the problems that need to be corrected to be in compliance, small-specialized learning communities, composed primarily of teachers, can begin considering how research can inform their work. The idea of forming learning communities is the key. (p. 57)

Significant research of what works best in terms of credible research on how to implement the process has emerged from various studies within the field (Black \& Wiliam, 1998; Elmore, 2005; Fullan, 2003; McEwan, \& McEwan, 2003; Mills, 2005; Rasmussen, Hopkins, \& Fitzpatrick, 2004; Richardson, 2003).

\section{Knowledge Management}

Kimmelman (2006) describes in practical detail how to create a site-based group of teachers and stakeholders who look at data, come to conclusions, find relevant research, and implement interventions 
The process of urban schools and how to take ownership for the decisions regarding implementing interventions is not simple. There is not a lot of valid research on various interventions, as Kimmelman points out. But the NCLB law's emphasis on peer reviewed research paves the way for teachers to start doing their own actionresearch and begin to take part in the shaping of education from the bottom up.

As written by Black and Wiliam (1998), teachers need to know about their pupils' progress and difficulties with learning so that they can adapt their own work to meet pupils' needs, needs that are often unpredictable and that vary from one pupil to another. Teachers can find out what they need to know in a variety of ways, including observation and discussion in the classroom and the reading of pupils' written work.

Tiwana's (2000) definition of knowledge management for business can be applicable for educators who, under NCLB, must create, communicate, and apply knowledge in ways that will enable them to meet specific achievement goals, teacher quality requirements, and improve school programs that are not effective.

There are two types of evaluation teachers should carry out within their classroom and the school: summative and formative evaluation. Formative assessment is an ongoing process of improvement, whereby the teacher is allowed immediate improvement opportunities, i.e., feedback. Usually, this means addressing a student's learning process in reference to a particular situation as it is happening. The main purpose remains to improve learning strategies, particularly as it applies to an evaluative process detached of student grading. Curriculum alignment or tools that shape professional direction often take place in this process and are usually connected to multiple learning objectives, 
whereby instruction quality is critically attached to the goals at hand. Objectives and the impact realized by the whole are immediately stressed.

On the other hand, summative assessment focuses on a retrospective evaluation of an educator's teaching strategy. Examples involve the teaching, comprehension, and retaining of knowledge of accreditation tests. To reiterate or clarify the idea, the concept can be summed up by saying the summative program tests what was learned and how it was taught. This information can be found in the ISAT assessments. Unfortunately, this information is often not used by teachers because it is not in a format or managed in a way that enables them to access it easily or align it to their classroom lessons.

According to the Black and Wiliam (1998), formative assessment is done during teaching and learning to adapt teaching to meet student needs. Research studies have shown substantial learning gains in classrooms where teachers use formative assessments as feedback. It helps low achievers more than other students and so decreases the ultimate range in achievement while moving the mean higher. But students must be actively involved by using feedback themselves for effective learning to occur. Highstakes external tests give teachers poor models for formative assessment because they provide limited summaries of achievement, rather than helpful diagnoses of specific learning strengths and needs.

For teaching with formative assessment to be highly effective: (a) assessments must go far beyond rote and superficial learning to deep understanding of complex ideas, (b) educators as a team must critically review their teaching in light of assessment results, and (c) quality of work must be emphasized over quantity. Self-assessment can empower students to determine for themselves what they must do to improve. Students must have 
the opportunity to try again. A test at the end of a unit or teaching module is pointless in terms of formative feedback.

Public policy has focused on external assessment for accountability. But policy should not neglect the extent to which research has proven the powerful impact of ongoing assessment inside the black box, and policy should support professional development and instructional practices in this area as a high leverage point for improving student achievement. Teachers need living examples of implementation, high standards of teaching performance, and a variety of support mechanisms to learn better pedagogy. If we are truly serious about raising standards, formative assessment of student work and teachers' pedagogy must be part of the process (Black \& Wiliam, 1998).

\section{Knowledge Implementation}

Knowledge implementation using research or evidence-based professional development or both will ensure that there are highly trained and informed employees in the organization (Kimmelman, 2006).

To make NCLB work, we need to hold schools or, more accurately, those who run and operate them, accountable for factors that they can control and that matter to student achievement yet not hold them accountable for factors beyond their control. We need to distinguish between schools that are failing their students and governments that are failing their schools, sanctioning and starving schools of promise in the communities that most need educational excellence. We must reward those who succeed with the tools, conditions, and resources needed to continue to do their jobs at a high level (Elmore, 2005). 
NCLB requires professional development programs funded with federal dollars to be research based, and enough credible evidence exists that the activities should be of a reform type, sustained over time, relevant to the participant's work, collaborative, benchmarked, aligned to the district and school missions, and structured to improve student achievement and teaching strategies. Anything less in this NCLB environment is wasting valuable dollars and teachers' and administrators' time (Kimmelman, 2006).

Rasmussen, Hopkins, and Fitzpatrick (2004) use a baseball metaphor to describe good professional development. They say that good professional development is like "a perfect curve ball, it's all in the commitment, planning, effort, and practice" (p. 16). They identify the key components of professional development as being coherent, research based, and capacity building. In other words, coherent professional development is aligned with school improvement efforts and agreed-upon goals. Research based means that all decisions are based on careful examination of effective practices. Capacity building means the participants agree to work together to learn new skills to become more self-sufficient. Rasmussen et al. cite six steps for successful professional development planning:

1. Gather and analyze the data

2. Set student-learning goals, and align school improvement efforts with those goals.

3. Define instructional strategies that address learning goals.

4. Identify what staff needs to know and be able to do to in order to implement new strategies.

5. Define professional development initiatives, and develop and action plan.

6. Create a professional development evaluation plan. 
The professional development work must be considered a high priority for teachers.

Kimmelman (2006) links implementation to teacher leadership. School administrators are encouraged to consider the idea of teacher leaders for professional development activities. He reminds administrators that this leadership should be real leadership. It should actually empower the teachers to accomplish the goals of the activity in much the same way that principals and other line administrators are delegated responsibilities.

Good professional development design includes both strong content and an effective process for making initial and ongoing decisions. Relevant content is essential to ensuring that professional development helps meet student learning goals. Good professional development content without a strong decision-making and organizational process to support it will be short-lived (Steiner, 2004).

The findings summarized above and this study's outline has implications for a variety of responsible agencies. Success would clearly depend on cooperation among government agencies, academic researchers, and school-based educators. One of the main points of our research is that standards can be raised only by implementing changes that are put into direct effect by leadership teams, teachers and pupils in classrooms.

\section{Research Questions}

The following questions guided this study:

1. Are school leaders collecting and analyzing formative and summative student data?

2. What kind of activities are school leaders conducting to search and identify best instructional practices?

3. What kind of data management systems are utilized by school leaders to examine and review summative assessment identifying achievement gaps and trends for various student populations? 
4. What kind of data management systems are utilized by school leaders to examine and review formative assessment identifying achievement gaps and trends for various student populations?

5. Are the schools creating learning teams or teacher work groups to generate successful knowledge about student results, student learning, and appropriate instructional strategies that advance curriculum goals?

6. What kind of professional development opportunities are available to teachers who are expected to work both individually and collaboratively to achieve targeted achievement goals mandated by No Child Left Behind?

\section{Study Design}

For purposes of this study, a qualitative approach was used to determine the attempts of urban school district leadership teams in implementing the mandates of No Child Left Behind. The qualitative method offers a way to investigate complex personal and social interactions between the participants in real-life situation (Merrian, 1988). Using the systematic procedural guidelines (Creswell, 2003), specifically, information was gathered through documents and artifacts, review and analysis, structured interviews, observations, and key information interviews.

This study was divided into three distinct parts: site selection, fieldwork and, data analysis. As a resource throughout this project, qualitative methodological literature by Merrian (1998) and Cresswell (2003) was used.

\section{Part I-Site Selection}

I used a deliberate sample that reflects comparable characteristics on key attributes of the schools. These attributes help define common characteristics found in many urban industrial communities in the Midwest. I interviewed, observed, and analyzed the activities, and documents within the case. 
The 47 school districts in South Cook County, Illinois, have 271 school buildings (Appendix A). Students enrolled in these buildings have a low of 204 enrolled students (Burnham S.D. \#154.5) and a high of 5,731 enrolled students (Orland Park S.D. \#135). The average district enrollment size is 1,771 students in South Cook County. The average building enrollment size in South Cook County is 383 students. Initially, 12 middle schools of similar size were identified as those fitting the description of urban fringe schools of a large city that are most likely following federal guidelines implementing NCLB (Kimmelman, 2006).

The first criteria was the location of the schools for the researcher's access to local educators at those sites. As other criteria were examined, two schools fit the cluster needed for this study.

The researcher analyzed comparative characteristics of 217 schools found in South Cook County. The characteristics examined for comparative purposes were: race, academic performance, income, and parent characteristics. More specifically two school were found that were relatively similar in eight characteristics (see Figure 1). The two schools that were selected had a cluster of similar categories. Table 3 provides comparative distributive data in the two schools that were selected-Washington Junior High School and Stevenson Junior High School (pseudonyms). 
Table 3

Comparative Distributive Data

\begin{tabular}{|c|c|c|}
\hline & Washington Junior High & Stevenson Junior High \\
\hline Enrollment & 486 & 540 \\
\hline White & $3.5 \%$ & $18.0 \%$ \\
\hline Hispanic & $20.4 \%$ & $7.8 \%$ \\
\hline Black & $75.5 \%$ & $73.3 \%$ \\
\hline Reading proficiency & $56.1 \%$ & $62.4 \%$ \\
\hline Math proficiency & $58.0 \%$ & $56.3 \%$ \\
\hline Combined math/reading & $57.0 \%$ & $59.4 \%$ \\
\hline Students per teacher & 15.7 & 15.4 \\
\hline Urban status & $\begin{array}{l}\text { Urban fringe of a } \\
\text { large city }\end{array}$ & $\begin{array}{l}\text { Urban fringe of a } \\
\text { large city }\end{array}$ \\
\hline Low income & $76.35 \%$ & $51.9 \%$ \\
\hline Single parent & $17.2 \%$ & $10.1 \%$ \\
\hline $\begin{array}{l}\text { Adults with at least a } \\
\text { BA degree }\end{array}$ & $20.7 \%$ & $28.9 \%$ \\
\hline $\begin{array}{l}\text { Adults with at least a } \\
\text { HS degree }\end{array}$ & $83.0 \%$ & $92.7 \%$ \\
\hline Mobility & $58.5 \%$ & $54.9 \%$ \\
\hline
\end{tabular}

\section{Part II-Field Work}

The researcher identified a population of school districts in South Cook County, Illinois (see Appendix A). Each school participating in the study has similar cluster categories, which are shown in Figure 1. 
1. Unable to meet AYP for 2 or more consecutive years

2. Title I Eligible

3. Reading Scores

4. Math Scores

5. Enrollment above the average of 383

6. Students per Teacher

7. Single Parent

8. Low Income

a. Small proportion low income

b. Medium proportion low income

c. High proportion low income

Figure 1. Cluster categories.

The following individuals were interviewed:

- Superintendent of Schools

- Director of Curriculum

- School Principal

- A minimum of six teachers

- Team Leaders-School Development team members

- Teachers with leadership roles

- Collective bargaining teachers' leaders

-Veteran teachers and non-tenured teachers

I analyzed the school improvement planning documents, the mentor meeting documents, and the curriculum staff development training documents.

This study was limited to the sample schools and to the organizational structure that was utilized. The results of this study came from perceptions taken from interviews 
with administration and the teaching staff who were actively involved in decision-making relative to the implementation of NCLB. Interviews were conducted in a systemic way utilizing the same interview questions. All interviews were tape recorded and analyzed.

Documents related to both implementing NCLB and school improvement issues were examined. Information gathered from school/community newsletters, staff meeting minutes and agendas, and faculty and parent handbooks were also part of the study.

A third school was identified as a backup-case in the event of either of the first two schools refusing to participate in the study. (Comparison and analysis need to be the same). The third selected junior high school has similar kinds of units. The two schools selected for analysis have key compatibility in the implementation of NCLB, age, academics, ethnic make-up and mobility.

\section{Part III-Review Information}

The study began with a review of background information and documents from committee and staff meetings, including state, district and school levels. Transcripts of interviews with board members, superintendents, principals, teachers and support staff, were also included.

\section{Part IV-Analysis of Data}

An analysis of all raw data was conducted in this phase. The case study analysis (interviews, field notes, collection of documents and focus group transcripts) was organized in such a way as to address all research questions). To insure confidentiality, the school, community, administration, faculty and representatives were given pseudonyms. 
This qualitative approach made knowledge claims based primarily on constructivist perspectives (i.e., the multiple meanings of individual experience, meanings socially and historically constructed, with intent of developing a theory or pattern (Creswell, 2003). As the process continued, the analysis began to focus on the main categories of this case study.

\section{Definitions of Key Terms}

Academic Early Warning List: a list, maintained by the Illinois State Board of Education, that includes those schools who do not reach the mandated levels of Annual Yearly Progress.

Achievement gap: the difference in school achievement among different groups of students, such as racial/ethnic groups, and income levels.

Adequate Yearly Progress (AYP): a measure of assessment, which rises incrementally by percentages, which schools must meet annually in respect to test results gained from the Illinois Standards Achievement test and the Prairies State Achievement Exam. AYP sets a common standard for all students in the state based upon statewide testing that has been developed to yield statistically reliable and valid results.

Evidence of effectiveness: a term used in NCLB that programs must "prove evidence of effectiveness," meaning a program must show through student achievement data that it improves achievement.

Formative evaluation: testing used before or during instruction to monitor learning progress, assist in planning, and diagnosis, which helps identify areas that need work. Its purpose is to provide continuous feedback to both students and teacher concerning learning success and failures. Feedback to students provides reinforcement of 
successful learning and identifies the specific learning errors that need correction,

Illinois Standards Achievement Test (ISAT): a test given to students in the third through eighth grades (third, fifth, and eighth—-reading, math, and writing; fourth and seventh—social studies and science) as a part of the Illinois high stakes testing program.

Illinois State Board of Education (ISBE): the agency under which all public school districts in Illinois operate: also, the name of the appointed individuals who serve as state board members.

Low performing school: a school that fails to make Adequate Yearly Progress in two consecutive years.

Proficiency: a student is able to do something he or she is supposed to do at the age and grade level.

Professional learning community: the working relationship that exists among teachers. This relationship can be characterized by high level of trust, commitment, responsibility, and accountability to achieve a shared vision.

Summative evaluation: normally given at the end of the course. Designed to determine the extent to which the instructional goals have been achieved and is used primarily for assigning course grades or for certifying student master of intended learning outcomes.

Supplemental services: services provided outside the regular school day to help students reach proficiency. Providers are paid with Federal Title I funds.

\section{Assumptions}

This study was based on the following assumptions:

1. All participants were truthful regarding their perceptions as educators in the State of Illinois. 
2. The school districts selected for this study were representative of urban school districts in the State of Illinois.

3. The questions asked were clear, concise, and appropriate for the participants.

4. The participating schools were willing to participate in this study.

5. The urban school district personnel subject to the interview were representative of those personnel across the State of Illinois employed by similar school districts.

6. Their stakeholders generally recognized all participants as effective educational leaders.

\section{Limitations}

1. Only two urban school districts from the State of Illinois participated; therefore, this work should not be generalized to the State of Illinois or to the nation.

2. Because of the wide scope of No Child Left Behind, this study should not represent all dimensions associated with the school reform efforts for each of the school districts studied.

3. The participants selected reflected a sample of the general population of school leaders. It was a purposeful sample, not a random sample (Creswell, 2003), aimed at understanding and gaining insight about how superintendents and school leaders are responding to a complex federal law. Their philosophy about educational leadership was unknown, but because of their organizational challenges, it was assumed that they were able to articulate their successes and frustrations. The sample was diverse with differences in gender, age, and ethnicity. 


\section{Significance of the Study}

Never in our educational history have the stakes for meeting learning standards been higher. NCLB promises sanctions against schools and districts that fail to meet the lofty goals of this federal mandate. This study will not only add to the scholarly research of the positive and negative experiences of school leaders who are responding to the mandates of NCLB, but will look at the ambivalent nature of educators as they examine the relationship between children of poverty and the education gap it causes.

Consequently, there is an ever-increasing need to study the response of school personnel to comply with the NCLB act.

Moreover, a longitudinal study of student achievement over time might provide further insight into the question of whether NCLB should be restructured. Additionally, this study may spawn similar research in studying the practices and implementation of school improvement by local urban school leaders.

NCLB remains a significant part to every educator's agenda. In 2007 in Illinois, 297 schools failed to meet No Child Left Behind standards (Chicago Tribune). Many failed because of a combination of subgroups not meeting the benchmarks including: special ed. status, race, and income. It is idealistic to expect students with a wide range of disabilities to suddenly match their peers.

By gaining insight as to how school improvement is attained, school boards, superintendents, principals, parents and teachers will be better equipped to implement practices that produce results accordingly. 


\section{Organization of the Study}

This study is presented in a five-chapter structure. Chapter I consists of the overview and present situation, statement of the problem, definition of terms, research questions, methodology, assumptions, limitations and the significance of the study. Chapter II contains an overview of the literature related to the problem statement. Chapter III of this study presents the research design and methodology. Chapter IV is a presentation and analysis of the findings. Chapter V includes a summary of the interpretations of the findings, a statement of conclusions, implications for practice and policy, and recommendations for future research. 


\section{CHAPTER II}

\section{REVIEW OF THE RELATED LITERATURE}

Federal and state efforts to improve schools and achieve higher levels of student learning and address inequity in student outcomes spans more that four decades. The 1980s and 1990s saw the emergence of the effective schools movement and subsequent federal and state attention to comprehensive school reform models. Throughout these reform efforts, the school was seen as the primary unit of change. Reform efforts aimed at individual schools have had success, but the gap in achievement remains, especially in many high poverty areas and in schools and districts serving large numbers of low income and diverse students. The $21^{\text {st }}$ century opened with a new reform; NCLB intended to overcome the limitations of earlier efforts. The expectations set by No Child Left Behind have created a sense of urgency to establish system alignment to improve every student's performance across America.

This chapter provides a brief history of NCLB and then develops a framework to examine critical issues of implementation facing educational leaders at three levels of decision-making: district, school, and the classroom. Consideration is also given to Paul Kimmelman's ideas about using knowledge to build organizational capacity to implement school improvement. Kimmeleman encourages practitioners to recognize the importance of acquiring, managing, and implementing knowledge to inform decision-making. Other works of recent school reform that support the NCLB framework are reviewed in this chapter. 


\section{NCLB Brief History}

President George W. Bush announced No Child Left Behind on the third day of his presidency $\left(107^{\text {th }}\right.$ Cong., $1^{\text {st }}$ Session, December 13,2001$)$. It is an accountability law that establishes adoption of comprehensive procedures for every state educational agency. The policies and procedures at state level have a direct impact on the work of school superintendents, assistant superintendents, principals, and teachers.

The "built-in accountability" includes establishing state standards in math and reading, yearly testing for students third through eighth grade, and statewide progress objectives with the hope that all groups of students will meet the standard within 12 years (§ 1001, 115 Stat. 1439). Groups of students are broken down by race, poverty, disability, and English proficiency. School districts and schools that exceed or meet annual yearly progress (AYP) are under constant pressure to reach higher standards in subsequent years. While school systems that fail to make AYP will go through restructuring, other means of remediation, and even closures.

In the few short years since its passage, the No Child Left Behind Act (NCLBA) has become the focus of many in education, from state superintendents to researchers to teachers. The massive bill contains many provisions designed to hold schools and districts accountable for student learning. The No Child Left Behind Act has had an incredible response from educators and others interested in education. Many commentators have observed that there has never been an instance when a federal education law had as much impact so quickly as the No Child Left Behind Act has had. (Abernathy 2007).

The design of the NCLB legislation allows states to maintain autonomy in defining expectations for student learning and how student learning is assessed. This 
flexibility still necessitates a federal accountability system. States are required to submit documentation of their assessment system for review by experts in the fields of standards and assessments (U.S. ED., 2004). This is referred to as the NCLB peer review process whereby experts review state assessment programs, as documented in submitted materials, and provide judgments and feedback to the United States Department of Education (U.S. ED) based on pre-defined review criteria.

NCLB includes a multitude of programs and requirements relating to standards, testing, accountability, teacher quality, reading research, and other topics. At its heart are the law's testing and accountability provisions that have dominated the public debate and that constitute the most visible and significant changes wrought by the law (Finn \& Hess, 2004).

Many commentators have voiced both criticism and support for several aspects of the NCLB system. The most criticized aspect of NCLB is certainly the expectation that $100 \%$ of students need to meet a given state's standard for proficiency by 2014 in reading and mathematics, which is considered an unrealistically high goal (e.g., Linn, 2005; Mathis, 2003). According to Linda Darling-Hammond (2004), the promises of Bush's education policy (NCLB) have not solved America's education problems.

Critics of No Child Left Behind have observed that, unless considerable flexibility is allowed in the interpretation of some aspects of the accountability components of the law, it seems likely that many more schools will be classified as needing improvement than can actually be provided with effective assistance. Such an outcome could seriously undermine the laws commendable goals of substantial improvement in instruction learning for all students, and closing the achievement gap (Baker et al., 2003). 
Public accountability systems like NCLB are particularly dependent on public support, because their successful implementation relies on the public's willingness to have faith in admitted imprecise testing metrics and accountability systems.

Proponents have difficulty standing firm on the details of any particular accountability system because essential components relating to content, testing, passing scores, and sanctions are inherently arbitrary. The closer one gets to crafting and enforcing standards the less defensible specific program elements can appear. In the end, standards are a useful artifice. (Hess, 2003, p. 72)

A final comment concerning NCLB accountability comes from Kimmelman (2006):

All AYP formulas are written by the states and not the federal government. Whereas some states have taken the responsibility seriously and set challenging goals for their school, others have chosen to develop less rigorous goals to look good statistically. In the end, NCLB has a check and balance provision (e.g., requiring states to participate in the National Assessment of Education Progress, a national assessment measuring the achievement of U.S. students in a variety of subjects and grade levels) that will illuminate results from those states whose standards may not be rigorous enough. (p. 40)

In the literature of NCLB, Illinois standards are never mentioned as especially tough or rigorous but local educators in Illinois have found them to be challenging and consideration has been given to school improvement endeavors intended to raise student achievement. This chapter addressees several critical issues in NCLB and the school improvement process.

The research questions for this particular study explore issues concerning the impact of No Child Left Behind in local school improvement planning practices. The questions are adapted to Kimmelman's knowledge framework. The following topics will be considered: (a) organizational capacity, (b) knowledge acquisition, (c) knowledge management, and (d) knowledge implementation. 


\section{Organizational Capacity}

Kimmelmann sees organizational capacity as the broad concept that he uses to organize a three-part knowledge process as knowledge acquisition, knowledge management and knowledge implementation. He never gives a clear definition of organizational capacity, but he borrows examples of organizational capacity from successful business entrepreneurs and sports teams. In both cases, highly successful organizations learn how to collect data and analyze them for the attainment of specific performance goals.

Organizational capacity is also related to both internal and external accountability

systems that require teamwork and continuous commitment to quality and improvement.

He makes the following argument about the relationship of organizational capacity and the reform agenda for public schools:

To build the organizational capacity of school districts will necessitate breaking the traditional cultural bureaucratic model of school organizations and incorporating more contemporary thinking used in organizations that focus their work around teams. In education, that process calls for using teacher leaders who are trained for their leadership responsibilities and given authority to make decisions to complete their work. That means breaking from the traditional idea that school administration is a line authority process beginning with the superintendent and going down the organizational ladder with assistant superintendents, principal, assistant principal, department chairs and so on. (p. 30)

Kimmelman and other researchers feel that school leaders can successfully implement No Child Left Behind if they adopt professional practices identified in a "knowledge framework" that is a synthesis of many current practices in school reform.

A study on organizational capacity was conducted comparing three urban school systems by William A. Firestone (2005). He suggests that district offices can influence teaching through professional development. District leaders can structure their programs to provide coherent and content-focused professional development. District differences 
in their organizational capacity affected coordination and planning of professional development. The district with the most coherent focus on helping teachers develop deeper knowledge about select subject areas had the greatest teacher-reported influence on teaching practice.

This study presents several principles to reform the system for preparation of school leaders. It focuses on the design of leadership programs. School leaders should focus on the instructional aspect of schooling rather than on administrative tasks. Firestone (2005) went on to say that school districts should be allowed to run their own training and certification programs for school leadership teams. Although most schools and districts find this process cumbersome and difficult, proponents have touted it as a valid practice to fuel the process of organizational capacity.

Lorraine Slater (2008) studied the impact of organizational capacity within the working of today's schools as principals share the lead and the load; the success of their performance is determined by their ability to inspire a culture of empowerment by acting as "hero makers" rather than heroes. Drawing on the resources of others is essential for the site-based breakthroughs or change in complex school systems and, in turn, builds human capacity and self-knowledge. Slater (2008) goes on to say that in order to develop human potential, the leader needs to know people well, look for strengths in individuals, and build upon them. Effective communication is essential in establishing collaborative relationships and is a key aspect of building leadership capacity in a school. The findings of this study describe how principals used communication strategies and skills to foster the empowerment of other stakeholders within the context of collaborative initiatives. The findings from this qualitative focus group study involving principals, parents and 
teachers demonstrated that leaders could use several communication techniques to encourage shared leadership and thereby build human and organizational capacity.

There is additional information in the literature to support the idea that teachers support organizational capacity, according to Jennifer York-Barr (2004). In her study, the concept and practice of organizational capacity and teacher leadership have gained momentum in the past two decades. Teachers are assuming more leadership functions at both instructional and organizational levels of practice. According to her study, empirical literature reveals numerous small-scale, qualitative studies that describe dimensions of teacher leadership practice, teacher leader characteristics, and conditions that promote and challenge teacher leadership. Less is known about how teacher leadership develops and about its effects. In addition, the construct of teacher leadership is not well defined, conceptually or operationally.

According to Elmore (2005), The No Child Left Behind Act of 2002 has placed the district at the forefront as federal and state accountability mandates hold districts increasingly responsible for the improvement in teaching and learning in their schools. After 30 years of focus on schools as the unit of change, results from research on the role of the district recognized that schools are embedded in systems and that the relationship between a district and its sites is critical to expanding the organizational capacity of the schools. Elmore states that many policy makers, reform organization, and foundations have emphasized the role of the district office in bringing about coherence in a complex policy environment and in promoting an environment of equity and support cross all schools in a system. A growing body of research documents that school districts are important agents of change and units of instructional renewal (Elmore, 2005; Baker et al., 
2000; Kaiser, 2005; Fullan et al., 2004; Mills, 2005).

Elmore also insists that the organizational capacity of schools requires leadership from a wide array of stakeholders. With respect to how leadership is shared, Elmore (1999) believes that school leaders are those who have the skills and knowledge to lead to the improvement of instruction and student performance. It is the responsibility of school leaders to "guide" instead of "control" teaching and learning. Elmore states that teachers as the "deliverers of instruction" have the best grasp of how to improve it. Thus, knowledge is shared or "distributed" in what he calls "distributed leadership" (p. 5). He defines distributed leadership as a system in which people operate in networks where expertise is shared as opposed to the traditional hierarchical forms of leadership where there is a clear division of responsibilities. Elmore feels that by distributing responsibilities for leadership and creating a coherent goal, improvement of instruction, the likelihood is increased that decisions made by principals and teachers will result in benefits for student learning.

After more than 30 years of effective-school research focused on the school as the unit of change, we know that schools are embedded in systems and that a close relationship exists between districts and schools. Fullan (2006) has argued that the organizational capacity for significant gains in learning achievement requires strong commitments coherent coordination from the district and local schools. As schools moved to comprehensive school reform models, many of which embraced all or some of the correlates of effective schools, it became apparent that actions by the district office could either support or constrain the effectiveness of the reform efforts. Research in the past 10 to 15 years recognized the critical role that a district may play in improving teaching and learning across the system. Studies have identified successful practices and/or strategies 
in successful districts that have resulted in system-wide improvement in instructional practices and student achievement.

NCLB has created a more tightly coupled educational policy system with an emphasis on aligned accountability systems and curriculum frameworks as a means of improving student achievement Kimmeleman (2006). The result has been an increased demand for coordinated communication and distribution of resources across the system. The research regarding effective districts emphasized coordinated efforts across the system when implementing reforms.

According to Kimmelman (2006), organizational capacity for educational practitioners is explained in the following terms:

It is essential to acquire the knowledge you need to do the specific school improvement work required by NCLB. Second, you need to manage that knowledge so it does not become so cumbersome that it makes the work too difficult, less likely to be focused, and not result in success. Third, you must use knowledge implementation, the process of professional development to transfer that knowledge into the actual work of the organization. (p. 32)

School leaders must draw on resources from the district to develop needed human capacity to acquire, manage and implement knowledge about student learning and the essential tools for continuous improvement.

\section{Knowledge Acquisition}

Kimmelman is asking educators to transform the data they collect into usable knowledge. He quotes a document from the American Association of School Administrators. In "Using Data to Improve Schools" (American Association of School Administrators, n.d.), the authors identify why data are important. They list 11 ways in which data for Knowledge Acquisition can be used for school improvement planning. Data should be used to: measure student progress, make sure students do not fall through 
the cracks, measure program effectiveness, assess instructional effectiveness, guide curriculum development, allocate resources wisely, promote accountability, report to the community, meet state and federal reporting requirements, maintain educational focus, and show trends.

Popham (2005) provides insight on how NCLB has cast a long assessment shadow over classroom instruction. Popham observes, "The authors of NCLB clearly wanted to improve student learning in the United States. Unfortunately, rather than spurring instructional improvements NCLB seems to be constricting the curricular thinking of education leaders" (p. 85). He points to a shift in focus toward NCLB compliance and assessment outcomes and not a student-centered approach to curricular improvement. Assessments within the context of accountability systems are frequently controversial. According to Kane, Staiger, and Geppert (2002), "The accountability debate tends to devolve into a battle between the pro-testing and anti-testing crowds. But when it comes to the design of a school accountability system, the devil is truly in the details" (p. 57). Kimmelman and other supporters of systemic school reform define these details in terms of specific steps that link the collection of student results with specific tasks of analysis that translate into concrete plans for changes in instruction for whole groups of students or targeted groups needing special attention.

No Child Left Behind, similar to other standards-based accountability systems, is predicated on a "Theory of Action" that standards, assessment, and accountability will result in transformative changes in public schooling. However, this theory is predicated on assumptions that may or may not result in desired outcomes. According to Elmore and Rothman (1999): 
Chief among these assumptions is the idea that teachers would institute effective practices if they had both the freedom and the motivation to do so. In addition, we question the assumption that motivated teachers would seek, guidance about improving instruction and districts would provide the support teachers need, largely by making more widely available the existing array of professional development opportunities. (p. 3)

Elmore and Rothman argue that standards-based policies need to be carefully tied to efforts to build the instructional capacity of teachers and administrators. They offer an expanded theory of action in which "the focus would be on teaching and learning, and the theory of action revolves around the links between all the elements of instruction" (p. 3). They propose a system where everybody (students, parents, teachers, administrators, and policy makers) has access to high quality information about instruction and student performance and uses this information to improve results.

According to Elmore and Rothman (1999), “Assessments in standards-based systems serve a number of purposes: guiding instruction, monitoring school and district performance, holding schools accountable for meeting performance goals, and more. No single instrument can serve all purposes well" (p. 4). They contend that the relationship between assessment and instruction needs to be well established and supported.

However, this is not always the case. According to Elmore and Rothman (1999):

The theory of action of the basic standards-based reform model suggests that, armed with data on how students perform against standards, schools will make the instructional changes needed to improve performance. Research on early implementation of standards-based systems shows, however, that many schools lack an understanding of the changes that are needed and the lack of capacity to make them. (p. 5)

If schools are to provide learning environments that are meaningful and engaging, educators must continually reflect on the quality of school systems and focus their efforts to make them better. 
Assessments can take multiple forms including essays, evaluating student performance, direct observations, portfolio assessment, and standardized tests, to name a few. However, norm-referenced or criteria-referenced standardized tests usually constitute the bulk of most assessment systems. Therefore, understanding some of the history and key issues associated with standardized testing is also necessary in understanding the theoretical underpinnings of No Child Left Behind.

Teams need to gather data that tell about the variables in the system on a continual basis. When working with achievement data, you do not want to make important programmatic decisions without a full view of how the students are learning. Yearly standardized tests are not adequate for a comprehensive assessment system. When analyzing the success of learning in the system, teams need to look at numerous sources of information to see if students are improving and showing growth. Therefore, state assessment data must be supplemented with other tiers of data to make sound instructional and programmatic decisions.

Kimmelman (2006) offers no specific definition of knowledge acquisition, but he outlines what he thinks is the most critical tasks for knowledge acquisition to build organizational capacity. He states: "acquiring and analyzing relevant data and using credible research or evidence-based information form reliable sources" (p. 35). This task is to help practitioners develop a knowledge framework for their school to build organizational capacity to comply with the No Child Left Behind Act (NCLB). It is important for school improvement teams to decide what data, research, technology, and professional development best fit their unique needs. 
Gathering data, using it properly, and supporting corrective actions with credible research and evidence-based programs will lead to successful school improvement. Using relevant data can eliminate guesswork about implementing new programs. Data will also provide concrete evidence regarding progress toward meeting specific goals.

Once schools have the data and educators have identified the problems that need to be corrected to be in compliance with NCLB, small, specialized learning communities, composed primarily of teachers, can begin considering how research can inform their work. The staff needs to make sense of the data and turn this data into usable knowledge. The learning communities should look at trends and patterns to see what they can do next to have specific patterns to correct difficulties they are confronted with. These teams can get organized so the data does not sit on a shelf and is therefore meaningless. A collection of procedures or sets should be in place for implementation. Evidenced based programs will lead to successful school improvement.

The "framework" developed by Kimmelman (2006) in this complex environment of high-stakes testing and accountability indicates strong leadership has multiple dimensions and can be carried out by many stakeholders in the system. Clearly, effective leadership can no longer be the sole responsibility of a single individual but rather effective leadership is about developing system-wide leadership capacity. The following section will examine the research regarding leadership capacity, with particular emphasis on distribution of leadership across the organization through expanding the role of the principal, the creation of professional learning communities, and finally the emergence of school leadership teams as a vehicle for building leadership capacity. 


\section{Knowledge Management}

In The Knowledge Management Toolkit, Tiwana (2000) states that knowledge is a "fluid mix of framed experience, values, contextual information, expert insight, and grounded intuition that provides an environment and framework for evaluating new experiences and information" (p. 5). The school has to acquire two kinds of useful knowledge: (a) local and state data and (b) curriculum resources and instructional practices that are reported in various research centers, universities and other educational agencies.

The best practice ideas for curriculum and instruction can be found in publications, web sites, and government educational documents. Kimmelman writes about knowledge management in the following terms:

In an era of information overload, it is important to know how you will manage knowledge so that it is both readily accessible and usable. Too much information can be overwhelming, but, contrarily, failure to use relevant information when it is appropriate can have a devastating effect on successfully implementing school improvement plans, which are critical to No Child Left Behind Act (NCLB) work. (p. 67)

In a field study, Amrit B. Tiwana (2001) tested the relationships between knowledge integration and e-business project execution success. A team-level theoretical model for knowledge integration was proposed and tested. Based on knowledgeintegration theory, the ability of temporary e-business teams to integrate their distributed, specialized knowledge into project-level architectural knowledge was hypothesized to influence project execution success.

This study extends information systems theory in five important ways. First, the influence of knowledge integration on project execution success was confirmed. Second, a new team-level predictive model for knowledge integration was validated. Third, a 
theoretically integrative measure for knowledge integration was developed. Fourth, the relationship between the structural attributes of temporary teams and knowledge integration was established, and finally, the frame of reference for success was conceptually extended and a scale was developed to capture the notion of project adaptation. Tiwana (2000) notes that knowledge management "enables the creation, communication, and application of knowledge of all kinds to achieve business goals" (p. 5).

Two British researchers, Black and Wiliam (1998), published an article summarizing a meta-analytic review of 250 research studies dealing with the use of classroom assessment. Their review resulted in two conclusions: (a) if teachers use appropriate classroom assessments with sufficient frequency, students better learn classroom material; and consequently (b) those students would also earn substantially higher scores on external achievement tests, such as those mandated by NCLB.

When feedback is specific to student performance and is given in a timely manner, then assessment becomes meaningful to students. Bringing the student voice into the assessment process also empowers students by helping them see their learning as an ongoing process on a continuum toward mastery, instead of a black and white or right and wrong judgment of their abilities. If a student is only subjected to communication of constant failure at the end of the learning cycle, the student begins to accept the message that he/she is not successful. In their noted work in formative assessment, Black and Wiliam (1998) state, "This cycle of repeated failure becomes part of a shared belief between such students and their teachers" (p. 2). The entire learning process is threatened when both teachers and students begin to develop this thinking. However, by empowering students to become a part of the assessment process and by incorporating 
their self-assessment along the way to mastery, student self-awareness and motivation toward learning can be cultivated.

Black et al. (1998) considered assessment to be any activity that provides feedback with the potential to modify teaching. The assessment becomes formative "when the evidence is actually used to adapt the teaching to meet student needs." Consistent with this definition, formative assessment comes in many forms; class work, homework, quizzes, class discussions, teacher observation, question and answer sessions, projects, performance assessments, simulations, and student conferences. The feedback or information from the activity must be used to enhance individual student learning. Implemented appropriately, formative assessment can be a powerful tool for increasing student achievement.

In Stiggins' book, Assessment Crisis: The Absence of Assessment for Learning (2002), he illustrates summative assessment as the attempt to summarize student learning at some point in time as a statement of judgment. These summative assessments (e.g., mandated state tests) are not designed to give feedback that would be useful to teachers or students during the learning process. Stiggins goes on to say that formative assessment (e.g., practice quiz) has all activities undertaken by teachers and by their students that will provide information to be used as feedback to modify the teaching and learning activities in which they are engaged.

Unfortunately, many struggling schools have few formal mechanisms for sharing information, and the flow of information is often top-down. As a result, the teacher grapevine is usually the primary means of communication. This information passed on from teacher to teacher is often incomplete. While it is acknowledged that increased use of formative assessment leads to higher quality learning, it is sometimes claimed that the 
pressure in schools to improve the results achieved by students in externally-set tests and examinations precludes its use.

School reformers argue that teachers and leaders in the future will need to use data warehouse information (Fullan et al., 2006). Kimmeleman describes knowledge management as "the process of using data warehouse programs that makes data and information accessible and understandable" (p. 68). It will include a wide array of assessment data on each student's academic performance, social conduct, and other pertinent information.

\section{Knowledge Implementation}

In his framework to support school improvement Kimmelman (2006) has identified knowledge implementation as the cornerstone of building organizational capacity. He believes professional development is the key to implementing a knowledge-driven system that is utilized by staff in a regular basis. The caveat is that the professional development must be researched based and follow the guidelines recommended by Rasmussen et al. (2004). The six steps for successful professional development planning that developed include the following: (a) gather and analyze the data, (b) set studentlearning goals, and align school improvement efforts with those goals, (c) define instructional strategies that address learning goals, (d) identify what staff needs to know and be able to do to in order to implement new strategies, (e) define professional development initiatives, and develop an action plan, and finally, (f) create a professional development evaluation plan.

Kimmeleman describes knowledge implementation as: "offering research and/or evidence based professional development that is embedded in the school's ongoing commitments to collaborative planning and the review of both successes and failures. This 
kind of collegial work setting is often defined as a professional learning community" (p. 92).

DuFour (2006) states that collaboration is evident in shared decision making and then stresses the idea that:

A school whose staff is learning together and participating in decisions about its operation requires a campus administrator who can let go of power and his/her own sense of omnipotence and omni competence and thereby share the leadership role of the school. (p. 2)

Principals cannot transform a school through their individual efforts. Building a school culture of collaboration is a collective effort that will ultimately lead to a school site with sustained professional learning communities. A community of collaboration has little chance to have sustainability without effective leadership. In the past, the role of principal has been identified by someone who was assertive and forceful, meanwhile, the more contemporary view of a principal defines a leader as someone who can work collaboratively with others (DuFour et al., 1998).

Professional learning communities empower the teaching staff to work together with administrators and other teachers to provide quality instruction and improve student learning. This portion of the review will explore the steps involved in establishing a culture of collaboration, the roles, the benefits and how teachers use data and share collaboratively to improve student achievement by changing instructional practices.

Based on research and experiences working in schools throughout the nation, DuFour et al. (2006) suggest the following steps that would help a school move forward in developing a professional learning community: Move quickly into action, within a short time a school should be able to establish a foundation by creating a mission, vision, establish a commitment to change, and create goals for the purpose of marking progress, 
build shared knowledge when asking people to make a decision, use collaborative teams to assist in the day-to-day decision of the school site, and use the professional learning community to identify existing practices that should be eliminated (p. 38).

As the commitment to developing professional learning community becomes fully embraced by a staff, the commitment to goals, the school's purpose and vision becomes more real, clearer, and more focused (p. 39). A key to developing a professional learning community is to build a culture in which teachers engage in reflective inquiry, share information, reflect on current practices, and are willing to change instructional strategies for student academic growth.

When a learner makes connections and learning takes place, it is because of focused teaching (Fullan et al., 2006). In an ideal world, the teacher would have precise and current knowledge of each student's starting points and also of what assistance each student requires to move to the next level. The way classroom instruction is currently conceived makes this virtually impossible. Most students, nonetheless, progress in their learning even though their teachers are not fully conscious of the specific learning needs of each of the students they teach. Students stumble through on the basis of trial-anderror learning and more or less appropriate instruction (Fullan, Hill, \& Crevola, 2006).

Coherence between the multiple levels of schooling, the classroom, the school, and the larger system (e.g., district, state, and federal jurisdictions) is an important precondition for successful school reform. The flow of schooling is disrupted when there is a lack of alignment and coherence. Teachers and school administrators receive mixed messages when no one direction is pursued consistently over time. Instead of flow, there is perpetual turbulence, and this tendency of systems to create turbulence confounds 
attempts to institutionalize systematic reform. When there is alignment, there is a much greater likelihood of sustained progress (Fullan, Hill, \& Crevola, 2006).

Spending a great deal of time on learning how to organize learning communities seems far less important than doing the substantive work that is required of learning communities (Kimmelman, p. 106). School improvement planners need to place a higher priority on involving teachers in substantive content and teaching strategy sessions than on devoting time to discussing how to organize the learning communities. The academic success of students is the ultimate goal of a professional learning community. School reformers such as Paul Kimmelman, Richard DuFour, and Michael Fullan make strong claims that successful cases of professional learning communities are now emerging in North America. Reformers now have the essential tools for implementing a knowledge system that can improve public school performance.

\section{Concluding Remarks}

This chapter has included Kimmelman's argument that the key to capacity building consists of three components: knowledge acquisition, knowledge management, and knowledge implementation. These are the essential building blocks for improvement, but will not be easy for many schools to successfully meet as they implement the requirements of No Child Left Behind (NCLB). In addition Kimmelman covers the implementation of NCLB by creating a knowledge framework to support school improvement and its major provisions of organizational capacity. Creating a knowledge organization will require time, commitment, effective leadership, reliable data, research, and resources. Kimmelman states: "The changes that are needed to improve education are embedded in the law and provide the basis on which school improvement should be planned" (p. 116). 
This chapter has also documented the historical background dealing with the No Child Left Behind Act of 2001 and its major provisions of accountability, scientifically based research, increased flexibility and local control. Furthermore, this chapter has explored new directions for developing a knowledge framework to support school improvement. This framework offers school leaders and policymakers new opportunities to answer the challenges of implementing No Child Left Behind. Chapter III will focus on the methodology of this study. 


\section{CHAPTER III}

\section{METHODOLOGY}

\section{Introduction}

The aim of this research project was to determine the positive and negative experiences of school leaders who are responding to the mandates of NCLB. It examines the ambivalent nature of educators as they examine the relationship between children of poverty and the education gap it causes. School leaders see the need for reform, but the mandates for improvement are never easy to implement.

The No Child Left Behind Act is intended to narrow the achievement gap between disadvantaged children and their peers in U.S. schools, ensuring that all students have access to quality teachers, and be proficient in math and reading. The process of change in urban schools and how to take ownership for the decisions regarding implementing interventions is not simple.

The following questions guided this study:

1. Are school leaders collecting and analyzing formative and summative student data?

2. What kind of activities are school leaders conducting to search and identify best instructional practices?

3. What kind of data management systems are utilized by school leaders to examine and review summative assessment identifying achievement gaps and trends for various student populations?

4. What kind of data management systems are utilized by school leaders to examine and review formative assessment identifying achievement gaps and trends for various student populations? 
5. Are the schools creating learning teams or teacher work groups to generate successful knowledge about student results, student learning, and appropriate instructional strategies that advance curriculum goals?

6. What kind of professional development opportunities are available to teachers who are expected to work both individually and collaboratively to achieve targeted achievement goals mandated by No Child Left Behind?

\section{Research Design}

As stated in Chapter I of this study, NCLB requires school improvement programs to be research based, sustained over time, relevant, collaborative, benchmarked, aligned to the district and school missions, and structured to improve student achievement and teaching strategies. By gaining insight as to how school improvement is attained, school boards, superintendents, principals and teachers will be better equipped to implement practices that produce results accordingly.

This study examined two urban junior high schools and how they are implementing mandates required by NCLB. This chapter addresses the qualitative inquiry of a two-school case study, the data collection process, and the analysis procedures.

For the sake of anonymity, pseudonyms were utilized for the names of the schools and the participants. In addition, when information was collected from sources (i.e., monthly school newsletters, district and school websites) in which the citation would compromise the confidentiality of the participants, the researcher cited the source with a pseudonym.

This research study was conducted using qualitative strategies in collecting and analyzing the data. This qualitative research project followed the method of "case studies, in which the researcher explores in depth a program, an event, an activity, a process, on one or more individuals" (Cresswell, 2008, p. 15). 


\section{Identification of the School District}

The researcher analyzed comparative characteristics of 217 schools located in South Suburban Cook County. The characteristics examined for comparative purposes were: race, academic performance, income, and parent characteristics. More specifically two school were found that were relatively similar in eight characteristics. The two schools that were selected had a cluster of similar categories (see Figure 1, p. 22).

This phase of the study involved the perceptions taken from interviews with administration and the teaching staff who were actively involved in decision-making relative to the implementation of NCLB. The participants for this study were selected from two urban South Cook County junior high schools: Washington Junior High and Stevenson Junior High (pseudonyms). The two junior high schools were selected for several reasons. First, the two schools had similar enrollment and similar ethnic student distribution. Second, the reading and math proficiency was similar. Third, both schools did not make Annual Yearly Progress for two consecutive years, which qualified both schools for Supplemental Educational Services (SES) in their third year. Distributive data is outlined in Table 2.

There are 47 school districts and 217 schools in South Suburban Cook County. After identifying the two junior highs, I contacted the superintendents to outline the study and to seek their approval and consent as gatekeepers of each of their respective school districts in an attempt to determine the efforts of two urban junior high schools implementing mandates of the No Child Left Behind Act (the reauthorized Elementary and Secondary Education Act). I assured the superintendents that the study would not intrude the day-to-day operations of the school, nor would the study in any way reflect their 
administration or the teaching abilities of their faculty. After securing their approval, I petitioned the school district for approval: Washington Jr. High and Stevenson Jr. High required proof of IRB approval as well as a written proposal before the study was approved. An Institutional Review Board (IRB) application through Illinois State University was submitted in March 2008. The approval was secured on April 3, 2008. After securing the IRB and School District approval, the assistant superintendents from both schools, the principals from both schools as well as three teachers from each junior high school were notified. The researcher provided the superintendents with an overview of the study and the selection criteria that was used for the two case studies. All key personnel agreed to participate in the research project.

All key personnel responded within 2 weeks of notification and indicated their willingness to participate in the study. Interviews were scheduled and conducted between April 2008 and May 2009. After interviewing all participants, Dr. Paul J. Baker, Principal Investigator, suggested I follow-up by scheduling a second interview with both superintendents and make follow-up phone calls to principals to clarify answers and perceptions taken from initial interviews about implementing NCLB.

The individual interviews were recorded to capture participants' exact wording and perspectives. Using Microsoft Word 2004, version 11.5.5, the interviews were transcribed verbatim by playing back the recordings (Merriam, 1998). The transcriptions were then transferred to Microsoft Excel 2004, version 11.5.5, under the appropriate numbered sections to promote organization and prepare for coding. All transcripts contained pseudonyms to protect the confidentiality of the participants. 
School site data collection occurred from April 2008 through May 2009. Followup interviews extended the data collection time line by 6 weeks. Ten days before each school site visit, the researcher requested specific documents and provided a copy of the interview questions. Prior to each school site visit, the researcher searched the district's internet web-site for background data and information for the particular school.

For the qualitative information, the researcher transcribed the interview notes. Once the notes were transcribed, the researcher color coded and organized the data into categories. This coding process suggested by the principal investigator allowed the researcher to categorize observation, interviews, and documents based on patterns to be able to retrieve such data at a later date. Once transcriptions, observer comments, field notes and documents were filed appropriately, the process of open coding began. Once a source of data was coded, it was transferred to the appropriate Microsoft Word section and then to index cards to facilitate the organization of data under specific categories.

The researcher and principal investigator reviewed all transcripts and coding and discussed the examiner's findings. In some instances, the principal investigator encouraged the researcher to consider other patterns or connections of the data and, in a few cases, questioned initial coding categories the researcher had developed. The researcher then reexamined and clarified those categories.

A case study for each school was written. Each case study captured the school's general background, history of implementing NCLB and Annual Yearly Progress (AYP) targets, key elements, and themes of the knowledge framework to support their school improvement process. 
A third school was identified as a backup-case in the event that either of the initial two schools refused to participate in the study (comparison and analysis was the same at all three schools). The third selected junior high school had similar categories of comparative distributive data. All three schools selected for analysis had key compatibility in the implementation of NCLB, age, academics, ethnic make-up, and mobility. Since the two initial schools agreed to be part of the research study, no backup school was necessary, so the third selected junior high school was notified and dismissed from the research study.

A qualitative approach was used to determine the attempts of urban school district leadership teams in implementing the mandates of No Child Left Behind. The qualitative method offered a way to investigate complex personal and social interactions between the participants in real-life situations (Merrian, 1988).

Using the systematic procedural guidelines (Creswell, 2003), specifically, information was gathered through documents and artifacts, review and analysis, structured interviews, observations, key information interviews and follow-up interviews.

\section{Data Collection}

This phase involved the fieldwork aspect of the study. The study was limited to the sample schools and to the organizational structure that was utilized. The results of this study came from perceptions taken from interviews with administration and the teaching staff who were actively involved in decision-making relative to the implementation of NCLB. Interviews were conducted in a systematic way, utilizing the same interview questions. All interviews were tape recorded and analyzed. Documents related to both implementing NCLB and school improvement issues. Information gathered from 
school/community newsletters, staff meeting minutes and agendas, and faculty and parent handbooks were part of the study.

Sixteen formal interviews took place during the 2008-2009 school year. Four interviews were with district superintendents, two were with assistant superintendents, four were with junior high principals, and six were with teachers. These interviews were always in an empty classroom, a teacher's private office, or an administrator's private office. They ranged from 45 minutes to 2 hours in length and were audio taped, transcribed, and coded. Both principals had their second-round of interviews via telephone. This study was not a random sample of the general education population, it was a purposeful sample (Creswell, 2003) aimed at understanding and gaining insight about how superintendents and leadership teams are responding to a complex federal law. This study consisted of a qualitative analysis of the data, using alignment of research questions with data collection strategies (see Table 4) as a guide in analyzing the responses of the interviewees as well as the information contained in the documents provided by the interviewees. Documents were used in the preliminary stage to interpret the district structure, organization, programs and actions directed toward NCLB. This helped the researcher make sound judgment of the interviews and observations. The data served as the basis for Chapter IV.

This study was divided into distinct components: site selection, rationale, data collection, fieldwork and data analysis related to qualitative methodological literature by Merrian (1998) and Cresswell (2003). A qualitative interviewing approach with descriptive methods of data collection was employed. To enhance trustworthiness, the 
researcher triangulated the data by utilizing "multiple sources (and) multiple methods to confirm the emerging findings" (Merriam, 1998, p. 204).

Table 4

Alignment of Research Questions with Data Collection Strategies

\begin{tabular}{|c|c|c|c|}
\hline & Observation & $\begin{array}{l}\text { Document } \\
\text { Collection }\end{array}$ & Interviews \\
\hline $\begin{array}{l}\text { Are school leaders collecting and analyzing } \\
\text { formative and summative student data? }\end{array}$ & $\mathrm{X}$ & $\mathrm{X}$ & $\mathrm{X}$ \\
\hline $\begin{array}{l}\text { What kind of activities are school leaders } \\
\text { conducting to search and identify best } \\
\text { instructional practices? }\end{array}$ & $\mathrm{X}$ & & $\mathrm{X}$ \\
\hline $\begin{array}{l}\text { What kind of data management systems are } \\
\text { utilized by school leaders to examine and } \\
\text { review summative assessment identifying } \\
\text { achievement gaps and trends for various } \\
\text { student populations? }\end{array}$ & & $\mathrm{X}$ & $\mathrm{X}$ \\
\hline $\begin{array}{l}\text { What kind of data management systems are } \\
\text { utilized by school leaders to examine and } \\
\text { review formative assessment identifying } \\
\text { achievement gaps and trends for various } \\
\text { student populations? }\end{array}$ & & $\mathrm{X}$ & $\mathrm{X}$ \\
\hline $\begin{array}{l}\text { Are the schools creating learning teams or } \\
\text { teacher work groups to generate successful } \\
\text { knowledge about student results, student } \\
\text { learning, and appropriate instructional } \\
\text { strategies that advance curriculum goals? }\end{array}$ & $\mathrm{X}$ & $\mathrm{X}$ & $X$ \\
\hline $\begin{array}{l}\text { What kind of professional development } \\
\text { opportunities are available to teachers who } \\
\text { are expected to work both individually and } \\
\text { collaboratively to achieve targeted achieve- } \\
\text { ment goals mandated by No Child Left } \\
\text { Behind? }\end{array}$ & $\mathrm{X}$ & $\mathrm{X}$ & $\mathrm{X}$ \\
\hline
\end{tabular}


The knowledge claims were based primarily on constructivist perspectives (i.e., the multiple meanings of individual's experiences, meanings socially and historically constructed with intent of developing a theory or pattern (Cresswell, 2003). As the process continued, the analysis began to focus on the main categories: organizational capacity, knowledge acquisition, knowledge management, and knowledge implementation.

\section{Data Analysis}

Data analysis involved a review of the documents associated with the implementation of No Child Left Behind. The researcher analyzed the school improvement meeting documents, background information, mentor meeting documents, and the curriculum staff development training documents. The researcher also examined school improvement documents and issues. Information gathered from school/community newsletters, staff meeting minutes, faculty agendas, and faculty handbooks were also part of this study.

The case was bounded by time and activity, and the researcher collected detailed information using a variety of data collection procedures over a 13-month period, from April 2008 through May 2009. After the 13 months had passed, the researcher reinterviewed the two superintendents for final clarification and concluding remarks. All of the interviews took place on school property.

\section{Case Study One-Washington Junior High}

Case Study One involved a K-8 school district located in an urban fringe suburb of Chicago, Illinois, with an enrollment of 486 junior high students. The district for this research had $76.35 \%$ low-income students and a $58.5 \%$ mobility rate. I interviewed key 
personnel including the superintendent, assistant superintendent, principal and three teachers all having various leadership responsibilities in complying with this complex federal law.

\section{Case Study Two-Stevenson Junior High}

Case Study Two involved a K-8 school district located in an urban fringe suburb of Chicago, Illinois, with an enrollment of 540 junior high students. The district for this research had 51.9\% low-income students and a 54.9\% mobility rate. I interviewed key personnel including the superintendent, assistant superintendent, principal and three teachers all having various leadership responsibilities in complying with this complex federal law.

\section{Limitations}

Some limitations to this study existed. For example, given the qualitative nature of this study, the findings could be open to other interpretation. Furthermore, since it was a case study, the findings may not be transferable to other schools with dissimilar socioeconomic make-up. Data collection was limited to the availability of data at each school site. Each site had varying capacities in their internal data collection systems. This impacted the ability of the researcher to collect specific information on No Child Left Behind at the two school sites.

\section{Summary}

This chapter presented the methodology and a rational for the methodology of this study. The population and sample selection were described. A description was provided of qualitative interviewing and data analysis procedures. The basis for validity and reliability of this study was detailed along with the ethical consideration of the study. 
To gain an in-depth understanding of how the implementation of NCLB addresses academic rigor and effective leadership, observations, document collection, and structured interviews were utilized. Meticulous data analysis, including open coding and personal interviews with key personnel, shed light on how NCLB's major provisions of accountability, scientifically based research, and local control illuminates the process and challenges school leaders and policymakers encounter when balancing a large range of tasks to meet federal and state accountability mandates of the No Child Left Behind Act. 


\section{CHAPTER IV}

\section{ANALYSIS OF RESULTS}

\section{Introduction}

This research study examined two junior high urban schools that are implementing No Child Left Behind. Special attention addressed the critical issues of building organizational capacity that allows schools to achieve higher levels of student performance. Chapter IV presents findings from a field study conducted at two urban junior high schools. The interviewees included district administrators, principals, and classroom teachers.

This chapter contains the followings sections:

1. A narrative case study report of two urban junior high schools.

2. Findings related to the six research questions that guided this study;

3. Emergent issues arising from the data not previously identified by the research questions.

\section{Case Study: Stevenson Junior High}

Stevenson Junior High is located in Cook County, Illinois, a collar suburb of the southern part of Chicago. It is situated 7 miles from the city limits. The population from the 2000 census was 28,000 . The community is served by four schools. The school district I studied consists of three buildings: an elementary (Pre-K-3), an elementary school (grades 4-5), and a junior high school (grades 6-8). This project focused on the junior high school. The school, which has an enrollment of 400 junior high students, is 
dealing with issues of low student performance, achievement gaps, and $66 \%$ of the students are low income. The mobility rate is well over $17 \%$; the state average is $15 \%$. Table 5 includes data from the Interactive Illinois Report Card and provides a profile of Stevenson Junior High.

Table 5

Profile of Stevenson Junior High School

Student Population by Grade:

$\begin{array}{ll}6^{\text {th }} \text { grade } & 117 \text { students } \\ 7^{\text {th }} \text { grade } & 142 \text { students } \\ 8^{\text {th }} \text { grade } & 138 \text { students }\end{array}$

Instructional Expenditure per Pupil:

$\begin{array}{ll}2005 & \$ 5,903 \\ 2006 & \$ 5,948 \\ 2007 & \$ 6,210\end{array}$

Operating Expenditure per Pupil:

2005

2006

2007
$\$ 8,415$

$\$ 8,592$

$\$ 8,599$

$\begin{array}{ccccc}\text { Ethnic breakdown: } & \text { White } & \text { Black } & \text { Hispanic } & \text { Multi-racial } \\ 2006 & 18.0 \% & 73.3 \% & 7.8 \% & .9 \% \\ 2007 & 10.7 \% & 77.0 \% & 10.1 \% & 2.2 \% \\ 2008 & 9.1 \% & 78.8 \% & 10.2 \% & 0.9 \%\end{array}$

Is the school making Adequate Yearly Progress? No

Is the school making Adequate Yearly Progress in reading? No

Is the school making Adequate Yearly Progress in Mathematics? No

2008-09 Federal Improvement Status: Choice and SES

2008-09 State Improvement Status: Academic Watch Status-Year 2

Note. Data from Interactive Illinois Report Card. 
Stevenson Junior High is located on the east side of town in a single-story building. The school is average in size compared to other junior high schools in the south suburbs. The staff is grade-centered with classes organized by grade level in designated areas of the building. The building is relatively new, very clean, well equipped, and well maintained, with many specially designed areas for student learning and student activities. Masters degrees are held by $41 \%$ of the staff, and the average class size is approximately 25 students. Teacher's salaries are significantly below the state average but are competitive for the market in Cook County suburbs, which competes for certified teachers. The school also has a principal and a full-time assistant principal.

The school missed the benchmarks for annual yearly progress for 2006-07 and 2007-08 years and now qualified for Choice and Supplemental Educational Services. The superintendent responded with a strategy to realign the district's resources to fund professional development, create teacher-hiring teams, and have multiple points of involvement for staff, community, and the school board. The failure to make AYP had a significant impact on the school improvement planning process. In 2008-09 the school made AYP.

In his address to the community from his web page the superintendent said the school would continue to emphasize quality educational programs. Their mission is "To do what is best for the kids to help maximize their potential as human beings." In addition they will be implementing their School Improvement Plan, which is based on the Illinois Learning Standards. The superintendent also stated that every employee of the district strives to accomplish these tasks on a daily basis regardless of his or her job assignment and that the administration will develop a quality organization where teachers will be 
managing systems based on sound educational routines.

The areas of NCLB implementation addressed by the superintendent included the specific requirements of the law for: testing students; providing school choice and supplemental services; and conducting family outreach.

A visit to the school validated the superintendent's comments. Administrators and teachers do have a philosophy that is student-focused, geared toward continuous improvement. The entire district uses teamwork strategies, with both standing and ad hoc groups, to focus on instructional issues and achieve desired student gains.

Illinois and federal law require that the Illinois State Board of Education provide technical assistance to schools and districts in academic early warning status (AEWS). Beginning in 2003, to help schools and districts improve their academic performance, especially in reading and mathematics, the Illinois State Board of Education established a regional system of support. Each regional service provider (RESPRO) offers its services to the schools and districts in its region that fail to make adequate yearly progress (AYP), especially those in academic early warning status (AEWS).

Stevenson Junior High has conducted Internal Reviews and has utilized that data in developing their school improvement plan, which identifies strategies, resources, and timelines for achieving their goals. For example, the staff focus is on reading and mathematic instructional reform strategies that address the learning needs of all students; however, the subgroup that is having difficulty in meeting AYP has been identified as the special education sub group. All other sub groups are making AYP.

Stevenson Junior High has worked hard to involve the parents. They have developed a parent involvement procedure and used mechanisms for parental outreach, 
such as parent coordinators, parent volunteer programs and school activities for parents. They also hold a yearly workshop for parents to explain NCLB requirements. Teachers make frequent parent phone calls to involve the parents. "I believe they [parents] stay because of the improvements we've made," said the principal. He added that the school's failure to meet its educational goals has served as a wakeup call. "The state test is forcing us to learn how to teach better. It has helped us do a better job of teaching." Central Office is responsible for developing the School Improvement Plan (SIP) that is a strategic plan for continuous school improvement. It is being developed through a collaborative effort with multi-stakeholders, including the building principal and teachers who chair selected school committees. The School/Building Leadership team is an 8-10 person group, which represents all subgroups within the school community, including community representation. The team meets weekly to generate reform plan suggestions, oversee local implementation of the school improvement plan, and participate in the evaluation of that implementation. The team generated the School Improvement Plan, and they work collaboratively to carry it out. This body makes local decisions regarding school-wide faculty professional development, expending SIP allocations to support implementation, setting agendas for faculty meetings, analyzing plan implementation data, and revising plans as needed to meet the changing circumstances. The School Leadership Team members lead by example, modeling reform strategies in their own teaching practice and communicate the reform model with fellow staff members. The data gathering teams conduct local walkthrough observations to document implementation of reform strategies. A leadership team spokesperson communicates to the parents and community regarding the SIP components and progress reports through 
face-to-face meetings, newsletters, and web publishing. The document includes specific strategies used to support targeted interventions. School leaders are concentrating on the goals they have set. This requires continuous monitoring of student performance data to ensure that students are achieving and reaching the benchmarks and identifying and targeting interventions to address achievement gaps.

In accordance with the No Child Left Behind Act (NCLB), students who attend schools identified as Title I Schools in need of improvement must be provided with the opportunity to request transfers to schools not in need of improvement. It is a complex and confusing process for parents, because the formalities of the procedure do not match local realities. The eligible schools in the area do not have space for transfer students. Choice is really an empty option. Schools are required to send a letter to eligible parents detailing the transfer process and given a timeline to follow. But, as the principal indicated, he believes the eligible parents allowed to transfer their child stay because of improvements Stevenson Junior High has made.

In 2007-2008, Stevenson Junior High did not make Annual Yearly Progress, which meant that their students were eligible to transfer to other schools. Since another junior high school does not exist in the school district, transferring within the district is not possible. The surrounding schools have denied any transfers to their schools. The superintendent sent letters to surrounding school districts asking them to accommodate his students, but was denied access to transfer. I was informed by the superintendent that no requests were submitted by parents to transfer. The district superintendent also denied any requests from other district superintendents wanting to transfer students into his district. His decision was based on unavailable space at the school. The principal 
believes there are a host of reasons for no one being able to transfer. Stevenson Junior High, like other South Cook County Schools, is in a large poverty area. Many parents are working more than one job and some do not speak English. Local educators sense that the parents may not feel well equipped to assess the advantages of choice as well as the merits of other schools surrounding their school district.

Stevenson Junior High is part of a curriculum cooperative called the Thornton Fractional (T. F.) Cooperative, which has a partnership with six public K-8 school districts in South Cook County. Partner districts share resources on several school improvement programs such as consolidated grant management, curricula development and alignment to Illinois Learning Standards Pre-K through grade 8. Articulation, professional networking, administrator academies, administrator seminars, customized staff development and in-class, on-site coaching are just some of the areas they cover. To promote teamwork, cooperation, and capitalize on effective strategies, the Cooperative pairs up schools. Administrators and teachers are given the opportunity to share ideas, resources, and strengths as they work to improve student performance.

Strong bonds have developed between paired schools and have encouraged administrators and staff to reach out to other principals and teachers, creating a larger personal and professional support network. The Stevenson Junior High principal stated:

I have at least six principals I can call for advice. It's gone beyond collaboration on curriculum and instruction, I can call if I have other issues, and if someone is having difficulty, we all pick up the phone to see what we can do. It has opened doors and fostered conversation and support.

The Cooperative has played a critical role in helping school leaders at Stevenson Junior High School develop various management projects. 
Stevenson Junior High test scores rose or stayed stable over the past 3 years, but I.E.P. students had missed the benchmark for 3 consecutive years (see Table 6).

Table 6

Stevenson Junior High's Math and Reading Global Scores

\begin{tabular}{|c|c|c|}
\hline Grade & Year & $\begin{array}{c}\% \text { Proficiency in } \\
\text { Reading }\end{array}$ \\
\hline \multirow[t]{3}{*}{6} & 2006 & 71 \\
\hline & 2007 & 63 \\
\hline & 2008 & 81 \\
\hline \multirow[t]{3}{*}{7} & 2006 & 70 \\
\hline & 2007 & 67 \\
\hline & 2008 & 73 \\
\hline \multirow[t]{4}{*}{8} & 2006 & 76 \\
\hline & 2007 & 83 \\
\hline & 2008 & 81 \\
\hline & & oficiency in Math \\
\hline \multirow[t]{3}{*}{6} & 2006 & 56 \\
\hline & 2007 & 68 \\
\hline & 2008 & 70 \\
\hline \multirow[t]{3}{*}{7} & 2006 & 61 \\
\hline & 2007 & 60 \\
\hline & 2008 & 57 \\
\hline \multirow[t]{3}{*}{8} & 2006 & 71 \\
\hline & 2007 & 68 \\
\hline & 2008 & 68 \\
\hline
\end{tabular}

Reading proficiency has remained strong and the students continue with substantial ability. The two weak areas they are working on are seventh and eighth grade math. Since the school failed to make AYP, it must now provide supplemental educational services. 
Table 7 shows wide variations in the sub group of students with disabilities in terms of meeting or exceeding math and reading. The students with disabilities scored significantly lower from all the other sub groups. In addition, there was a significant difference in the Black sub group and Economically Disadvantaged subgroup in meeting/exceeding mathematics.

\section{Table 7}

Stevenson Junior High's Math and Reading Disaggregated Results 2008

\begin{tabular}{lcc}
\hline Group & $\begin{array}{c}\text { Meeting/Exceeding } \\
\text { Reading }\end{array}$ & $\begin{array}{c}\text { Meeting/Exceeding } \\
\text { Mathematics }\end{array}$ \\
\hline White & 80.0 & 78.0 \\
Black & 75.2 & 61.4 \\
Hispanic & 77.8 & 68.5 \\
Students with & & \\
Disabilities & 28.0 & 23.5 \\
Economically & & \\
Disadvantaged & 73.2 & 61.0 \\
\hline
\end{tabular}

Interviews with the teachers from Stevenson Junior High reinforced the themes that they are trying to understand NCLB requirements. These reoccurring themes were lack of knowledge and lack of staff input. For the purpose of this study, lack of knowledge is defined as a general lack of understanding of expectations, components and premise behind the development of NCLB legislation, including issues of race/ethnicity, class, and gender. To quote these sentiments from teachers: "lack of training," "it's an accountability system," "poor communication from administration," and "poor communication about implementation." 
Stevenson Junior High began complying with this federal act the year of its enactment in 2002 . There seemed to be a willingness to comply with the law as indicated by the following statements from three different teachers. The first teacher acknowledged the importance of the NCLB act and embraced its goals.

The more everyone knows about this, the better off we can deal with the obstacles in our way and go forward with it, and enact the legislation to its fullest extent.

The next teacher reflected on the NCLB act as it included the parents and their role with the act.

The more I can educate my parents, the better off the whole community is going to be. The more we understand, the easier it is to deal with the parents and their issues with the law.

The next teacher felt that is was fundamentally under funded and it was a punitive law with counter productive sanctions.

I understand somewhat how it applies, and to special education and understand it doesn't come with adequate funding. How all students must be included in the assessments and annual yearly progress is a puzzle.

All the teachers at Stevenson Junior High school are required to participate and help facilitate the act. This is not an attitude problem; rather, it is a greater opportunity to develop needed improvements in the development of curriculum, instruction and assessment. More issues are discussed later in the research questions. For a 3-month span, I interviewed a proportion of the Stevenson Junior High staff trying to understand what their duties were and let them reflect their understanding of the NCLB act.

\section{Case Study: Washington Junior High}

Washington Junior High's community is part of a large first ring suburb in the metropolitan area of Chicago. The community is a first step for families eager to leave the City of Chicago. 
The closing of numerous business and area steel mills and factories has left Washington Junior High community and the surrounding south suburbs economically depressed. Unemployment has given rise to a number of related social problems, including substance abuse, violent crimes, family violence, and broken families. The school district, therefore, has a diverse population of students in terms of income, culture, and national heritage. The family income ranges from substandard poverty level to middle income, and the percentage of student turnover is extremely high. The mobility rate is well over $58 \%$, three times the amount of the state average. The low-income rate is $81.5 \%$ and climbing. These are challenging times for the district. In the last general election, the school referendum failed, and they have a growing school population. Table 8 provides an overview of the school.

Understanding the Washington Junior High community make-up and student populations is essential in gaining insight into local conditions that affect student learning and contribute to poor test scores. The socioeconomic status of the community surrounding Washington Junior High has changed considerably over the years from a solid, bluecollar working community to one with poverty well above the national level. A total of $81.5 \%$ of the students at Washington Junior High are eligible for free or reduced lunch.

The school district has a total enrollment of 1,302 students pre- $K$ through eighth grade. They employ 72 certified teachers plus 15 non-certified or support personnel. The class size average is 23 . The student population is 465 students in the junior high school. Master's degrees are held by $69 \%$ of the staff. 
Table 8

Profile of Washington Junior High School

Student Population by Grade:

$6^{\text {th }}$ grade

$7^{\text {th }}$ grade

$8^{\text {th }}$ grade
166 students

144 students

159 students

Instructional Expenditure per Pupil:

2005

2006

$\$ 4,623$

$\$ 4,637$

2007

$\$ 4,870$

Operating Expenditure per Pupil:

2005

2006

$\$ 8,156$

2007

$\$ 8,178$

$\$ 8,600$

Ethnic breakdown: White

2006

2007

2008

$3.5 \%$

$3.9 \%$

$2.2 \%$

Black

$75.5 \%$

$74.6 \%$

$73.4 \%$

Hispanic

$20.4 \%$

$20.6 \%$

$23.1 \%$

Multi-racial

$.6 \%$

$.9 \%$

$1.2 \%$

Is the school making Adequate Yearly Progress?

No

Is the school making Adequate Yearly Progress in reading? No

Is the school making Adequate Yearly Progress in Mathematics? No

2008-09 Federal Improvement Status: Restructuring Implementation

2008-09 State Improvement Status: Academic Watch Status-Year 6

Note. Data from Interactive Illinois Report Card.

Table 9 shows broad difference in the sub group of students with disabilities in terms of meeting or exceeding math and reading. The students with disabilities scored significantly lower from the other sub groups. In addition, there was a significant difference in the Black sub group and Hispanic subgroup in meeting/exceeding mathematics. 
Table 9

Washington Junior High's Math and Reading Disaggregated Results 2008

\begin{tabular}{lcc}
\hline Group & $\begin{array}{c}\text { Meeting/Exceeding } \\
\text { Reading }\end{array}$ & $\begin{array}{c}\text { Meeting/Exceeding } \\
\text { Mathematics }\end{array}$ \\
\hline White & $*$ & $*$ \\
Black & 69.3 & 55.4 \\
Hispanic & 75.5 & 74.5 \\
$\begin{array}{l}\text { Students with } \\
\text { Disabilities }\end{array}$ & 48.5 & \\
$\begin{array}{l}\text { Economically } \\
\text { Disadvantaged }\end{array}$ & 68.5 & 41.5 \\
\hline
\end{tabular}

* Only the scores of subgroups with 20 or more students are used to calculate AYP with exception of Special Education and Limited English Proficiency, which must have at least 40 students.

Upon careful review of their school improvement plans, weekly and monthly school newsletters, website information about the school mission, vision and building goals and improvement initiatives, I was able to extract from their documents the core ideas about District's strategy to implement No Child Left Behind. The district office is making an effort to design a framework that identifies the goals, policies, and targets of Washington Junior High. "I think it is important for a faculty to have a common set of beliefs," the assistant superintendent stated. The building principal said, "Sometimes teachers get so wrapped up in the little stuff that they need to be reminded of where they are going."

Their mission statement was developed and adopted 8 years ago using a lead consultant, community members, staff, and students. The mission of Washington Junior High Junior is to develop responsible, productive, well-rounded citizens by providing a 
balanced curriculum that promotes self-esteem and creative, independent problem solving skills in a safe atmosphere of trust, respect, and cooperation.

The school leaders assert a deep commitment to the education of the children.

The principal explained:

We realized that we needed a framework to express to students [and parents] who and what we would like our students and school to be-that is, an environment that fosters respectful and responsible students.

Washington Junior High had not met Annual Yearly Progress since 2003 and, therefore, qualified for Supplemental Educational Services, Choice, Restructuring and other sanctions. Reading and math after-school extended learning had been offered to Title 1 students that qualified for the supplemental education service (SES) as outlined by NCLB. Data on the use of SES by eligible students at Washington Junior High was sketchy at best. The district did not have data available regarding the percent of eligible students using SES, making it difficult to gauge whether these students had access to adequate and appropriate Supplemental Educational Services. Table 10 presents trend data for the past 3 years. The math and reading scores show all areas are consistently above the AYP benchmark apart from the 2008 seventh-grade math.

Missing State benchmarks results in a school not making AYP. Progress was made at Washington Junior High even if it wasn't enough to make AYP. For example, the junior high shows noteworthy gains when these pass rates are compared to the last 2 year's final pass rates listed in reading and sixth-grade math. The seventh and eighth grade math proficiency shows a slight decline in the 3-year results.

Washington Junior High adopted school uniforms for students and a 6-hour 40minute student day. They also employ two school resource police officers and strive for 
a safe and comfortable school environment for students, community, teachers, and administrators.

Table 10

Washington Junior High's Math and Reading Global Scores

\begin{tabular}{llc}
\hline Grade & Year & \% Proficiency in Reading \\
\hline 6 & 2006 & 44 \\
& 2007 & 51 \\
& 2008 & 60 \\
7 & 2006 & 51 \\
& 2007 & 52 \\
& 2008 & 75 \\
8 & 2006 & 71 \\
& 2007 & 61 \\
& 2008 & 73 \\
\hline & & \% Proficiency in Math \\
\hline \multirow{2}{*}{6} & 2006 & 53 \\
& 2007 & 56 \\
& 2008 & 65 \\
7 & 2006 & 54 \\
& 2007 & 60 \\
& 2008 & 54 \\
& 2006 & 65 \\
& 2007 & 52 \\
& 2008 & 56 \\
\hline
\end{tabular}

Note. Data from Interactive Illinois Report Card.

Another program identified to foster teacher collaboration is a teacher-mentoring program. Washington Junior High has a formal mentoring program that has been in practice since 1995. Each new teacher is assigned a mentor for 2 years. I was invited to 
attend a mentoring meeting and observed the program as being part of the school's professional development program and not just an informal meeting. They encourage and support professional teacher growth. I was told during my interviews they believe it is a way to retain experienced staff and new teachers.

Washington Junior High has adopted a behavioral education model to maintain order in the classroom and throughout the school. It is labeled Classroom Community and is recognized as a common discipline program for the entire staff, who view it as a content curriculum area similar to math, science, social studies, and language arts. It would be described as a discipline model. The staff view it as a content area similar to math, science, social studies, and language arts. By accepting discipline as another subject area, the staff accepts the responsibility of planning and teaching "discipline lessons." The overall goal of this preventative discipline approach model is for students to learn to be self-disciplined and ultimately responsible on both an individual and social level.

Students learn how to make good sound decisions. The principal explained that she wants the teachers to provide students the information and skills required to make decisions, allow them to make the decisions, and, most importantly, respect them enough to allow them to accept responsibility for their outcomes, both positive and negative. This is done systematically by having students develop Community Contracts, establish goals, participate in Community Meetings and, when necessary, design individual Responsibility Plans. By continuously putting students in situations to make individual and group decisions and helping them to accept their victories and defeats, they develop an internal locus of control. They learn that they alone control their outcomes. They 
realize that they always have a choice to make, alternative behaviors from which to choose and, most importantly, the ability and responsibility for choosing and acting on their best socially responsible option.

Washington Junior High replaced its principal at the end of the 2007-2008 school year. No other options or choices were acted upon as a restructuring school. Other options included: entering into a contract with an outside organization with a record of success and effectiveness to run the school, reopening the school as a charter school, and turning over the school to the state. As I spoke with the superintendent about the school board and administrative actions, he thought policymakers should broaden, not narrow, the options available for restructuring school and consider using strategies that specifically use data to identify areas in which students are struggling.

As stated earlier, the superintendent released the junior high principal and brought in a new principal from outside the school district to address the low achievement and gaps in student learning and to address their School Improvement Status according to Illinois Law, Corrective Action and Restructuring Implementation. During the last few weeks of my interviews at Washington Junior High, the faculty expressed surprise after hearing of the principal's dismissal.

While the administration and the teachers see No Child Left Behind as good for the most part, with its upcoming reauthorization, they are hoping the law will take into consideration the struggle schools are having, especially schools located in high poverty locales with very high minority student populations and high mobility. They are hoping that targeted categories will be eliminated and consideration will be given to models of growth and gains. 


\section{Findings}

In this chapter, I examined how the participants in this study demonstrated the Implementation of No Child Left Behind in their districts, buildings, and classrooms. I interviewed superintendents, assistant superintendents, principals, and teachers and asked six questions regarding their understanding of NCLB legislation and their view and role within their school as it relates to NCLB. The majority of the respondents conveyed openness on the subject of NCLB.

Three major themes are identified as critical to the successful implementation of

NCLB: knowledge acquisition, knowledge management, and knowledge implementation.

The six research questions are derived from these three themes:

1. Is your school district collecting and analyzing formative and summative student data?

2. What kind of data management systems are utilized by your school district to examine and review summative assessment identifying achievement gaps and trends for various student populations?

3. What kind of data management systems are utilized by your school district to examine and review formative assessment identifying achievement gaps and trends for various student populations?

4. What kind of activities is your school district conducting to search and identify best instructional practices?

5. Does your school district create learning teams or teacher work groups to generate successful knowledge about student results, student learning and appropriate instructional strategies that advance curriculum goals?

6. What kind of professional development opportunities are available to teachers who are expected to work both individually and collaboratively to achieve targeted achievement goals mandated by No Child Left Behind?

\section{Research Question 1}

Is your school district collecting and analyzing formative and summative student data? 
In the past two decades, the conventional wisdom for school improvement has made a fundamental change. When schools design curriculum, choose instructional strategies, and prepare for program implementation, they must also plan for data analysis. There are two essential perspectives for data analysis: summative analysis and formative analysis. Summative analysis is collecting and presenting information that is necessary to make final statements and judgments about the value of an activity, usually at the end of a period of instruction. Formative analysis is the continuous monitoring of short-term results and procedures to provide feedback to learners as information to improve achievement. Students must be involved in the assessment process. The use of descriptive feedback would be helpful and must be useful information for the student, for example, a practice quiz. No judgments in this process should be made by the teacher.

With the prominence of summative assessment (ISAT) by the Illinois mandated annual test, the vision is often skewed because staff sees the summative aspect of assessment and data analysis as providing sufficient information and motivation to increase student learning. To counteract this situation, many school reformers argue that administrators and teachers must collect and analyze additional formative student achievement data to help improve instruction and student learning (Stiggins, 1997).

The intent of Research Question 1 was to provide a framework for understanding the merit for making informed decisions about various aspects of assessment. Are district and school leaders using several approaches to collect and analyze both summative and formative assessment data? I looked for standards of accuracy and quality in classroom assessment to see if clear learning targets had been established. I also looked for assessment methods to see if they matched learning targets. One of the more interesting themes 
that emerged from this study was the differing focus and design of the educational staff involved in planning and implementing "Knowledge Management."

Stevenson Junior High. The superintendent strongly expressed a concern that in two student demographic groups, ESL and Special Education, the annual yearly progress did not show sufficient progress to meet the AYP targets. On the other hand, because of the changes in testing practices brought about by NCLB, the superintendent felt that the methods used to assess student achievement has slightly improved across all student demographic groups.

We analyze the ISAT data after the state analyzes the data and sends it back to us. We look at how the students are doing. Are they making progress? We are looking at reading scores, math scores and computation scores and things like that. We are using those scores as they come back from the state.

During my interview with the superintendent I wanted to examine the basic issue of formative and summative assessment at Stevenson Junior High. I was looking to see if they had a system in place for teacher training, data analysis and student feedback. I framed my interview to extrapolate the superintendent's thoughts, ideas and common practices along with his judgment and strategies regarding student learning. He talked about formative assessment for meaningful student achievement. He also indicated that he constantly reinforces his curriculum director and building principal to provide staff with the assurance that good instruction and quality formative assessment will result in higher scores.

Let me be clear about my mission as educational leader here. I know we have to improve, and I know we have an obligation to this community to help students learn and we need to show this community evidence that students are learning. The superintendent expressed a feeling of frustration with other factors along with mediocre student achievement including discipline, teacher union grievances, lack of 
local, state and federal funding and dealing with difficult parents. After listening to his candid concerns, we refocused on student learning and how his office is using formative assessment as a more productive process. He feels that instructional decisions made dayto-day in the classroom are having the greatest impact. He stated that they are working on building their formative assessments so the building principal, consultants and lead teachers can model for the classroom teachers and then teachers can execute and bring about meaningful student performance.

My research on the effects of formative and summative testing yielded the fact that, according to the superintendent and his administrative team, once-a-year standardized tests cannot provide sufficient information or motivation to increase student learning. In contrast, supportive classroom assessment with small test score gains can be attributable to the presence of proper use of classroom assessment as a high-quality school improvement tool.

The assistant superintendent had a clear idea of what needs to be accomplished to satisfy requirements of the law. He indicated that they will continue to try and design, deliver, and analyze additional sources of meaningful student data and distribute the results to the principals, teachers and parents.

When we design curriculum, choose instructional strategies and prepare for implementation, we are also planning for data analysis. With state-mandated tests, our vision is skewed because we only see the summative aspect of assessment and data analysis. We want to actively collect and analyze other formative student achievement data to help improve student learning.

The assistant superintendent expressed concerns for a push for Federal standards to level the playing field. He felt that the definition of proficiency is up to the interpretation of each individual state. Very little prevents states from developing easier tests to 
avert poor scores and then schools with high state standards are similar schools as underperforming. State standardized testing, as it exists across the United States, encourages only superficial progress. If the entire point of the individual state exams is to hold students to a set of standards, and no real standard is even established, the tests are not accomplishing the goal of closing the gap.

The building principal discussed the school practices of educating the whole student with an ongoing process of improvement. He supported the idea of continuous improvement at Stevenson Junior High.

The second year I was here the teachers put in graduation requirements. Even fifth through seventh grade need requirements to move to the next grade. On a quarterly basis we send out a report sheet to all parents letting them know where the child stands. The teachers generate this report. This program has been put into place with the help of the staff. There is a rubric in place and students need to qualify by points in this rubric to move up to the next grade level. This is our "Standards of Promotion."

The principal described the importance of teacher leadership in developing the Standards

\section{of Promotion.}

The eighth grade teachers, one in particular, started doing some research and looking at student report cards in student files and found that students not making the grade to qualify for graduation were the same students that were failing all the way along their grade level and in various subject disciplines.

This teacher focused on students and their attitude about learning and student achievement while at Stevenson Junior High. Assessments and results took a seriousness that was previously missing. The school rarely monitored grade-to-grade level performance throughout the students time spent in their school system.

The leadership team wanted other faculty to listen to them. As a team they would look at different types of models and various types of research and they would put together trend data. This document would then hold up as a standard. I thought it was a good idea that they put in Summative and Formative results to guide their study. We have student accountability with three components; one is 
achievement on the ISAT, having a solid GPA and, good solid behavior. Again, we call it "Standards of Promotion."

As a result of "Standards of Promotion," all assessments became more accurate, and teachers adjusted accordingly.

Some teachers at Stevenson Junior High are aware of the need of several assessment tools to help students prepare for the rigorous academic and social demands of successful high school participation and completion. Schools can only get from here to there if we create structures that enable them to be learning labs.

One teacher, who had been a middle school teacher for 9 years, explained:

We do some cognitive and ISAT testing in the spring. We do pre and post test for reading, math, phonics and writing. We also use Aimsweb, we test three times a year and kids that are monitored are tested every 2 weeks. . . We have been collecting data for some time now. The District looks at the ISAT and reports to Parents and I look at the classroom tests and report to the Principal and Parents of my students.

This teacher believes in the practical detail by looking at the data, coming to a conclusion, finding relevant research, and implementing interventions.

While some teachers spoke about the importance of collecting and analyzing student data, others did not seem informed or involved in the data analysis. As one teacher stated:

We really don't analyze data. The assistant superintendent meets with the principal and talks about ISAT, we really aren't involved.

Another teacher had similar views:

You don't have everything to make sure you are not leaving any child behind... there's a lack of training, there's a lack of knowledge, there's um... it's hard to explain.

The narrative statements of the last two teachers interviewed show a limited understanding of knowledge management. The third teacher (teacher \#3) shared common 
beliefs in not taking ownership for decisions regarding implementation of interventions to assist in progress or identify difficulties in student learning. Anything past benchmark attainment and yearly test preparation was beyond her reach. This educator still appraises student learning the way her predecessors did 25 years ago, because she has not been given the opportunity or chooses not to learn about new insights and practices.

Washington Junior High. The Washington Junior High superintendent acknowledged that district-wide reform is complex and involves many levels of leadership and teacher cooperation:

We work within the existing NCLB rules and regulations to maximize benefits for every student. I see our staff as being on the same page and the same team. It's a complex process, but it's guided by simple principles.

The superintendent distributes a formal bulletin at the beginning of the school year to all staff. According to the bulletin, the message supports his claim of NCLB being a complex process but that there would be performance standards distributed, review of initiatives, and workshops throughout the school year to assist staff to analyze student data.

Washington Junior High has a history of academic failure, according to the State report card and requirements of NCLB. They are in restructuring and struggling to keep pace with Adequate Yearly Progress.

We have been given standards and benchmarks by the State, and these standards are a roadmap to instruct our students to attain higher scores. Our students are struggling; we keep seeing reduced achievement, increased dropout rates at our feeder high school and cloudy futures for our students, especially our minority students.

The planning process is in place and has the required elements: vision, need statement, ISAT assessment data, goals, objectives, and strategies. What seems to be missing is a relationship to what happens in real day-to-day activities in the building and classrooms. 
This is a district that has had, since the inception of NCLB, 6 years of failed attempts that yielded very little improvement and cannot get limited-English learners or special education learners to the baseline proficiency for AYP. The superintendent agreed they should, at the very least, identify the things that don't work.

My head is on the block, if we don't make AYP this year, and we won't make it, I will have some serious issues to contend with. We need to make AYP for 2 consecutive years to get off this academic watch list. We are in restructuring and we need to make some tough decisions. We can't figure out how to motivate the students.

The superintendent verbalized that they have to work on school reform and restructuring. Too many teachers continue to think of schools as being a static environment, as if it will never change. He worries that the teachers and principal will continue to follow an image of public education that may no longer work. The very purpose of schooling may be shifting, whether we want it or not. Somehow, schools need to be interactive and on the forefront of societal change. Unfortunately, the superintendent was unable to articulate a clear vision of what the school needs; he is placing his hopes on the principal.

We will need intense human resource work and the ability to adjust to meet these new challenges. Our building principal calls this productive conflict.

The superintendent believes the right attitude and strategies need to be in place for his district. The assistant superintendent sees this attempt in large-scale improvement as a "crusade." The assistant superintendent had a succinct answer to the question raised.

Yes, it is our duty to collect and analyze formative and summative student data. Performance data is collected and assessed to fine tune identification of where we need to be.

Although the assistant superintendent has taken an active role in the school reform process, with all of her other job responsibilities, she stated that she could not shoulder the 
entire burden on her own. She had to rely on her building principals to further the effort.

The principal's remarks echoed the superintendent and assistant superintendent's remarks:

We do analyze formative and summative student data in order to improve our scores. Our primary focus was math and secondary was writing. The assistant superintendent meets with me and we talk about strategies and techniques for student learning. We are all working to get from the bottom rung of the academic watch list.

Although they analyze data, there was little evidence to show high quality formative assessment and needed resources to support school-wide reform initiatives. Prior to the NCLB act, the school improvement practices at WJH were quite limited in scope. What summative and formative analysis occurred was limited or nonexistent.

While interviewing the staff, there was little evidence that data analysis was being used. Evidence of training was not apparent nor were committed activities or practices regarding knowledge management. There doesn't seem to be a sustainable practice in place. Quotes from three teachers explain:

Yes, We have been collecting data over the years. I look at the formative results and report to my building principal and parents at open house.

Yes, we do monitor test scores.

I rely more on my test results then the ISAT scores that are distributed to me for student learning.

All three teachers felt that it has taken several years to understand the requirements of NCLB, and they still don't fully understand the act.

These teachers spend significant amounts of time concentrating exclusively on the material covered in the yearly ISAT exams. They complain that more time is spent stressing the basic skills that the exams cover. Students cannot excel if they are constantly being held back at a fundamental level. Proponents of the testing argue that it 
is a necessary means of measuring proficiency in certain academic areas. These teachers feel it is an inconvenience but will go in the direction given by the Administration.

Seven months after these interviews, the building principal was released and Washington Junior High went to single gender classes at the sixth, seventh, and eighth grade level. Again, this is Year 6 for School Improvement. The Law states: Schools not making AYP are identified as "School Improvement," "Corrective Action" or "Restructuring." Washington Junior High is in restructuring.

\section{Research Question 2}

What kind of data management systems are utilized by your school district to examine and review summative assessment identifying achievement gaps and trends for various student populations?

Stevenson Junior High. Certain kinds of traditional assessments that are used for summative purposes contain useful information for teachers and students, but these assessments are usually infrequent, come too late for action, and are too coarse-grained. According to the superintendent, the success or failure of district leadership is determined by how well all students perform on these tests. The district office at Stevenson Junior High produces annual reports addressing the ISAT test results that are shared with all members of the faculty, students and parents every fall as required by the Illinois State Board of Education. The administrators at Stevenson Junior High shared with me the need to actively pursue a data management system that would assist in providing additional academic help and identify subgroups not achieving on par so they can keep pace with the rest of the states accountability requirements. The Stevenson Junior High teachers I interviewed have a desire to provide timely and effective academic help to subgroups not achieving on par with the rest of the district's students. 
The superintendent indicated that the district gathers and uses achievement data to modify and develop programs to meet the needs of the entire school population. It was apparent during the interview that the superintendent delegated the leadership of each school and program to the school principals and other administrators. He did have an understanding of knowledge assessment methods.

Once we get the ISAT information back from the State that information flows back to the principal and then the principal talks to the leadership teams about the analysis. The principal then reports to my office or the assistant superintendent during our administration cabinet meetings. We enhance or work the ideas and then the principal takes it back to the teams and then back to the classroom so it is a constant two-way flow.

This superintendent is a strong leader and embodies many traits of an instructional leader.

We do get preliminary data as early as June. We have a RESPRO program through the ISC \#4, they came in and spent a half-year with us meeting with the principal, teachers and even me. They kinda developed a picture, if you will of curriculum and instruction. From the report we make adjustments and changes. We will do curriculum mapping in Math. We have reading specialist in both buildings and we feel that we have spent a lot of time and resources on reading. Now we are going into the neighborhood of math.

He pays attention not only to his principal but also takes into account teachers' perceptions of student learning and how to go about achieving it.

The superintendent indicated that he has an open door policy. He encourages administrators along with team leaders to give input and ideas regarding the flow of summative student data and how the scores can keep pace with the annual yearly progress that has been established by NCLB. He talked candidly about achievement gaps, goals, action plans and timelines. It was the superintendent's opinion that his school has gained a great deal of ground the last few years in analysis of data, data decisions and delivery of best instructional practices using summative data. 
The assistant superintendent meets with Stevenson Junior High staff members and encourages close communication among all parties. "I usually meet with the Title I director, Resource Lead teachers and the Principal. We meet three times a year." He is aware that Stevenson Junior High faces some challenges in the area of effective curriculum development and instructional practice to improve student performance. He assured me that the district's curricular practices were moving in a positive direction. Efforts were underway to use results from formative and summative assessments in math and reading; however, the district has a need to established a system and gather this information from each classroom so that principals and teachers can examine grade-wide results. He believes some progress has been made: "As a result of an examination of data, the district increased instructional time in core content areas to address student needs."

Probably the most apparent aspect of the assistant superintendent's involvement in the NCLB act is the support and encouragement he gives the principal and teachers. He seems to be in total control of the budget, computers, and facilities. He knows about NCLB, but it is apparent he relies on the principal, special ed director, and team leaders to carry out the work of closing the achievement gap. When asked if his experiences with NCLB had caused him to become more involved in data analysis, data management systems, achievement gaps and trend data, he answered with a resounding 'yes'.

The principal has some very clear thoughts about summative assessments. The principal reflected on what his experiences have been while dealing with summative data and being the man in the middle.

The documents from the State arrive in the fall, typically late October. We then sit down with the staff and get a game plan. The results are handed down from the district office. We have one level of shared ISAT information. The district 
and the building identify the data jointly. In the past we have gone back 3 years looking at trend data to compare if there is academic growth with the students.

His leadership has a relentless focus on student achievement. Everything he talked about and planned always came back to the children's learning. He frequently talked about data and practices and worked to get teachers to do the same.

Our school reform strategy relies heavily on examining and reviewing summative assessment. We use the Northern Illinois IRC for manipulation and coding gaps and trend data.

The principal clearly articulated his views on the importance of the investment in knowledge management. He went on to say that looking at and knowing what the data indicates about student achievement and instructional practices that need to be improved is paramount. This will be an essential task for our teachers.

I use the ISAT data; I disaggregate it per group and per grade level. I use to do all the charts and data, but now that the State does it for us. When it is legitimate data that really is accurate I look at it and I will look for the red flags and say uh oh. It is extended response they were really weak on. I will then develop a professional development day that will actually explain writing so that it is specific not to just teach the students how to write but how to write and explain how they learn.

Thus, the principal makes a concerted effort to secure resources that helps move the school's vision and focus on achievement forward. He then went on to describe the crucial role of leadership teams.

The teams are responsible for setting up the ISAT schedule. The leadership team, along with the administration reviews the ISAT results. We download the data onto spreadsheets and look at trends and patterns. Each building is responsible for the collection of the data and then it is sent to district office. We let every staff member use the data to their advantage and encourage them to use this data for identifying gaps and help group students. We identify gaps and filter the information to appropriate staff. We review the results through the State website and NIU's website. Our assistant superintendent relays results and stanine scores of students so we can focus in on specific students for extra help to achieve and meet AYP. 
He also makes extensive use of the IRRC assessment tool.

We use the IRRC. It's a very powerful and informative web based software package than can segregate data to meet our needs and assist with our analysis.

The school's administrators and especially Stevenson Junior High principal, and teacher leaders are committed to the data analysis. The principal and his lead team are trying to understand what the summative data is saying about student achievement and the instructional practices that need to be re-examined to yield better results. The school's teaching staff that I interviewed also concurred with the sentiments of their administrative team. There needs to be student information and achievement data that can be used by classroom teachers to inform them of their work at different times of the year.

We review summative data with our grade level teams. Usually, three times a year. We work with the administration to extrapolate the data. Our reading specialist along with the assistant principal collects the data.

As mentioned earlier, the principal does his best to secure the resources teachers need. Also, by listening to teachers and trying to work through their issues with them, and supporting them in different situations some teachers feel his leadership is genuine. But other staff are not on the same page or feel that they are part of the total movement as reflected in this statement. To quote one of the teachers:

We receive computer-generated reports, so I guess it's stored on the computer. We distribute the ISAT data to the students to take home. The principal usually dedicates certain faculty meetings to discuss the scores. It's a one-way discussion, he talks we listen. We have not been asked to review the results with him, but that's not a bad idea.

In general, Stevenson teachers are held accountable for their teaching quality, and data analysis. The statement that follows reveals the close tracking student data teachers maintain, including math, writing, reading and communication assessment for each 
student. This is no small task:

With the ISAT results I look at the scores from last year. I teach Math so I look at the Math extended and short response to see how much focus I need to put at the beginning of the year until March so the students will have opportunities to do well on the test. Our grade level team will look at ISAT in reading and writing. In October we see how we did last year. ISAT results are sent home to the parents in late October. I am not sure the parents fully understand the data. We evaluate each student with team leaders.

Washington Junior High. Many observers have written about the challenges

facing district superintendents who are more focused on carrying out their management functions than on developing their capacity to improve the schools under their jurisdiction. The superintendent from Washington Junior High reflected this tension between managements tasks and instructional leadership. The following narrative statements illuminate the student achievement support the superintendent gave while serving in this leadership position. To quote the superintendent: "I am constantly being pulled in so many directions. I have full faith in my administrative team to execute academic decisions and support the staff with data that will drive instruction."

Our assistant superintendent is responsible for collection, and she takes that data and submits it to the principals and they analyze it together. We have set up teams to look at trends in data and report back to the teaching staff.

He has chosen to delegate the school improvement agenda to his subordinates.

He delegates this function to his assistant superintendent for curriculum and instruction. The assistant feels that he does not support her efforts or in some way he does not cause the principals to act with urgency on her behalf.

The assistant superintendent said that efforts were underway to use summative assessments in math and reading; however, the district had not yet established a "system" to gather the data from each classroom so that principals and teachers could examine 
grade-wide results. The assistant superintendent meets with all staff members and encourages close communication among all parties. She understands that the district faces some challenges in the area of data analysis, effective curriculum development, and instructional practice to improve student performance and she assured me that district was moving in a positive direction.

The assistant superintendent articulated a much clearer vision for leadership at the classroom level then the superintendent of schools. She alluded to the fact that the most important aspect of this process is to manage this information that makes it relevant and understandable. She stated:

Unfortunately, I have modeled for the principals, I have spoken with them, I have sent them to professional development, and seminars and nothing seems to move them. They don't fully understand the consequences of failing to read data that supports instruction. They just don't get the importance of managing the data.

It was apparent the assistant superintendent was frustrated with the lack of enthusiasm the principals show in analyzing, utilizing and distributing the data to staff to help increase achievement and fill in the gaps.

We use the NIU website. It is a tremendous web site. I have downloaded our data to our website. I use to send them a data disk so they could manipulate it. The idea is that I don't have to hand score the test, make up graphs myself, all of the data is there if the principals are going to use it, the leadership team should use it, and it's a great tool. That's where all the plans are and also the E plans. So if you have school improvement plans, district improvement plans, Title 1 plans, or instructional plans all of them are electronically submitted. When you are doing a plan you have the data built in so all you do is see what it is. They really make you become aware of data analysis, looking at data and how they use it. There are passwords to get it and I have given the principals all their passwords one for School Improvement Planning and one for data, so they are secure passwords. I want to empower the principals to become users of IIRC, unfortunately there is very little follow thru from the principals. The principals are role models and the team leaders get very little encouragement to use this data. Sustainability in using this data is difficult and almost non-existent. 
There seems to be a disconnection between staff. The superintendent delegates the assessment quality to the assistant superintendent and she, in turn, does not have confidence in the building principal's assessment responsibilities. The assistant superintendent said she rarely meets with staff members and that she will continue to encourage the principal to do her part and work with the teachers. It seems that the teachers are left alone to figure out results from summative testing and analysis of summative data to move forward with effective instruction. The leadership teams and lead teachers who understand the data, use it accordingly. But this does not filter to all teachers in the building. According to the principal,

The teams are responsible for setting up the ISAT schedule. The leadership team, along with the administration reviews the ISAT results. We download the data onto spreadsheets and look at trends and patterns. Each building is responsible for the collection of the data and then it is sent to district office. We let every staff member use the data to their advantage and encourage them to use this data for identifying gaps and help group students. We identify gaps and filter the information to appropriate staff. Our assistant superintendent relays results and stanine scores of students so we can focus in on specific students for extra help to achieve and meet AYP.

Within Washington Junior High, one characteristic was consistently evident with regard to Knowledge Management at the classroom level. It was noted, through observation and interviews with the teachers, that the management of summative data sounds simple but there is an overwhelming amount of information thrust upon teachers, and there is a missing link between central office and the core tasks of assessment at the classroom level.

The teachers' perception of analysis, practice and data driven decisions are dissimilar from the superintendent and assistant superintendent, as illustrated in a quote from the following teacher. 
Our principal handles that, I don't know how they collect summative assessment. It all has to do with the reading series, ISAT and NCLB. As a matter of fact the ISAT test is administered in March and the results typically arrive in late September early October, results come so late they are useless to me. I think the process is too slow.

Later, it will be shown that this lack of administrative support and sense of no urgency to analyze data is also reflected in professional development and learning teams. Another teacher speaks about analyzing achievement data as a detached possibility for the future.

I only work with my students for 9 months. I can see how trend data would help the district track student achievement. Trend data would help me identify weak areas in individual student achievement.

Not all teachers have this apathy. One teacher stated:

I absolutely look at the data when time allows during the school day. We identify gaps during our grade level teams. We try to focus on reading and math.

This teacher actually looked at every student assessment described above and kept charts for each of her student's progress.

Teachers acknowledged this type of data collection required a lot of paperwork from them, though some seemed to mind it less than others. Others, though, felt there was just too much paperwork, that teachers and student achievement were monitored, and that it stemmed from the principals control issues. This balance of pressure and support is a delicate one to maintain, and the field data suggests that some staff members felt uncomfortable working with the principal and consequently remained minimally involved with the tasks of assessment.

\section{Research Question 3}

What kind of data management systems are utilized by your school district to examine and review formative assessment identifying achievement gaps and trends for various student populations? 
Stevenson Junior High. The superintendent had full knowledge of the expectations by his principal and teachers to examine all formative assessment and to identify achievement gaps. He stated:

We identify various student populations through a partnership between staff, parents and community. We use local assessment developed by our curriculum team. Building a community of learners is a strategic goal of our District. Some students are more productive and on task than others. We hope through our Standards of Promotion Program our students and parents will buy in to the notion that we view ourselves as a team and that all students can achieve to their individual achievement level.

In his initial years as superintendent, he told me the district did not have a data management system or a review of formative assessment to identify achievement gaps in place. He wanted and needed the support of his administration to develop and help design a system that would examine and review assessments that would identify various student-learning opportunities. He provided an overview of Standards of Promotion.

Standards of Promotion, includes promotion and retention, it includes a tentative promotion to where the student has to go through a particular program and once they go through the requirements of the program at a satisfactory level then he or she is promoted, its pretty intense and this is our first year using it. The School Board loves it and it was only going to be for middle school but the Board of Education wanted us to move it down to the lower grades 3 through 7.

The superintendent spoke in general terms about formative assessment, but he seemed unaware of any of the specific instructional strategies that are needed to connect the assessment results with new opportunities for greater learning. He relies heavily on the building principal and team leaders to do the detail work.

During my interviews with the assistant superintendent, knowledge of data management was not his responsibility. He acknowledged the importance of identifying achievement gaps yet he felt his role in tracking academic trends for various student 
populations is not outlined in his job responsibilities. He stated:

We have two buildings and two principals K-4 and 5-8. I don't know how they split up their duties but both buildings have an assistant principal. These four people report to the superintendent with assessments and academic concerns.

As he talked about having strong principals and their high expectations for the teachers and team leaders, he discussed the assessment review process for various student populations as being thorough and systematic.

The leadership teams meet on a consistent basis and along with the superintendent, principal and team leaders they take on the responsibility of collecting and analyzing student data.

Interviews indicated that the superintendent has other duties and priorities that take precedent over his involvement in the examination and review of assessment data. The assistant superintendent's main functions in this organization included: finances, personnel, technology, and operations of the facilities.

When I interviewed the principal, he reflected on how his staff works well with him. According to his statements, the principal said teachers are engaged in "a reflective and analytical process" to review their student formative results at the building level.

The teachers developed a sequence of grading systems. It is for student accountability. We use Standards of Promotion. Teachers buy in to this program and support it fully.

The principal helped develop the Standards of Promotion program 3 years ago with his reading teachers and a few key staff members. They planned the program through curriculum mapping and now use curriculum materials, software and other means in looking at assessments to determine student progress. The principal explained:

We use Student Data Systems SDS as a software component for tracking student achievement, attendance and discipline concerns. The data is stored at three levels: one: computer generated grades, two: teacher grade books, and three: Study Island software. 
If kids screw up they have to go to extended school year, which is 90 hours of summer school math and reading instruction. If a student is failing they have to take extra classes during the day. They will skip Industrial Arts, PE, Home Economics, which are our Specials.

The principal went on to explain the consequences for students who fall behind:

There is an immediate system of communication for the administration to promote quality to students and parents. In several ways (weekly communication, verbally and electronically), school teachers focus on academic achievement, which is articulated through high expectation for teachers and students.

On a quarterly basis we send out a report sheet to all parents letting them know where their child stands in the Standards of Promotion. This shows when a child is in danger of failing. Shows the Gaps and the child will not graduate. We also use SDS student management system. We address the students in the third and fourth Stanine that are part of the program. We feel that these students will make the most significant movement. This will effect our annual yearly progress.

The principal understands his role to be proactive and visionary with a plan. He

has set high expectations and asks for staff to be loyal to the district's Mission. He acknowledged a veteran teacher's work and pointed it out to me.

The eighth grade teachers, one in particular, started doing some research and looking at Student Report Cards in the student files and found that the students not qualifying for graduation were the same students who were failing all the way along in various subjects at the fifth sixth and seventh grade. We monitor each student from fifth grade on. We can identify problems before they get out of hand. We try to be proactive and get help to the student early in their schooling.

The teachers use formative assessment to help support and enhance student learning. They believe the principal is a proactive instructional leader who understands what is going on inside the school. The teachers make summative judgments about a student's achievement at a specific point in time for purposes of placement, grading accountability, and informing parents and future teachers about student performance.

My teaching is based on my student scores. I have a wide range of learners in my seventh grade classes. As I move along during the year we try to keep pace with the other team. 
The teachers recognize the principal's backing and commitment and they feel that he has created a supportive environment for them as they work through their examination and review of formative assessment and they comment on him favorably.

Well, we have a very supportive building principal. He helps administer and monitor the star reading and math assessment, all students at this grade level are given the assessment and we then analyze the data with the principal. We either continue with the curriculum or re-teach. Decisions are a team effort and we encourage everyone's input. We do this a few times a year to see how we are teaching and if the students are getting it. Again, the team reviews general knowledge and growth, its up to me to monitor my students' gaps, ability and pacing of math and reading.

The three teachers I interviewed kept referring to differentiated instruction, which refers to teaching with student variance in mind. It means starting where students are rather than adopting a standardized approach to teaching that presumes that all learners of a given age or grade are essentially alike. Thus, differentiated instruction is "responsive" teaching rather than "one-size-fits-all" teaching. Again, according to the teachers, the principal stresses the use of and recognizes the importance of differentiated instruction.

Other formative assessment that we keep would be Pre and Post from the textbook series and we also make up our own assessment. Other formative assessment we are discussing is that next year we are going to use tests from the new reading textbook series.

The clerical staff even gets involved with the day-to-day monitoring of assessment, as stated by the third teacher I interviewed.

Building secretaries collect the teacher data. The data is then entered in a computer-generated report card that is distributed to parents. The secretary's hard work allows us to stay focused in teaching and working on student assessments.

Stevenson Junior High has identified achievement gaps and trends for various student populations. They are meeting the challenge to align curriculum, instruction, and 
assessment so that students know what standards they need to meet and are also given the support to become engaged in achieving those standards.

Washington Junior High. There are tremendous challenges in educating students who are at risk of academic failure because of social and economic disadvantage; Washington Junior High struggles with these challenges. For 6 straight years they have failed to meet Adequate Yearly Progress in two categories (Special Education and ESL), and as Adequate Yearly Progress benchmarks continue to rise, Washington Junior High will continue to perform poorly and be in restructuring status. The superintendent relies heavily on his assistant superintendent of curriculum to organize the effort to increase student learning, meet AYP benchmarks, and return confidence to the teachers, students and community.

While the superintendent is aware of ISBE standards and assessment mandates, he does not become involved in designing or executing a data management system. I asked him who is responsible for the data collection and the analysis of formative data? He responded, "This data gets collected at the building level with the teachers. This data does not get kicked up to district level. I think it is stored in the teacher's grade books."

He went on to repeat his overview of how things are handled at Washington Junior High. There is no sense of urgency in his vision of the data management system or the accountability piece with his assistant superintendent, principal or teachers.

Its gets collected at the teacher level. I am not sure how they store the data or the specific teacher tests because they have many options and we give them a great deal of autonomy. The formative data is never sent to district. It is used at the building level and the teacher is responsible for analysis and distribution using the methods they design during team and staff development time. I would hope the teachers use trend data. I think it's hard to utilize from year to year because 
obviously students change and buildings change but they can utilize it to see how they're effectively teaching and see how the student is performing.

The superintendent said he makes management decisions based primarily on building budgets, union pressure, operations and maintenance and transportation.

He added to our discussion by saying that he also expects the special education director to assist in the process of analyzing formative data. He encourages the special education director to open up discussions about student achievement at staffing meetings, RTI meetings, and faculty meetings along with building team meetings chaired by the special education director.

The assistant superintendent feels they have a process in place that supports the teachers and principal. Most recently, RTI has been introduced as an assessment intervention system.

The new thing from reauthorization is RTI-Response to Intervention Plan. It says that every district has to come up with universal screening of all students and then provide appropriate intervention in three tiers so students are not caught falling between the cracks and they can identify issues with the students before they get referred to special education for a learning disability.

She knows Washington Junior High continues to perform below average on state assessments and she recognizes they need to change. Her approach to reform is to work with the principals and special education director.

We have meetings together (assistant superintendent and principal) regarding data collection. We rely on our principals and special education director to manipulate the data and let staff manipulate the formative data to share with their students.

The principal feels that teachers have a structure that helps them make the best use of their time while assessing students. Although the principal is very positive and upbeat, the assistant superintendent says there is no follow thru or sense of urgency to improve student scores from the principal. 
We use RTI testing. I have a staff member who is in charge of data collection. The teacher collects the data for RTI and shares student information with other teachers and the teams. Once the initial screenings have taken place the information is put into a computer and then is stored.

From the interviews, it was determined that the teachers have the responsibility to understand, analyze and use the RTI data in a meaningful way. One teacher said:

The information is kept in a grade book. I use my calculator to summarize and crunch the test data. No other software is used. I analyze all my tests. From those results I'm able to inform the students, identify gaps and check my teaching methods

And another teacher talked about reviewing the tests, and making students accountable.

Our grade level team periodically discuss how we should review all input from students. Assignment completion, grades, and participation are expected from all my students. We want them to be responsible to complete tasks and move on.

In the teachers' comments there was never a mention of the school principal working with teachers to develop a plan or how well the school will meet Adequate Yearly Progress.

The third teacher was clear that she works independently. "My tests are my tools that I use to identify weak and or strong areas that need to be reviewed or celebrated. I give my grades to my building principal only when asked."

In review, the teachers I studied identified areas that need to be improved but only in their own classrooms. I could not find evidence that supports fundamental change. More time is spent on the ISAT testing analysis than any formative analysis strategies.

As I looked through the Washington Junior High parent newsletters and faculty meeting agendas, I discovered that they do have extended day programs, student assignment books, parent conferences and remedial programs (Title I, Star Reading, Star Math, and ESL programs) to help the students increase their academic skills. This reform never 
has increased traction in academic achievement and is being muffled by lack of urgency from the superintendent, principal reluctance, and, possibly, teacher passivity.

\section{Research Question 4}

What kind of activities is your school district conducting to search and identify best instructional practices?

According to supporters of NCLB, districts that use best instruction practices and make improvements based on that knowledge have a significantly greater chance of successfully complying with the challenges of NCLB than those that do not.

Stevenson Junior High. Stevenson Junior High has diverse student needs, and they described relevant and rigorous instructional practices they use. When asked about best instructional practices, the superintendent explained:

The plan is to address instructional delivery and accountability with changes starting at the very top and ending with the individual classroom teacher and his/ her students. Classroom observations will be done frequently by both the building leadership team and the oversight committee to document that on-going monitoring by both committees will ensure that best instructional practices will be implemented. Our plan is to use scientific research based instructional strategies that have evidence of meeting the learning needs of our student population being targeted.

The superintendent has concerns about best instructional practices and he wants

his teachers to have the best opportunity to succeed in teaching. He says the junior high students are more social than academic and they work best with routines. Having said that, he wants to give the staff every method of instruction that will be a good fit with the diverse student population that they serve.

We continue to encourage teacher input in activities that will identify best instructional practices. In the next few years we will look at technology initiatives that will give teachers a clear measure on whether student achievement is impacted during the year, particularly with regard to the state's high stakes standardized tests. 
The assistant superintendent relies heavily on the curriculum/staff development coop they have joined. The Thornton Fractional Area Educational Cooperative serves six K-8 school districts in the south suburbs of Chicago. The assistant superintendent showed me a newsletter from the coop stating that the vision is supported by a sense of urgency for improvement. He shared a statement from the newsletter.

There is much to be excited about as we approach the New Year. Let us continue to seek opportunities to improve our practice and embrace changes that help us to grow as professional and as people. Let us never be content to do anything merely because we always have. Our world is changing at breakneck speed. Let us have the courage to move with it. .

The assistant superintendent told me that they pay a percentage of their Title I money to belong to the T. F. Cooperative. Member districts of the T. F. Cooperative work together to create curriculum maps and unit plans aligned to State of Illinois Learning Standards, Illinois Assessment Frameworks, and Illinois Classroom Assessments and Performance Descriptors. The result is a guide to maximize the benefits of classroom instruction, to maximize efforts to improve student learning, and to ensure that, in terms of student achievement, no child is left behind. "Our source is scientific and our 6-member Coop recommends best practice, a sound curriculum and they provide summer workshops along with quality conferences."

The principal spoke of the support he receives from his superintendent, assistant superintendent, the coop, and staff.

Curriculum maps and unit plans are dynamic in that they are subject to constant review and revision. Classroom practice and the resulting dialogue among practitioners in and across the member districts are critical to keeping our formal explicit curriculum relevant and timely. 
The concerns and ideas of those ECHO Cooperative Superintendents and ECHO Cooperative Junior High Principals, along with a multitude of teachers, can come together both informally and formally. They can call each other for advice and input. This structure has gone beyond collaboration on curriculum and instruction methods. This can open many doors and foster educational conversations and support. The assistant superintendent spoke of the results of their hard work:

Similar to the itinerary for a road trip, maps and unit plans provide routes to a destination - every student's achievement of learning standards. The actual journey made by students and their teachers may entail many stops and detours along the way. Our universal and overriding purpose is to reach the same destination with every child in our charge.

The principal prefers scientifically based curriculums, as you can see by his statements above. The principal has a passion for quality, loyalty, and support. He continued with the following statement:

We believe in curriculum sustainability; $75 \%$ of our staff are new or have been hired as new employees over the last 9 years. We want our staff to buy into our adopted curriculum and Middle School Concept. We have teacher orientation that every member attends and we set up discussions to review the teacher handbook and curriculum overview. We use curriculum mapping. Anything we use needs to be data driven. We prefer scientific sources. We start our school day with a 25 -minute advisory. It includes social development, comprehension and reading activities.

A typical day at Stevenson Junior High is jam packed and tightly scheduled with the success of the child in mind.

During the teacher's interviews, the staff seemed to be motivated and genuinely concerned about best instructional practices (Teaching for Understanding, Differentiated Instruction, Literacy Instruction and Technology Integration). Teachers discussed how each grade level further defines best instructional practices based on their student needs. 
The first teacher responded, "I would say our administration has focused on best instructional practice over the last 5 or 6 years since NCLB has been around."

With the attention given to standards based education in Illinois, it is clear that most middle school teachers believe that all students have the right to a challenging curriculum. For example, one teacher stated:

My expectations are the same regardless of the level of the child. My expectations are definitely the same- that doesn't change. However, the vehicle that I use to get the teaching across - the text I use, is it going to be a poem or short story, or which video- the vehicle I use to get the teaching done might change but my expectations do not. I expect excellence and it doesn't really matter to me which level you are but it might mean I need to change the way I get the student to learn.

It is also interesting to note that, while these teachers see themselves as competent providers of knowledge, they also see students as the builders of knowledge, indicating their belief in a strong relationship between teaching and learning. The teachers I interviewed said they place importance on student similarities when making curriculum decisions and almost the same level of importance that they place on considering student differences. The teachers I interviewed felt it is "important" to modify curriculum and instruction based on individual learning differences, and it is also important to continue to encourage the development of student strengths through curriculum modification

In addition to developing teaching strategies, the administration has also worked to help staff recognize the role diversity plays in the classroom. For example, one teacher stated:

I think it has helped to raise awareness about differences and diversity whether we are talking about academic ability or race or gender or ethnic background. It makes me more aware of making adjustments accordingly. I mean, over time I think it has helped. 
The teachers are expected to help guide classroom procedures. From my conversations with the staff, they do listen to their students, they do listen to their needs and concerns.

Washington Junior High. The superintendent emphasized the importance of delegating curriculum development to the assistant superintendent as a means of schoolwide instructional leadership. He says he is not a micromanager. He gives his administrators a task and then holds them accountable for job execution and performance. He says he is on board with using scientifically based curriculum, as stated:

The assistant superintendent identifies best instructional practices. We always try to work with different types of professional development activities throughout the school year and identify best practice whether it be reading that we come across and like. We also incorporate an organization called AIMS-web and they bring out their best practices and they institute best practices during professional activities we provide to our staff.

It was clear he relies heavily on his administrative team to further the effort of student learning at Washington Junior High.

We prefer scientifically based curriculum. We have to rely on scientific because many times grants are written using our curriculum. The State dictates using scientifically based best practice, curriculum and instructional practices.

It is used by adoption of conventional curriculum materials published by major test book companies that make claims of selling scientifically based curriculum.

From the responses of the assistant superintendent and principal, there was the notion that the administrative respect and practice was followed. One administrator went so far as to say, "For the most part, we appreciate each other and we respect each other."

While some schools appear to be successful with leadership through delegation, this junior high is struggling and needs a different approach to get from their low student 
achievement status. The assistant superintendent shared her frustrations with me:

We are trying to get our staff to make sense of data-driven decision making. We are trying to sustain data-driven decision making from the central office to the school to the classroom. Data management is an important source of information to guide improvement at all levels of the education system and to hold individuals and groups accountable. We are trying. I am always checking to see if we are heading down the wrong road.

The assistant superintendent acknowledged that when she started working at Washington Junior High 9 years ago the staff was mature, on-task, and willing to engage the students in delivering a high quality education. She said that has all changed and she needs to understand the dynamics of the changed staff, changed student demographics and changed community. I asked if the teachers get trained in best instructional practices and her response was:

Not as much as I would like to see. Scientifically based research makes a world of difference. The staff does not like administrators walking through their classrooms unscheduled and they are called walk through, not evaluations but walk through. They have threatened to file grievances if we continue the practice of walk through. They are quick 3-minute walk through where the principal walks around to find out what is going on in the classroom. They don't need to evaluate, do you know how much you can tell in 3 minutes? You can tell about their classroom management skills, you can tell if their on task, you can see if there are interruptions from the intercom, teachers talking to someone else. You can see so much, one of the things that research has shown is that there is not enough time spent on time on task, you couple that with all the vacations students get and all the time off it is no wonder why our students are not achieving. The teachers need to be in the classroom to start the class on time, not 15 minutes of taking attendance or trying to get everyone quiet.

Creating best instructional practice, and a system that is well aligned to do that work, is a monumental task for Washington Junior High. Any accountability system, any system of improvement, any professional development strategy must relate to the particularities of the student body, the classroom, the school, and the system to the overall demands being made on the entire school system by No Child Left Behind. 
Here, the principal talked about what the administration team thinks the topics should be. In the administrators' attempt to increase student learning at Washington Junior High, these workshops were meant to give staff some direction and resource to pull from. "We have a consultant coming in this year to discuss classroom management and single gender classes. And another topic this year will be 'Teaching the Black Child'."

The importance of teacher input and the importance of what the administration sees to be important are not apparent or certain groups have not been given the opportunity to be collaborative, or create a collegiality setting. I asked the principal if they use scientific based curriculum?

We use both systematic and scientific based curriculum. We can see that some studies are helpful, especially with our single gender classes. Our sources to search and identify best instructional practices include textbook representatives, educational consultants and workshops.

The superintendent often suggested a link between the instructional direction of the principal and the execution of instructional practice by the staff. But the principal was less certain. In some of her statements, she thinks the staff are union driven and are more concerned with school schedules and school order than best instructional practices. From my interview, the principal feels the need to direct and not ask for input from the staff exactly what is needed to deliver clear instructional practices and increase student achievement.

As I moved on to interviewing the teachers, some saw value in best instructional practices. They believed it can support and increase student achievement while complying with the requirements of NCLB. The majority of the teachers spoke of the benefits associated with best instructional practices. In one interview, the teacher responded: 
Whatever I'm given from the building principal. I am not sure if it is scientifically based. It does mirror the standards and benchmarks. We look at instructional practice in Reading and Language-Arts.

The principal does look at scientifically based material and encourages the use of selecting different teaching methods in the deliver of instruction. The teacher described her principal as more of a manager than a leader who doesn't do much or very little at best. The principal, according to this teacher, does more with discipline and building concerns and clerical administrative tasks than alignment of curriculum, instruction, and assessment. Another teacher talked about training and sustainability,

We haven't been trained in best instructional practice in the past few years. Over the years we have had teaching styles presented. But there is no sustainability or follow-up of teaching styles.

Although they appeared to have some focus, a group of teachers at the time of their interviews were not too actively involved. There was a division in the staff, which made it appear difficult to have a full commitment from the faculty and full support for identifying and implementing best instructional practices.

Throughout all of the documents and artifacts that were analyzed, clear evidence was present to substantiate that the building lacks a consistent agenda for the improvement of instruction during recent school years.

\section{Research Question 5}

Does your school district create learning teams or teacher work groups to generate successful knowledge about student results, student learning and appropriate instructional strategies that advance curriculum goals?

Many educational reformers have raised an important question: What could be more natural than teams of professional teachers working on content and skills? The answer to this question is a complex innovation only because it requires a radical change 
in relationships among teachers and between teachers and administrative personnel. An "organized school culture" will make the combined decisions that will generate schoolwide improvement efforts. The formation of teams offers the possibility for greater faculty cohesion and focus and, in turn, facilitates more skillful shared decision-making. A skillful staff development program results in sustainability as well as new knowledge and skills for teachers and increased learning for students.

Stevenson Junior High. The district superintendent spoke with a great deal of clarity regarding teacher work groups. He wants to make sure the school board and his administrative team provides the staff the potential for significant change that can bring about improvement in student performance.

The team meetings are broken up into different topics, one day they will discuss units of instruction, the next day they will discuss academics. Day three they will discuss behavior following that they will discuss standards and so on and so forth.

The teams were formed in the late 1990 s as part of the district's school improvement program. The superintendent is pleased with the development. He sees teachers working in viable and cohesive teams. He went on to say that as they look at each sub-group of students and analyze student results, they plan new approaches to help student learners.

Now we have the three sub groups, Caucasian, Hispanic and African-American, they do a gap analysis between our ethnic sub-groups and that's done through teams and they use the ISAT to initiate that gap analysis. The teams meet on a regular basis and the gap analysis is discussed and improvement practices are laid out. This occurs on an annual basis.

The use of staff input provides opportunities for teachers to interact in smaller groups and discuss school related information that is specific to their needs and interests.

We have a very active development plan for our team, we approach it in two ways, the first is based on the initiatives active within the district. We go out to 
the teachers on an annual basis and ask them what area do you need more help in or help in resources. We have worked hard for this structure and it works. We have a great staff and a great union. I feel blessed. My Board of Education sets the stage each year. The teachers feel the support.

The superintendent sees the school as a self-contained entity with few distractions.

He asserts that there are two main reasons for learning teams: data analysis and student

learning. He believes this support from the board of education sustains the learning teams and the teams' track record of conducting quality curriculum cycles and attaining

curriculum goals. The assistant superintendent referred to this practice as the "demand for productivity."

I do know that the principals have organized instructional strategies, each grade level has a plan time together and the team goes over those strategies. That is grade level teams productivity. The Tech team meets once a month, the grade level teams meet daily at the middle school. The K-5 team meet twice a week. We have strong principals at the helm and they demand productivity in lieu of extensive planning time.

Moreover, when asked about his role as assistant superintendent working with the teams generating successful student results, he deferred to the principal and stated "our building principal kind of holds the reigns."

I then moved on to the principal, who coordinates the work groups and learning teams. The principal values these team meetings. It was clear that the Stevenson Junior High principal works persistently with his staff; he made it a priority for his teachers to share effective teaching strategies. The expectation was clearly articulated by the principal, who discussed how the effective teams work.

Our reading specialist pulls together her reading committee and makes sure everyone is on the same page. She works with all reading teachers, grades fifth through eighth. She wants everyone to use the same common terminology. We are also going to implement collaboration reading strategies for next year, so when students are working on comprehension skills the vocabulary that the 
teacher uses in the classroom will be the same vocabulary as the students work through in their grade-level. We want to continue with curriculum mapping and math this summer and all of next year.

Stevenson Junior High staff collaborated in many different ways once they were familiar with data trends and identified school needs. With specific plans, such as curriculum mapping in math, for example, the teachers targeted their efforts on creating common assessments, using a common vocabulary.

The Reading Teacher trains the staff on how to interpret data. We have grade level teams. We use curriculum mapping. RESPRO is used in our district. The service center facilitated the training in classroom management, and data interpretation. I have five team leaders. I meet with them monthly. I will give them tasks and then they go to their teams and come back with input from the staff and we implement. We have school improvement teams and leadership teams we will do data analysis, school improvement development and let the staff have input.

Using data to plan improved instruction, the staff began to work collaboratively to under-

stand the strengths and weaknesses of their students and school. The principal explained,

I meet with the teams on a monthly basis as a group and we have two meetings at the beginning of the school year where I give them tasks to complete or research during the year. The team leaders go back to their teams and then we follow through, enhance, change and tweak final decisions about the school year.

The principal offered an extraordinary look at creating and leading the teams. He is unwaveringly focused on student achievement, relating everything back to his primary goal, resources available to the school, professional development, data collection and analysis, along with continued support for teachers and students.

I also have a School Improvement team that does data analysis; SIP development and then they go back to their teams and report out....Outcomes include fewer and fewer retentions each year. This year we have 19 students that are expected not to graduate and will attend summer school. That is our lowest number to date. We hope to lower that number. At least that's our hope.

Much of what the teachers articulated was consistent with the observations made by the administrators. To quote one of the teachers, 
We have a seventh-grade team that meets every day, the curriculum committee I spoke of earlier, the reading committee, the TF Coop committee for new ideas and I think that's it. I know there's more but I can't think of them right now.

Creating learning teams is an important part of the Stevenson Junior High's path

to success. Another teacher explained the history of teams at her school and some key topics.

Yes, teams are vital. In the last 10 years we have used middle school/teams. I like the model. The kids are getting tougher to teach, but I like the teacher team model. It is very supportive to our needs. We work in grade level teams. We are productive when we need to be. We discuss everything, from volunteer luncheons, birthdays, busing and sometimes it is definitely not curriculum based.

All the teachers interviewed know that the principal works hard to support his staff in many ways. The teachers also reported that they feel supported. The teachers have a driven leader who recognizes the staff's hard work and the importance of both sides being supportive which translates into desired results.

We had assigned leaders last year, this year no one special, usually the Title I, principal or resource teacher will start the meeting and we all join in. We discuss topics as we make it happen. We keep minutes of these meetings. Occasionally our principal will attend the meeting to explain learning styles, teaching styles and best instructional practices.

An important characteristic consistently observed during interview discussions was the professional language used. Specifically within team leaders that colleagues seemed to understand and respond accordingly.

Equally important, it was observed that staff exhibited responsiveness to qualityoriented continuous improvement procedures and practices. The teachers, principal, and superintendent felt that their school was a productive collaborative environment in which continuous learning opportunities were important factors to improve the quality of teaching and learning. 
In terms of the professional community at Stevenson Junior High, there were staff members who appreciated the collaborative role the school had taken and it served students better, while there was a tone set at Washington Junior High that staff disliked it, because they viewed collaboration as more work.

Washington Junior High. The superintendent built his hopes on the work of consultants and outside trainers who have been conducting various workshops over the past several years. He described how he took steps to ensure the implementation of NCLB and how he addressed collaborative issues within the schools.

Teachers are trained by consultants, and staff workshops, I would hope that they are life long learners and are open to ideas that would help the student, school, and our community.

The superintendent hopes his staff participates in these workshops as life long learners. He explained the teacher work groups and various topics they cover in a typical school year, along with their school's successes and accomplishments.

We use mentoring, grade level teams, leadership teams and cross grade teams that meet on a daily basis and they should be working on student models to help the students succeed. For the most part, the staff work on learning and they accomplish a lot of things as they try to make the student successful. Our principals believe in both interdisciplinary teams and grade level teams. We are not a Junior High, we function as a middle school.

Although the superintendent requires all types of teams, and all types of programs have been generated, a visit to the school indicated that there was little sense of urgency to finish projects with exit reports, and teams did not focus on their tasks with a sense of self-satisfaction of a job well done.

In the interviews with a few of the administrative team members, there was an indication that closure rarely happens at Stevenson Junior High. 
There are some leadership teams that exist in the buildings. The administration has a leadership team that is driven by me and there is another administrative team that is driven by the assistant superintendent. We ask the principal to participate in all other building teams, whether it's to give direction, set agendas or be in attendance. I do not know how often they meet. I do not know if they use agendas, report out or keep a record. This should be chaired and monitored pretty much by the building principals. My assistant monitors all teams and committees. She would know what is expected of the groups.

Again, the superintendent depends on his curriculum director to generate success-

ful knowledge and appropriate instructional strategies that will advance curriculum goals.

"I do not have hard evidence. The only evidence I have is that the building principals use anecdotal notes and share with me the productivity of teachers."

The assistant superintendent cited a lack of training, resources, and planning by the principal as factors that impede NCLB's success.

Well, we have had teams in place for over 10 years so the School Board and superintendent feels they are critical for the production of sound achievement and learning. Again, we are better off with the teams and there are positive aspects of getting this group together. I would like to see more accountability.

She went on to name the various teams. There are quite a few teams to be monitored by the principal.

The names of teams we have include: advisory, teacher team that function in our school include Jr. High Committee, Textbook Adoption teams, Social Teams, Mentor teams, I'm probably leaving out a few but off the top of my head those are the ones.

The principal is matter-of-fact about the demands put on staff members. Given those demands, the principal said it was not easy to find time to engage all the staff in teamwork and the restructuring process. A lack of union support was another roadblock. As the principal put it, the teachers' union issue continues to be a challenge.

We schedule agendas at the beginning of the school year and then stick with the schedule. The first few weeks are unproductive, in the sense that everyone is just 
getting used to each other, especially when we hire as many new teachers as we do. The union always request kick-off meetings at the beginning of school for new members and they have fair share which means even if the teachers don't join the union there is an amount of dues taken out of their check that goes to the teachers union.

She understands the stress that teachers encounter ever day. She is under constant pressure to raise student achievement and lower teacher turnover rates. The mandated goals of reaching $100 \%$ of students for learning and success by 2014 is going to be difficult and nearly impossible at Washington Junior High. She has been very frustrated with the process that has been set up.

As a principal I participate with the teams and I hold them accountable. I pretty much set the agenda for all teams. Sometimes the staff has an agenda and I let them discuss their issuers. There are no written documents, minutes or reports; it is all verbal. New ideas are generated and implemented from this process.

The principal faces many challenges to get all teachers unified on a common improvement agenda, but some of the teachers still enjoy the opportunities of working together in teams.

It should be noted that the teachers and team leaders acknowledged and appreciated the support they give each other. For instance, though she felt there are a lot of meetings, this teacher said she would have a tough time working through challenging issues without the help or input from her colleagues.

We have an eighth-grade team with two leaders. We are given information from the principal to pass on to the team. Other teams include two seventh-grade teams two sixth-grade teams, leadership team, and mentoring team. We meet 5 days a week 15 minutes a day. No agenda is used. It's time focused on students.

Another teacher shared her experiences as a team member.

We discuss problems as they happen. We do not keep minutes of these meetings. Occasionally we will let parents attend the meeting to discuss their child's learning or behavior with the team. We offer suggestions for the School Improvement Plan. The team reports back to the principal. 
The message they were sending was the teachers have meetings that have some benefits, but the processes of renewing evidence and making decisions is rather informal and lacks any sense of coordination with the principal. The teachers report that the culture for them at Washington Junior High School is disconnected. They frequently work independently.

We have the Leadership team and Mentoring team. The principal has not attended any meetings so far this year. She has in the past but has not this year. We have a middle school philosophy. We do not have agendas but in the past we did have agendas, I would like to see them return. No minutes are ever taken. Some of the topics are student's achievement and discipline issues. We make suggestions but I don't think we are being heard.

The staff did not uniformly agree with some of Washington's administrative practices, such as the data collection or their instructional practices. Staff I interviewed questioned how much shared decision making actually existed at Washington Junior High School, citing the principal's distant tendencies and uneven attempts to control the school's agenda. However, even with these complaints, staff members agreed that they are committed to student achievement and work hard to support each other in many ways (e.g., respect for each other's time, sharing innovations helping each other find needed resources).

\section{Research Question 6}

What kind of professional development opportunities are available to teachers who are expected to work both individually and collaboratively to achieve targeted achievement goals mandated by No Child Left Behind?

Leaders in both districts I studied believe that their students should benefit from

NCLB. As student learning hinges on the skills and knowledge of teachers, teacher quality must be a critical foundation of any serious reform. The results of student test scores across the state have been disappointing. As a result, the schools must understand 
the extent to which high-need low-performing schools require additional strategies to provide quality teaching to the high-need low performing students. Professional development represents a vital on-going activity that all teachers should address in order to remain current in their academic disciplines and up to date on educational trends that might affect their teaching methodologies, curriculum, and assessment.

In any given week throughout the duration of the year at both Stevenson Junior High and Washington Junior High, teachers and administrators attend workshops, conferences, and participate in other professional development opportunities. We will be looking at both schools to professional development that helps to reach the goals mandated by NCLB.

Stevenson Junior High. The superintendent said that professional development programs each year are determined by the results of student data. He illustrates this approach in the following quote:

For instance, we look at data and we look at where the students are struggling. Take writing, our students have consistently not done well with writing. And we have always been below proficiency. So we wanted to look at what can we do with writing to move students to a proficient level. And so that helped us decide, well, for this year, we are focusing on writing for professional development topics.

Because of the emphasis placed on results of student data by the superintendent, for both the district level and building levels, staff development will be provided to train teachers and the principal in writing skills.

The superintendent talked about the opening days of school and how the practice of school improvement and professional development allows everyone to give their thoughts and input to develop a list of specific topics. 
Prior to school opening we have a one-day retreat with the leadership team. Each year we develop a list of specific things staff are doing to help improve student achievement. The school-improvement team meets with all staff to encourage every member of the school staff to sign this list showing their commitment to improving student achievement. We then post this list and revisit the list at periodic staff/team meetings.

The assistant superintendent, when asked about professional development opportunities, responded:

I continue to coordinate district grants and search out and apply for additional funding so our junior high school can bring to its table outside consultants, curriculum mentors and literacy experts to assist in staff development.

As part of the assistant superintendent's grant writing effort, staff opportunities were greatly expanded. Through his efforts he was able to hire a literacy coach to come to Stevenson Junior High School and work with the learning teams and also spend time in the classrooms 2 days a week to observe and make recommendation or validate what the teachers are accomplishing. As explained to me, the literacy coach worked with the teachers closely and knew the school's strengths and weakness by analyzing student data. The aforementioned literacy coach also offered ideas for reading instruction and reading interventions, as needed. The literacy coach supported teachers and was a regular presence for a year. The ongoing assistance was a local and relevant form of staff development, and the work was highly valued by the superintendent, assistant superintendent, principal, and staff.

In still another area of teacher learning through professional development the principal arranged training so that he and the staff could analyze school level data based on samples of students writing. These data were used early in the school year in order to help teachers develop curriculum and instructional strategies prior to ISAT writing tests. 
The principal went on to tell me that the educational cooperative trains teachers to make decisions with student data. By reviewing students' performance on a variety of formative and summative assessments, the area of professional development concentration is determined. These assessments are neither random nor disjointed. They were specifically connected to the district's learning standards in the different subject areas, and the school continues to work towards using common assessments. "We're not $100 \%$ there, but we're much farther than we were," the principal stated. The education plan established the specific skills to be focused upon, the supplies needed and the professional development topics for the year. Thus, data were analyzed to look back and also to plan for the future.

The principal explained,

Every year a survey is sent to all school districts in the educational cooperative. They narrow the topics to a manageable amount, decide on the most popular topics and then hire consultants and professionals that have strong background in that particular area.

The principal explained that the T. F. Cooperative member districts are slated to begin a comprehensive, 2-year math curriculum study. The study will begin in January 2009 and continue through June 2010 and will focus on updating the current curriculum to utilize more user-friendly map and unit plan templates.

During the first year of the study, committee members will map the curriculum for grades K-8 to state standards and will create unit plans that correlate to grade-level maps. Unit plans will be designed to incorporate scientifically research-based instructional strategies. In addition, math teachers, special education teachers and reading specialists across all member districts will work together to incorporate accommodations, interventions, and modifications to assist in RTI efforts. 
Teacher training at Stevenson Junior High is thorough and ongoing. It should be noted that the end product of the math curriculum effort will serve to enhance the math initiatives already in place in the member districts. Some of the comments made by the teaching staff included:

They do send me out for differentiated learning instruction. Teachers can get up to three outside training sessions during the school year. We are encouraged to bring back and share what we liked about the workshop attended. We also started sharing with each other what works well in our classrooms thru the T. F. Cooperative

In earlier years, the work of good teachers often remained with the teacher as private knowledge. Now all teachers are encouraged to share their successful strategies and reflect on each other's work. Professional development workshops for individual teachers become professional learning opportunities for the rest of the teaching staff.

Progress with professional development training is monitored frequently and meaningfully. It is apparent that NCLB has intensified these efforts. As one teacher stated, I have been going to staff development classes since the beginning. Now the District and NCLB requires me to increase my awareness of best instructional practices. The principal encourages teachers to attend workshops and even lists the topics of staff development in yearly teacher evaluations.

All teachers belong to a curriculum cooperative and receive training thru the T. F. Cooperative. Teachers are occasionally asked to report out to the rest of their learning team or grade level members. It has been a challenge to make professional development as relevant as possible, according to this teacher interviewed.

A strong instructional leader supports his staff members by ensuring they are equipped with the skills to raise student achievement. Professional development is therefore an important aspect of achieving targeted goals mandated by NCLB and 
Stevenson Junior High School understands that. As described above, the school used student performance data to determine teachers' staff development needs.

At Stevenson Junior High the teachers are validated from successful student learning in the classroom and not just a conference certificate saying that they attended a workshop. You can feel the support from the superintendent to the building principal at Stevenson Junior High.

Washington Junior High. The superintendent did not seem to be open to new ideas or is keeping professional development in a holding pattern. Some comments he made during the interview included the following:

We offer each teacher the ability to go to one professional activity every school year and, as I said earlier, we bring in consultants that conduct professional development. Three or four times a year.

As the chief financial officer in the district, he stated, "For budgetary purposes, we have always tracked our teachers requests and their involvement in professional development. The assistant superintendent commented that she feels Washington Junior High has a small staff and, given the size of their school, careful attention is given to provide staff opportunities that larger schools are sometimes given. She sees these opportunities as flexible and focused in school improvement.

The teachers are allowed to select outside professional development activities as long as it ties into our school improvement plan.

The assistant superintendent has a unique role, and her understanding of that role is to ensure continuity and quality in the teaching force and assist the staff in choosing relevant professional development. She talked about the core areas and encourages staff to include these core areas when choosing staff development for instructional improve- 
ment. "The core areas we encourage the staff to address include discipline issues, teacher led teams, aligning curriculum to state standards and skills for delivery of instruction."

The principal shared the following about her view and her input regarding professional development.

I've found, as a building principal, that even when asked for feedback, teachers do not take the time to respond and then I end up creating professional development during the school year for teachers rather than with teachers.

She went on to comment in the decision making process,

The assistant superintendent and I make the decisions. We work collaboratively with District Office. I ask for teacher input for teachers' institutes but rarely receive any. The staff goes outside for school improvement workshops. They are allowed to go to one workshop a year outside the District. We also meet six times a year in our buildings. Two full-day school improvement days and four half-day school improvement days.

During the interviews at Washington Junior High, the teachers expressed a feeling of change in direction every year in staff development, and workshops. They expressed a need for continuity and sustainability in professional development.

The focus changes every year from district office. We have covered differentiated instruction, classroom management, and single gender classes, we have different topics every year.

Professional learning opportunities at Washington Junior High have been moving in a zigzag path that the faculty would like to see more focus with a clear sense of direction.

It fluctuates from year to year depending who is in charge. New principals have different ideas. I have had three different principals since I started here, all with different direction and agendas.

The staff would like to have more input with staff development. Veteran teachers spoke of losing young teachers at an alarming rate. They felt that a focus on staff develop- 
ment and even site-based professional development would help the junior high grow in academics, teacher longevity and building relationships between teachers and the principal.

Professional development is stagnant. The teams should be asked to give input. I know teachers who need help and I know who has talent to assist and lead in helping others. There are teachers who I struggle to help. We have a high turnover of staff. The professional development is too generic and does not meet my needs or the needs of our team. Targeted achievement will be met if class size was smaller, instructional time longer and more help in the development of critical skills, especially at the junior high.

The teacher concluded by noting the tendency to keep a status quo system.

The Professional Development has not really changed in the last few years. We have a set schedule and we stick with it. The staff has a number of opportunities to receive cpdu's and receive teacher training.

\section{Holistic Summary of Two Junior High Schools}

This study has presented observations about the complexity of implementing the school improvement agenda mandated by NCLB. Findings were reported at three levels of decision making: central office (the superintendent and assistant superintendent), the school (principal), and the classroom (teachers). Kimmelman and many other scholars of accountability in the late $20^{\text {th }}$ century and the $21^{\text {st }}$ century assume a linear connected system that flows both down from the district office to the classroom and upward from the classroom to the district office. Such conventional wisdom typically offers optimistic scenarios about successful implementation. The two case studies in this investigation suggest that linear alignment is rarely tightly coupled to the chain of command from the superintendent to the classroom teacher.

In the Stevenson Junior High case, the critical focus for the implementation of No Child Left Behind came from two key persons: a superintendent who took a strong role as an instructional leader and a principal who shared a similar education vision. The 
superintendent hired the principal with clear expectations for significant changes within the school. In fact, some of the most important initiatives for school reform came from the teachers. The impetus for change was not always a top down process.

Both the principal and the superintendent relied upon the Thornton Fractional Cooperative and the Service Center \#4 for critical resources to implement a variety of academic programs. This resource network allowed teachers to become competent team leaders who shared the same sense of urgency about achieving higher academic standards.

The key actors at Stevenson Junior High did not work in conventional hierarchy framework. Planning, training and implementation of various agendas of No Child Left Behind were rather dynamic and fluid for the superintendent, principal, and teachers who worked together in various settings. The school is part of a small district where there are frequent opportunities for interaction and give-and-take consultations among all the administrators and teachers.

Washington Junior High was in sharp contrast, because critical relationships among staff members as the three levels of planning and action often broke down. At all three levels of decision making, administrators and teachers often seemed trapped in unproductive dead ends.

The superintendent described his leadership position: "I am not a micromanager." Consequently, he remained aloof to the critical components of No Child Left Behind that needed constant attention by both principal and teachers. Instead, the superintendent delegated to the assistant superintendent all responsibilities for instructional leadership in the district. The assistant superintendent was well informed about the critical path of 
implementing No Child Left Behind, but the principal was unable to have either the technical requirements of instruction or the normative commitment for the extra efforts to bring needed changes. The breakdown of relationships between the superintendent and assistant superintendent meant that the teachers were left adrift. Their training often consisted of segmented special support programs for targeted groups of students. There was also a tendency to change the reform agenda each year. Over time, teachers became increasingly removed from the district's agenda and within their building there was no consensus of any success strategy for implementing No Child Left Behind.

Conventional wisdom about the operations of a three-tier hierarchical system does not describe either district. Rather, this study suggests that a complex set of relationships at various levels exists that either allows teachers to share in the leadership agenda or constrains their role to small circles of private consultation. If, for whatever reason, relationships break down between the district office and the teachers, there is little likelihood that the teacher and the principal can form a consistent and coherent path for involvement and improvement. 


\section{CHAPTER V}

\section{CONCLUSIONS, IMPLICATIONS, AND RECOMMENDATIONS}

Chapter V presents a review of the Stevenson Junior High and Washington Junior High case studies, including the design of the study and the research questions. The findings from the study presented in Chapter IV will also be summarized as well as the researcher's conclusions based on the findings. Finally, Chapter V examines the implications of this research project for those educators faced with the challenge of implementing and building organizational capacity to meet the requirements of NCLB Federal Education Legislation.

\section{Overview of the Study}

\section{Statement of the Problem}

This study investigated two urban junior-high schools that are implementing the mandates of No Child Left Behind (the reauthorized Elementary and Secondary Education Act). It looks at the challenges facing educators who are held accountable for the academic achievement of children of poverty. Special attention addresses the critical issues of building organizational capacity to determine the extent to which two schools utilized key components of a knowledge framework to support school improvement.

\section{Design of the Study}

The methodology chosen for this case study was qualitative. This approach allowed for broad, detailed descriptions of the programs, practices, and instructional 
strategies utilized at the school sites. This qualitative research project followed the method of "case studies, in which the researcher explores in depth a program, an event, and activity, a process, on one or more individuals" (Cresswell, 2008, p. 15). Fieldwork and data collection took place over 13 months, from April 2008 through May 2009. The results of this study came from perceptions taken from interviews with administration and the teaching staff who were actively involved in decision-making relative to the implementation of NCLB.

Interviews were conducted in a systemic way utilizing the same interview questions for each respondent. All interviews were tape recorded and analyzed. Documents collected related to both implementing NCLB and school improvement issues. Information gathered from school/community newsletters, staff meeting minutes and agendas, and faculty and parent handbooks were also part of the study. Crossreferencing data from all of the collection methods allowed for triangulation and to increase the validity of results. The review and careful analysis of data provided insight into the program, practices and leadership strategies.

\section{Descriptions of the Cases for Study}

Stevenson Junior High. Stevenson Junior High is located in Cook County, Illinois, a collar suburb of the southern part of Chicago. It is situated several miles from the city limits. The population from the 2000 census was 28,000 . Four school districts serve the community. The school district consists of three buildings: a primary school (Pre-K-3), an intermediate school (grades 4-5), and a junior high school (grades 6-8). This project focused on the junior high school. The school, which has an enrollment of 400 junior high students, is dealing with issues of low student performance, achievement 
gaps, and $66 \%$ of the students are low income. The mobility rate is well over $17 \%$; the state average is $15 \%$.

Stevenson Junior High is located on the east side of town in a single-story building. The school is average in size compared to other junior high schools in the south suburbs. The staff is grade-centered with classes organized by grade level in designated areas of the building. The building is relatively new, very clean, well equipped, and well maintained, with many specially designed areas for student learning and student activities. Masters degrees are held by $41 \%$ of the staff, and the average class size is approximately 25 students. Teacher's salaries are significantly below the state average but are competitive for the market in Cook County suburbs, which competes for certified teachers. The school also has a principal and a full-time assistant principal. After many years of failing to make AYP, the school successfully achieved AYP in 2008-09.

Washington Junior High. Washington Junior High's community is part of a large first ring suburb in the metropolitan area of Chicago. The community is a first step for families eager to leave the City of Chicago.

The closing of numerous business and area steel mills and factories has left Washington Junior High community and the surrounding south suburbs economically depressed. Unemployment has given rise to a number of related social problems, including substance abuse, violent crimes, family violence, and broken families. The school district, therefore, has a diverse population of students in terms of income, culture, and national heritage. Family income ranges from substandard poverty level to middle income, and the percentage of student turnover is extremely high. The mobility rate is well over $58 \%$, three times the amount of the state average. The population of the city in 
the 2000 census was 39,201 . Washington Junior High is one of three buildings in the district; an elementary (grades K-2) an elementary (grades 3-5) and a junior high (grades 6-8). The enrollment of the junior high is 486 students. The low-income rate is $81.5 \%$ and climbing. These are challenging times for the district. In the last general election, the school referendum failed, and they have a growing school population.

Understanding the Washington Junior High community make-up and student populations is essential in gaining insight into local conditions that affect student learning and contribute to poor test scores. The socioeconomic status of the community surrounding Washington Junior High has changed considerably over the years, from a solid, blue-collar working community to one with poverty well above the national level. A total of $81.5 \%$ of the students at Washington Junior High are eligible for free or reduced lunch. During the past several years, the school has not been able to make AYP.

\section{Summary of Findings and Conclusions}

Paul Kimmelman developed knowledge framework for building organizational capacity to improve schools. It is a synthesis of school reform literature of the past quarter century. Three major themes are identified in the knowledge framework to build organizational capacity:

1. Knowledge acquisition

2. Knowledge management

3. Knowledge implementation.

The following six research questions were derived from these three themes. A summary of findings for these questions and a conclusion for each question follows. 


\section{Research Question 1}

Is your school district collecting and analyzing formative and summative student data?

Stevenson Junior High School. Two student demographic groups, ESL and Special Education, did not meet Illinois proficiency goals. Although the school as a whole improved learning across all groups, the superintendent was encouraged with school-wide measured student growth, but not meeting the yearly benchmarks of NCLB's Illinois proficiency growth was disappointing to him.

The district has its share of student discipline, union grievances, lack of state and federal funding along with difficult parents. The superintendent does not use those factors as an excuse for mediocre achievement scores; instead, he has adopted reforms supported by scientifically based research to create and implement a variety of approaches to move forward and attain improvement. He also continues to work with his junior high principal to bring about meaningful student learning and performance.

The principal and teachers at Stevenson Junior High have established graduation requirements for eighth graders. Also, fifth, sixth and seventh grade students need to reach benchmarks before they move on to the next grade. All grade levels have rubrics in place and students need to qualify by point values in this rubric to move to the next grade level and to graduate.

During my interviews, the Stevenson Junior High teachers described their efforts to align the curriculum with the ISAT State tests. They viewed it as being positive, since they preferred the content of state standards to what they had to work with previously in their adopted textbook series. The principal and teachers also continuously sought meaningful ways to document and assess student performance using both formative and 
summative assessment. In a unified voice, all teachers and administrators that I interviewed spoke about the positive impact NCLB had on accountability policies, practices and student achievement.

Washington Junior High School. Prior to the passage of No Child Left Behind Act, Washington Junior High School's efforts at school-wide improvement seemed nonexistent and restricted. There was no evidence of systematic or sustained successes. The researcher was unable to uncover the use of formalized data, a systematic teacher mentoring program, or effective team meetings.

The school fell short of the benchmark in two sub-categories (ESL and Special Education), outlined in the federal mandates of Annual Yearly Progress since the inception of NCLB. The Assistant Superintendent was a former Illinois State Board of Education Quality Assurance consultant who placed a great deal of emphasis on curriculum and instruction. Therefore, she was making various adjustments to the collection of both the summative and formative assessment data that was available for the principal and teachers to use if they wished to analyze this data. Unfortunately, there was no encouragement by the superintendent or principal to use the data as a systematic study of student learning. Triangulated data collected by the assistant superintendent was never made available to teachers to analyze the students performance in their own classrooms; furthermore, the data were kept on file at the district office. Summative data from ISAT and Stanford Achievement formed the core of the Washington Junior High School accountability system.

The teachers used local assessment results during the first few weeks of school in preparation for placing students in groups during the first semester. In the second 
semester they would use student test results and classroom observations for grouping. Although the teachers use a variety of sources; quizzes, teacher tests, observation of students, homework, other teachers' observation input, and pre- and post-tests, these results do not flow back to the district office or the principal to be analyzed.

Teachers complained about the pressure to achieve higher student scores and the adverse effects of stress, competition among students and among schools that focused on correct answers rather than deeper understanding of concepts. The teachers' use of data, especially timely formative assessment data collected in the classroom by the teacher to inform instruction is at best minimal. Their accountability system and school leadership training had no degree of intensity and was fragmented.

Conclusion. Although shared leadership has become a concentrated effort at Stevenson Junior High, it still relies on a small core group of teachers. The effort to spread their leadership has not yet taken place with all teachers. The leadership team at Stevenson Junior High recognizes gains that have been made, but they are challenged to make sure teachers do not lose momentum. The capacity building of the past few years has prepared Stevenson Junior High to manage changes more successfully then previous years. These gains may either stall as a partially developed system, or may provide the foundation for further development to increase capacity to reach higher levels of student achievement.

Conversely, Washington Junior High School has a long way to go in both language arts and math achievement. The pass rate in Illinois to make AYP keeps increasing each year. Washington Junior High School will have trouble getting all its sub groups to meet Annual Yearly Progress. 
Washington Junior High School lost its principal at the end of the year after the completion of all interviews. The principal was replaced by a first-year principal who clearly will be adjusting to personnel, community demands and her assimilation into the Washington Junior High School philosophy. The new principal faces a huge challenge to move the school forward in a new direction. This study did not include any evidence about any plans for school improvement that are urgently needed for the coming years.

Stevenson Junior High's efforts to improve the collection of data was led by the superintendent and principal; they modeled and sought input from the teaching staff, which resulted in a plan of building leadership among a core group of teachers who were committed to focused goals of student achievement. In contrast, Washington Junior High had no support from the superintendent or principal leaving the assistant superintendent adrift and unconvincing to the teachers. Furthermore the teachers had become cynical toward the NCLB mandates because of what they viewed as a lack of follow through and support on the part of the state and their own administration. Despite the fact that Stevenson made strong attempts to meet AYP in all sub groups and Washington made weak attempts to meet AYP, neither had succeeded in all sub groups of the Illinois Proficiency Goals for 2007-2008. Both junior high schools in this case study face major challenges in the coming years as Annual Yearly Progress continues to rise.

\section{Research Question 2}

What kinds of data management systems are utilized by your school district to examine and review summative assessment identifying achievement gaps and trends for various student populations?

Stevenson Junior High School. The superintendent is looking to acquire a data management system for the district that will track grade level, teacher level, and student 
level achievement data. They would like to add that component to assist the teacher in the identification of student level achievement and growth. In a clear manner, the superintendent assigns the knowledge assessment methods to the junior high principal. The principal utilizes training opportunities and measurement methods provided by the Service Center, RESPRO, and IRRC to give his staff a snapshot of the achievement at Stevenson Junior High. From these reports, adjustments are made and changes take place to facilitate student learning. They also have a reading specialist who assists teachers in implementing the districts achievement based on summative data received.

In the superintendent's opinion, his junior high has gained a great deal of growth the last few years since the inception of the NCLB. The assistant superintendent at Stevenson Junior High is seen as a technical assistant, financial assistant and building supervisor. From my interviews and observations, no academic responsibilities are on his agenda. The curriculum development mainly flows from the building principal to the teachers. The principal has some very clear thoughts about summative assessment. During my interviews with the principal he emphasized the importance of summative data monitoring including ISAT information as well as the Stanford Achievement test, both data banks are available to the staff.

The teachers utilize grade level teams to review ISAT information, Stanford Achievement and IRRC data. The teachers are held accountable and they maintain close tracking of the students. During my interviews the formative information and data analysis appears to flow one-way from the principal to the teacher. Not all teachers are equally responsive to input from the principal. Leadership opportunities in the building 
appear to be available to all teachers but there is still some reluctance on the part of groups to become fully committed.

Washington Junior High School. The superintendent of Washington Junior High School has difficulties choosing between management-oriented activities and instructional-oriented activities. The superintendent feels that he is pulled in many directions and has delegated developing instructional capacity to his assistant superintendent. The assistant superintendent feels that the superintendent does not support the efforts of the curriculum office agenda. Through my interviews I found that the assistant superintendent has not established a consistent system to distribute standardized data to the building principal or teachers.

The assistant superintendent has a clear vision for a knowledge framework to be created; unfortunately, limited support from the principal to implement a data management system exists. At all levels of decision-making there is a disconnect between teachers, principal, assistant superintendent, and superintendent.

From teacher interviews and documents, I was able to see evidence that a few lead teachers use summative data for there own data analysis, unfortunately this does not filter to all teachers in the building. The teachers feel that the assistant superintendent supports data analysis and data flow but there is no formal training of data retreats or professional development to help the staff identify achievement gaps. The teachers realize data collection is an enormous task. They conduct business as usual and teach without sharing data or student information with each of their colleagues. The teachers have become jaded toward managing knowledge because of what they view as a lack of follow through and support from the principal, lack of support from the assistant 
superintendent and a superintendent who is concerned about budgets, maintenance of buildings and managing daily tasks.

Conclusion. The results of this study may provide insight for future NCLBrelated initiatives. Stevenson Junior High lead teachers are included in decisions involved with the review of summative data. Stiggins (2002) emphasizes that teacher control is vital to the success of assessment. But all teachers are currently not participating in this vital collaborative work. Washington Junior High teachers had no clear measure of student achievement of the past year that might be analyzed to improve the next round of high stakes standardized tests. Only one teacher referred to the ISBE test reports during interviews. Stevenson Junior High was successful in increasing teachers' comfort level when using summative data because of extensive training in data management while Washington Junior High was unable to successfully institute such a procedure.

From the evidence of current trends in the literature, it is apparent that Stevenson Junior High's recent developments are more in line with new norms that are identified with a standards-based approach to school reform. Washington Junior High School, on the other hand, did not require teacher competency in the area of assessment. Whereas Stevenson Junior High had the support of their educational cooperative organization for the examination and review summative assessment, this practice was missing at Washington Junior High School

\section{Research Question 3}

What kinds of data management systems are utilized by your school district to examine and review formative assessment identifying achievement gaps and trends for various student populations? 
Stevenson Junior High School. The superintendent had full knowledge of the task of developing, collecting, training and distributing formative assessment data. The principal developed a "Standards of Promotion" program for students and parents. Students and parents are given full and current information of achievement and achievement gaps. Adopting "Standards of Promotion" allows the student to take part in the learning process. It allows students and parents to see successes and gaps in the learning.

Parents are kept informed of their children's learning at Stevenson Junior High School through parent letters, web pages and open house. The various kinds of achievement data are manipulated by a software package the Board of Education purchased years ago to help crunch data and understand how the data can help the staff make sound decisions. If a student continues to under achieve, learning gaps will be apparent. The principal has added extended school, tutoring, and additional class time for students who qualify for such help. They also have a support system of communication that keeps the parent in the learning circle. Teachers focus on academic achievement, which is articulated through high expectations for teachers, students and parents.

The principal at Stevenson Junior High School is proactive and is a visionary with a plan for student learning. The teachers feel that support and cooperation from their principal. They are using a variety of instructional techniques, because they know that different students respond differently to various instructional methods. Given the students' level of knowledge, modality of learning, and interest in the subject, a given instructional approach may or may not be effective. Since one size does not fit all, different strategies are used. Curriculum alignment, differentiated instruction and assessment is being carried out so that students are given the support and opportunity to become engaged learners. 
Washington Junior High School. Washington Junior High School has a tremendous challenge in reaching organizational capacity and managing knowledge. The Washington Junior High School continues to perform poorly. The superintendent has yet to develop a plan for a formative data management system to be incorporated into their schools plan. He has no sense of urgency and relies on the teachers and their individual grade books to track local assessment results. The assistant superintendent has a process in place that supports the teachers and encourages the teachers to keep their own formative data. She periodically meets with the teachers and instructs, supports and encourages the teachers to keep formative data in a meaningful way. The principal feels the same way as the assistant superintendent regarding the staff and letting the teachers separately manage formative data.

From teacher interviews it was determined that the teachers have a general awareness of their responsibility to identify formative data, analyze the data, and use it in a meaningful way. This awareness does not lead to collective action. For the most part, teachers work independently. There was no evidence that supports fundamental change at Washington Junior High School.

Washington Junior High School does have extended programs for low achieving students; supplemental services for Title I students, student assignment books, parent conferences, open house and remedial programs. The list mentioned has not increased traction in the academic arena at Washington Junior High School. Many teachers seem somewhat passive about these limited results. There appears to be a lack of urgency about the need for new assessment tools to advance student achievement. 
Conclusion. The effects of reviewing formative assessment and identifying achievement gaps and trends for various student populations is sharply contrasting. Stevenson Junior High School developed "Standards of Promotion," manipulating data with software, extended school, additional class time, and tutoring. In contrast, Washington Junior High has yet to developed a plan to manipulate data or identify and analyze formative data. There is no sense of urgency from the administration. The teachers at Washington are aware of the lack of direction, training, and support from their principal. The teachers perceive examination of formative assessment not as an opportunity to conduct meaningful data review, teaching, re-teaching and examination of assessment results, but as nothing more than another compliance expectation. The teachers and principal at Washington Junior High believe they have already exhausted the available school and classroom changes they thought necessary to satisfy the accountability demands and avoid threatened sanctions.

Evidence from fieldwork in this study suggest that Stevenson Junior High's experience is more in line with norms and practices of effective schools that have emerged during the past two decades.

\section{Research Question 4}

What kind of activities is your school district conducting to search and identify best instructional practices?

Stevenson Junior High School. The kind of activities Stevenson Junior High is conducting to search and identify best instructional practices starts at the very top and filters to the individual classroom teacher and students. Stevenson Junior High, along with six other school districts, belongs to an educational cooperative. This cooperative has a vision of "urgency of improvement" for their members. Member districts work 
together to create curriculum mapping, unit plan alignment, assessment framework along with summative and formative assessments and finally performance descriptors. The cooperative supports the six school districts and believes that the schools must be reinvented and transformed to meet the new mission of NCLB. The principal benefits from the support he receives from this outside support system. He is proud that their curriculum is relevant and timely. Over the past 4 years, teacher leaders from each building involved in the educational cooperative worked with a lead consultant to design a curriculum in language arts, math, science, and social studies. These curricula, also known as "intended" curricula, are aligned with Illinois state standards that are tested each year on the ISAT. There is a difference between the "intended" curriculum and the curriculum in the classroom or the "taught" curriculum (Marzano, 2003). It is the goal of the Board of Superintendents of the Thornton Fractional Educational Cooperative that the curricula are audited every year. The teacher leaders, along with the lead consultant, find the gaps of duplication in curricula, and then re-define the "taught" curriculum using the "intended" curriculum as the framework. This self-evaluation process occurs through building-based team meetings under the guidance of trained teacher leaders and administrators that belong to the educational cooperative.

Student achievement increases when the school and district have a guaranteed and aligned curriculum. With an aligned curriculum, schools can guarantee that students have an equal opportunity to learn. Students will have an equal opportunity to learn when schools and districts ensure that the intended and taught curricula are aligned to standards (Popham, 2004; Marzano, 2003). 
Interviews indicated that the principal and many teachers are interested in best instructional practices. They review assessment data and participate in new training opportunities at the cooperative, which helps them recognize critical relationships between teaching and learning. During the interviews the teachers described the junior high students as more interested in social settings than academic settings; the teachers went on to say the junior high students work best having daily scheduled routines. Teachers seem to feel that, overall, school standards, goals, and benchmarks have been set at a high standard, which requires children to work harder but also influences the staff to focus heavily on best instructional practices, test preparation, and developing good learning skills in students.

Washington Junior High School. The superintendent holds his assistant superintendent and principal responsible for searching and identifying best instructional practices for the school district.

The superintendent has an understanding and knowledge of the need for best practices and scientifically-based curriculum, and he indicated during interviews that many of the grants they receive mention these practices. (Whether any of these practices spelled out in the grants are implemented were not identified or observed in this study.)

The assistant superintendent indicated during interviews that best instructional practices by the faculty are weak and no intensity exists to build organizational capacity. She argued that the staff was union driven and they are more concerned with school schedules, plan time, release time and secondary activities than best instructional practices or continuous improvement. Teachers approach the issues of improving their instructional practices as solo practitioners who occasionally search out workshops for inspiration and new techniques. 
Conclusion. Both Washington and Stevenson Junior high schools have diverse student needs; in some ways they are similar in demographics, but the comparison stops there. Stevenson Junior High School develops instructional strategies to relate to the student, the classroom and the school. The staff work together on thematic units, current data received from student assessment and teacher performance expectations which is sustained by the team leaders and building principal. The researcher found Stevenson Junior High School had strong instructional leadership, a strong sense of mission and practiced frequent monitoring of students.

In contrast, Washington Junior High has a division between staff members and administrative staff. While individual teachers struggle with the need to improve their instruction, there is no collective agenda for the improvement of the knowledge base to meet the rigorous requirements of NCLB.

\section{Research Question 5}

Does your school district create learning teams or teacher work groups to generate successful knowledge about student results, student learning and appropriate instructional strategies that advance curriculum goals?

Stevenson Junior High School. Stevenson Junior High School has a very active plan for the teacher teams. The superintendent led the initiative to develop teacher work groups in each school several years ago. He encourages everyone to get involved including teachers, teacher aides, secretaries, board members and administration. He has two main reasons for learning teams: data analysis and student learning. The assistant superintendent refers to work groups as "demand for productivity." The principal is focused on using teacher teams to focus the school agenda on student achievement. He 
feels that teams have contributed to a positive change in the learning process since the implementation of No Child Left Behind.

The staff feels the support from the principal and they have responded to work on various topics of school improvement. Creating learning teams is an important part of the Stevenson Junior High's path to success. The teachers seem to feel that, overall, school standards, goals and benchmarks have been set at a high standard which requires children to work harder but also influences the staff to focus heavily on test preparation and developing good learning skills in students.

Washington Junior High School. At Washington Junior High School, teacher work groups do exist but there is no strong collaboration happening with the teams. Work groups have existed for several years, mentoring teams, grade level teams, leadership teams, and cross grade teams, but more recently administrators do not attend scheduled meetings or monitor their deliberations or outcomes. On the other hand, the assistant superintendent would like to see more accountability. She cited lack of training, lack of resources, and lack of curriculum path by the principal, and she has no intention of filling in for the building principal to complete these tasks.

The teachers shared with the researcher that they do support each other in their teams and work groups and help each other get through the day. No particular agenda is set and minutes of meetings are nonexistent. This analysis showed that the teachers are less concerned about the negative effects of the NCLB Act; they are more concerned with questionable focus on standardized test scores and maintaining their own credentials.

Conclusion. In terms of the professional community at Stevenson Junior High School, staff members appreciated the collaborative roles developed in the school, while 
a tone was set at Washington Junior High that staff worked in isolation as solo practitioners. In contrast to Stevenson Junior High School, the process at Washington Junior High School in reviewing evidence and making collaborative decisions is relatively infrequent and informal and lacks any sense of coordination with the principal.

\section{Research Question 6}

What kind of professional development opportunities are available to teachers who are expected to work both individually and collaboratively to achieve targeted achievement goals mandated by No Child Left Behind?

Stevenson Junior High School. Professional development, according to the superintendent, is driven by gaps found in the analysis of their student's ability to achieve learning goals. There is an on-going cycle of a 2-year long professional development program that identifies special topics or themes that address future goals for student learning. The 2-year cycle is a strong sustainable practice at Stevenson Junior High. The principal gives his staff a sense of purpose, and a shared understanding of the school mission. He helps staff see the connection between school wide goals and professional development.

Their professional development opportunities include retreats, workshops, outside consultants, curriculum mentors, literacy experts and conferences. It is all driven by results of student data. The educational cooperative that they belong to coaches teachers to make decisions with student data results. This cooperative manages six other districts and as a very large team they narrow topics to a manageable amount, decide on the most pressing topics and issues then bring in consultants that have strong backgrounds in that particular area and develop the needed program. No Child Left Behind has intensified their cooperative efforts. Professional development is an important aspect of achieving targeted goals mandated by NCLB. 
Washington Junior High School. Washington Junior High is in a holding pattern with future professional development. It is looked at as a revenue drain of the overall budget and is targeted as a first line item to be trimmed from the annual fiscal budget according to the principal. The assistant superintendent spoke of core areas and encourages staff to consider core areas when selecting outside workshops. Professional development is seen as an individual choice for off-site training and not as a collaborative effort. The principal distributes surveys to the staff and when surveys are returned to the principal a plethora of directions and themes are noted. The staff's focus at Washington Junior High changes so quickly sustainability in any meaningful direction toward school reform cannot be realized. Since there is no clear sense of direction, professional development has a limited impact in school improvement.

The teachers in this study noted they have had three different principals in the last 5 years. Along with building principal turnover they also lose new teachers at an alarming rate. These unstable conditions create the urgent need for a coherent framework that integrates school improvement endeavors with a comprehensive strategy for professional development. Unfortunately, opportunities for such developments were not apparent during the period of this field study.

Conclusion. The two junior high schools are different in that Stevenson Junior High School is more thorough and ongoing with professional development opportunities. In contrast, Washington Junior High School has random and disjointed professional development. Stevenson Junior High has shared knowledge and reflection among their staff, but Washington Junior High defines professional development as private knowledge. 
Administrative and teacher longevity is strikingly different at the two junior high schools. Stevenson has 10-plus years for district level administrators and teacher leaders, whereas Washington has a high turnover with district level administrators, principals, and teaching staff. Stevenson Junior High has targeted the critical skills needed in professional development programs that contribute to collective goals. But at Washington Junior High, professional development is stagnant and action plans break down to dispersed projects for individual teachers.

Recent studies provide examples of effective, embedded, and ongoing schoolbased professional development to support teachers, use of timely, formative and summative assessments and to inform targeted instruction that will accelerate student learning. Stevenson is moving in this direction because of a concerned staff, strong principal, and supportive superintendent. Washington Junior High School alternatively needs to move professional development toward collective goals and not just a private career channel for casual input.

\section{Emergent Findings}

This study is especially important because it views use of student performance data from the perspective of teachers in the classroom, building principals, and central office staff. It identifies some of the complex factors that contribute to teachers' decision-making and highlights the importance of organization arrangements that advance or impede collaborative opportunities to develop systematic strategies for school improvement.

There is broad consensus among school reformers that systematic use of data analysis must occur not only by administrators at the central office level, but more 
importantly, it must be embedded in schools, as teachers collectively set both schoolwide goals as well as individual goals for the students in their classrooms. The important translation from data collection to data use requires school-based leadership, the development of a school culture of inquiry, and the implementation of structures that support teachers in their ongoing learning by studying current research in their fields, planning collaboratively looking at student work, and sharing instructional strategies and tasks that have proved successful. In this field study, one school appears to have found the path that can lead to continuous development of a collaborative school that focuses on collective goals of greater student achievement. Another school has struggled with problems of leadership turnover and conventional patterns of teacher isolation that have contributed to a stalled agenda for systematic school improvement.

\section{The Kimmelman Knowledge Framework: A}

\section{Holistic Appraisal from the Field}

When Paul L. Kimmelman created his concept of a Knowledge Framework to Support School Improvement, he did so with the idea of continuous improvement as the most prominent aspect of his theory of school development. His position to build the organizational capacity of school districts calls for breaking the established bureaucratic model of school organizations and incorporating more contemporary thinking used in organizations that focus their work around teams. In education, that process calls for using teacher leaders who are trained for their leadership responsibilities and given authority to make decisions to complete their work. "That means breaking from the traditional idea that school administration is a line authority process beginning with the superintendent and going down the organizational ladder with assistant superintendent, 
principals, assistant principals, and department chairs" (p. 31). When the Knowledge Framework is applied to administrators and teachers, they must work together to enhance the organizational capacity of the school to help all students reach their full potential. The key to these new collaborative arrangements is a three-part knowledge framework.

Kimmelman "identifies organizational capacity as a three-part knowledge process" (p. xx). He goes on to write, "To successfully improve schools will require an intense effort that is necessary to acquire, manage, and implement knowledge" (p. xxi). The first step (Knowledge Acquisition) requires school leaders to collect and analyze usable evidence about student achievement, demographic characteristics of the student body and other relevant information about the school. The leaders must also search for high quality instructional programs that are based on sound research and evidenced-based practices. The second step (Knowledge Management) requires designing an information system "that makes data and information accessible and understandable" (p. 68) to classroom teachers and administrators. Two kinds of data are especially important in this information system: results from formative assessments and summative assessments. The third step (Knowledge Implementation) concerns the professional development opportunities of teachers and others who must learn new skills to master and effectively use all the knowledge generated in the first two steps. Two aspects of professional development are especially important. The professional development program must be aligned to student learning goals and the school improvement plan, and the teachers' training activities must be embedded in collegial teams and other work groups that have an immediate impact on the daily working practices of teachers. 
Are the two school districts and the two schools developing Kimmelman's framework in their efforts to implement NCLB? This question is examined by identifying the six components of the three-point Knowledge Framework found in Table 11. A threepoint developmental scale is employed to designate a continuum of development: Minimal, Partial, and Full. Kimmleman's Knowledge framework is summarized in Table 11.

Table 11

Building Organizational Capacity Through Knowledge Framework

Components of the Framework

A. Knowledge Acquisition

1. Acquiring \& Analyzing Data

2.Information: Curriculum/Instruction

$\begin{array}{ll}\text { Full Development } & \text { Minimal Development } \\ \text { Full Development } & \text { Partial Development }\end{array}$

B. Knowledge Management

3. Formative Assessments

4. Summative Assessments

C. Knowledge Implementation

5. Professional Development: Aligned to School Improvement Plan

6. Embedded in Collegial Networks
Level of Development

Stevenson Jr. High

Washington Jr. High $\begin{array}{ll}\text { Partial Development } & \text { Minimal Development } \\ \text { Partial Development } & \text { Minimal Development }\end{array}$

Full Development Minimal Development Partial Development Minimal Development

Table 11 is a summary of the detailed information reported in the research questions in Chapter IV of this dissertation. The designation of levels of development (minimal, partial, full) represents this investigator's holistic interpretation of the findings identified in observations, documents, and interviews. When all six dimensions of school development are examined holistically, a clear distinction is recognized between the two schools. Stevenson Junior High has made significant advancements in the two com- 
ponents of knowledge acquisition and professional development. All other components are at the level of partial development. Washington Junior High, on the other hand, lacks local school development in most of the components of Kimmelman's knowledge framework. The partial development in curriculum and instruction is attributed to the expertise of the assistant superintendent. Unfortunately this expert knowledge has not be shared successfully with the teachers in the school.

\section{Consideration for Further Research}

It should be noted that this study was limited to two Chicago south suburban junior high schools. Therefore, it would be very difficult to generalize the findings of this research study to the many junior high schools across the State of Illinois that have the same requirements to meet the mandates of No Child Left Behind.

Nevertheless, this study has provided meaningful data that can be used to generate conclusions and suggest recommendations for further study. The results of this study support the need for further research in the implementing of No Child Left Behind. Future investigators could choose to replicate this study in a larger sample of junior high schools that are implementing No Child Left Behind. This would expand the sample base and thus provide more external validity to the consideration of the relevant facts or evidence reached in this study. By expanding the research base, the limited evidence of this type of study's conclusions would be more valid. Such a multi-site design allows the results to be applied to a greater range of situations (Merriam, 1983).

The two case studies of this research project fall along a continuum first suggested by Rosenholtz: stuck and moving schools. The Washington Junior High School appears to be closer to a stuck school that has failed to respond to the prescription for 
improvement outlined in the NCLB Mandate. Stevenson Junior High School, on the other hand, appears to be responding to NCLB as a moving school with possibilities to continue improvement in the coming years. A case study of two schools does not allow us to know which of these schools represent the coming trends for School Development in the United States. A larger sample is needed to determine if NCLB is bringing about the needed conditions to transform stuck schools into moving schools.

\section{Implications}

Every school faces its own unique challenges. What appears to be more important than the obstacles, however, is the attitude and work of the school staff. What we do know is that what works at one school may not work at another. Schools and teachers have to be open to trying a number of different strategies before finding what is effective at their site. When schools are committed to change and experimentation, they will learn more about themselves and, in turn, develop a system for providing a quality education for their students.

Moreover, education program implementation is more complicated than other types of reform since there is an ongoing need for technical expertise, professional development, human and material resources, the appropriate political and economic climates, as well as other institutional factors. Consequently, attaining full and uniform compliance at all levels and especially in the classroom is not often possible. Teachers, administrators, and district personnel have traditionally used programs, curricula and strategies based on personal opinions and latest trends. To change that to an evidencebased form of practice involves multi-level leadership and coordination that will demand much time, consistent effort, and intensive monitoring to implement. 
While it is difficult to determine if the knowledge framework for mastering organizational cooperation and the findings of Stevenson Junior High School will be unconditionally effective and transferable at other schools, what is certain is that it takes a special group of people working cohesively and patiently for a collective vision.

Stakeholders inside and outside the school must understand that it will take tireless work, which may or may not produce positive results during the first years. What is also apparent is the lack of structure at Washington Junior High along with isolated work patterns that will have to be changed and revised to yield greater productivity for those working at the school. They need to establish a knowledge framework to support school improvement to answer the challenges of No Child Left Behind.

\section{Recommendations for Policy and Practice}

I offer the following recommendation to address the implications of implementing the mandates of No Child Left Behind while looking at the challenges facing educators who are held accountable for the academic achievement of children. This study points out that accountability policies regarding the use of formative and summative data, staff development, data management systems, and best instructional practices suggests that achievement at the two junior high schools studied is not easily attained. Individual interviews cited the misunderstanding of summative and formative data results and, in some cases, the absence of best instructional practices. Furthermore there was evidence in some instances that professional development, support, or incentives were in place to support the collection, analysis, and use of formative or summative data for making instructional decisions. To increase the collection, analysis, and use of formative data for making instructional decisions and giving students focused, individualized feedback as 
the key to accelerating learning, action is needed on all levels to shift emphasis from focusing primarily on standardized, summative tests used for accountability at the state level to meaningful and effective formative assessment at the classroom level. It is essential to change the interrelated factors of district, school, and classroom culture and teacher beliefs and experiences. These changes will require action at all levels.

The more exemplary use of data by teachers at Stevenson Junior High confirms recent research by suggesting the importance of teacher leadership (the principal delegated leadership to the teachers) and peer collaboration. The following recommendations are offered.

\section{Recommendations for District-level Leadership}

1. Design and implement better measures of student progress and better communication of this information to teachers, students and parents.

2. Enact peer-led professional development on creating, using, and learning from formative assessments.

3. Develop timely and manageable data systems for tracking and reporting progress and identifying early interventions.

\section{Recommendations for School Leadership}

1. Devote more time for teacher planning and looking at student work by: (a) content area at a single grade level; (b) content area across grade levels: and (c) interdisciplinary approach at a single grade level.

2. Develop short- and long-term classroom-based goals for student achievement that are transparent to students, teachers, parents and administrators. 
3. Provide special supports and interventions to accelerate learning for students performing below grade-level expectations.

\section{Recommendations for Classroom Teachers}

1. Develop careful initial diagnosis of each student's very specific current level of understanding, skills, interests, and learning style.

2. Develop contract or learning goals for each student.

3. Focus on importance of discovering what students already know and building upon hidden understandings rather than repeating instruction to which they have previously been exposed.

4. Develop a systematic process for using data warehouse programs that makes data and information accessible and understandable.

These recommendations represent a three-tiered strategy to develop a knowledge framework for building organizational capacity to improve schools. This field study of two junior high schools suggests much work lies ahead as policymakers continue to work to reach the lofty goals of No Child Left Behind.

\section{Conclusion to Chapter V}

Few observers of recent American history would question the generalization that the No Child Left Behind (NCLB) Act is the most comprehensive and controversial educational reform of the past half-century. It set out lofty goals of greater student achievement for all students and required extensive use of high stakes tests to demonstrate continuous improvements from one year to the next. Each state enacted new policies and procedures to implement the Federal mandate. In Illinois, the State Board of Education 
(ISBE) developed a full set of regulations and supporting arrangements to help local educators make the needed changes to assure greater learning opportunities for students.

NCLB applied to all public schools in the nation, but policymakers and school reformers were especially interested in using the power of the law to bring needed changes to schools in low income communities. Much attention was given to the sense of urgency to prod and support schools that served children of poverty. High expectations were set for NCLB as a new legislative instrument to help local educators make the necessary improvements in their schools. Superintendents, principals, and teachers were expected to make major changes in their districts and schools that would transform the learning environments for students. Seven years have passed since the enactment of NCLB. Many questions are now being raised about the effectiveness of this law to make the needed changes in America's public schools. This dissertation examined two schools that are located in the kinds of communities where the need for school improvement is often believed to be most acute. This investigator probed one of the questions that now deserves careful study: Have local school leaders made the kinds of changes for school improvement that are required by the guidelines stipulated by NCLB? This question was addressed by using the Knowledge Framework of Paul Kimmelman who identified a set of core tasks to implement NCLB.

This study answers this question with mixed results. One school (Stevenson) provides a qualified yes to making needed changes. Several steps have been taken in the past decade to suggest that the foundation has been set for further improvements. But little has happened in the other school (Washington) that meets the needed requirements of NCLB-except minimal compliance with external mandates. 
Both school districts are large enough to enjoy specialized support from the central office. They are located in an urban area with many resources for professional development opportunities and supported by regional and state programs that address specific tasks of implementing NCLB. Despite these advantages that are available to both schools, one school has failed to move forward. The needed changes have not followed in the way proponents of NCLB had expected.

What was missing? Perhaps the most important factor was the failure to develop a coherent three level system of decision-making and communication from the district office to the school and then to the classroom on all critical matters pertaining to curriculum, instruction, and assessment. Secondly, administrators and teachers failed to focus on substantive professional development that allows the improvement in the way teachers instruct and assess their students. Punitive efforts designed to scare people into change does not work. More positive effects can be gained by first bringing forward effective models of instruction that provide teachers and administrators with time to analyze data and implement change in real time, increase student engagement by lesson and unit design that brings students to higher levels of thinking, and develop essential long-term relationships between students and teachers.

Replacing school leaders does not necessarily make the job of meeting AYP more likely to be performed successfully. In schools with high needs, it is imperative that one administrator be solely focused on improving teaching and learning with no responsibility for other duties, such as discipline, transportation, and facilities. There should also be in place a teacher evaluation system that includes student achievement as part of the annual review and the evaluation system for the principal that includes school- 
wide data on discipline, student achievement, school climate, parent satisfaction, and teacher morale. This study suggests that, at least one urban school district understands Kimmelmans's ideas about a coherent three-fold knowledge system framework and is successful in implementing these ideas. 


\section{REFERENCES}

A Nation At Risk. (1983). Retrieved from http://www.ed.gov/pubs/NatAtRisk/risk.html

Abernathy, S. F. (2007). No Child Left Behind and the Public Schools. Ann Arbor: University Michigan Press.

American Association of School Administrators. (n.d.). Using data to improve schoolsWhat's working. Arlington, VA: Author.

Ashby, D., Baker, P. J., \& Rau, W. (April 2000). Achieving manageable coherence in school renewal: The Illinois core-enhancement framework for school development. Paper presented at American Educational research Association, Normal.

Azinger, A. T. \& Baker, P. J. (2003, March). Setting standards and getting results: Lessons learned from school reform. Working draft of article prepared for the Illinois School board Journal.

Baker, P. J. (1999). The leadership challenge: Caught in the middle of the school reform era. Planning and Changing, 30(3\&4), 154-174.

Baker, P. (2002, December 15). No Child Left Behind: Implications for the future of Illinois public education. Synopsis of presentation presented at the Illinois Economic Development Conference, Illinois State University, Normal. Retrieved August 22, 2004, from http://coe.ilstu.edu/edpolctr/NCLB.htm.

Baker, E. L., Betebenner, D. W., \& Linn, R. L. (2002). Accountability systems: Implications of requirements of the No Child Left Behind Act of 2001. Educational Researcher, 31(6), 3-16.

Brady, M. (2003). "Education standards flunk the why test." Florida Coalition for Assessment Reform (FCAR).

Barr, J. (2004). What do we know about teacher leadership? Findings from two decades of scholarship." Review of Educational Researck, 74(3), 255.

Black, P., \& Wiliam, D. (1998). Inside the black box: Raising standards through classroom assessment. Phi Delta Kappan, 80(2), 139-148. 
Black, P., Harrison C., Lee, C., Marshall, B., \& Wiliam, D. (2004). Working inside the black box: Assessment for learning in the classroom (electronic version). Phi Delta Kappan, 86, 9-21. Retrieved June 3, 2009, from http://www.pdkintl.org/kappan/kappan.htm

Cassidy, J., \& Cassidy, D. (2008). What's hot for 2008. Reading Today, 25(4), 1, 10-11

Creswell, J. W. (2003). Research design-Qualitative, quantitative and mixed methods approaches. Thousand Oaks, CA: Sage Publications.

DuFour, R., DuFour, R., Eaker, R., \& Many, T. (2006). Learning by doing: A handbook for professional communities at work. Bloomington, IN: Solution Tree.

Darling-Hammond, L. (1997). The right to learn. San Francisco: Jossey-Bass Inc.

Darling-Hammond, L. (2004). From "separate but equal" to "No Child Left Behind": The collision of new standards and old inequalities. In D. Meier \& G. Wood (Eds.), Many children left behind: How the No Child Left Behind Act is damaging our children and our schools (pp. 3-32). Boston: Beacon Press.

Educational Testing Service (ETS). (2005). Ready for the real world? Americans speak on high school reform. Princeton: Author. Retrieved July 6, 2006, from http://www.ets.org/Media/Education_topics/pdf/2005highschoolreform.pdf

Elmore, R. F. (2000). Building a new structure for school leadership. Washington, DC: The Albert Shaker Institute. Retrieved March 19, 2009, from http://www.ashankerinst.org/Downloads/building.pdf

Elmore, R.F., \& Rothman, R. (1999). Testing, teaching, and learning-A guide for states and school districts. National Research Council. Washington, DC: National Academy Press.

Elmore, R. (2005, Spring). School improvement requires new knowledge, not just good will. American Educator, 27.

Firestone, W. (2005). Leading coherent professional development: A comparison of three districts. Educational Administration Quarterly, 4I(3), 413.

Fullan, M., Bertani, L., \& Quinn, J. (2004, April). New lessons for district wide reform. Educational Leadership, 6I(7), 42-46.

Fullan, M., Hill, P., \& Crevola, C. (2006). Breakthrough. Thousand Oaks, CA: Corwin Press.

Guskey, T. (2000) Evaluating professional development. Thousand Oaks, CA: Corwin Press. 
Hess, F. M., Rotherham, A. J., \& Walsh, K. (Eds.). (2004). A qualified teacher in every classroom? Appraising old answers and new ideas. Cambridge, MA: Harvard Educational Press.

Johnson, J., Arumi, A. M., \& Ott, A. (2006b). Is support for standards and testing fading? (Public Agenda Reality Check 2006 No. 3). New York: Public Agenda.

Kane, T. J., Staiger, D. O., \& Geppert, J. (2002). Randomly Accountable. Education Next.

Kahn, D.S. (2006, May 26). How low can we go? The Wall Street Journal, p. W11

Kaiser, R. (2005, May 24). Focus on schools helps Finns build a showcase nation. The Washington Post, p. A12.

Kimmelman, P. (2006). Implementing NCLB, creating a knowledge framework to support school improvement. Thousand Oaks, CA: Corwin Press.

Leithwood, K., \& Riehl, C. (2003). What do we already know about educational leadership? W. A. Firestone \& C. Riehl, (Eds.). A new agenda for research in educational leadership. New York: Teachers College Press.

Leithwood, K., Lewis, K., Anderson, S. \& Wahlstrom, K. (2004). How leadership influences student learning: Review of research. New York: Wallace Foundation.

Linn, R. L. (2005). Fixing the NCLB Accountability System. CRESST Policy Brief \#8.

Marzano, R. J. (2003). What works in schools. Alexandria, VA: Association for Supervision and Curriculum Development.

Mathis, W.J. (2003). No child left behind: Costs and benefits. Phi Delta Kappan, 84(9), 679-686.

McEwan, E., \& McEwan. P. (2003). Making sense of research: What's good, what's not, and how to tell the difference. Thousand Oak, CA: Corwin Press.

Merriam, S. B. (1998). Qualitative research and case study applications in education. San Francisco: Jossey-Bass Publishers.

Mills, L. (2005, September). Show me the data. School Administrator, 62(8), 8.

National Conference of State Legislatures. (2005). Task Force on No Child Left Behind; Final Report. Washington, DC: National Conference of State Legislatures.

No Child Left Behind Act of 2001. (2001). Retrieved May 21, 2003, from http://www.ed.gov/policy/elsec/leg/esea02/index.html 
Popham, J. W. (2004). America's "failing" schools: How parents and teachers can cope with No Child Left Behind. New York: Routledge Falmer.

Popham, J. (2005). The age of compliance. Educational Leadership, 84-85.

Public Law 107-110 107 $7^{\text {th }}$ Cong. 115 Stat. 1425. No Child Left Behind Act of 2001. An Act, December 13, 2001 H.R.1.

Public Law 107-110 107 ${ }^{\text {th }}$ Cong. 115 Stat. 1425. No Child Left Behind Act of 2001. An Act, January 8, 2002 H.R.1.

Rasmussen, C., Hopkins, S., \& Fitzpatrick, M. (2004, Winter). Our work done well is like the perfect pitch. Journal of Staff Development, 25(1), 16-25.

Reeves, D. B. (2002). Holistic accountability. Thousand Oaks, CA: Corwin Press.

Richardson, V. (2003, January). The dilemmas of professional development. Phi Delta Kappan,

Riddle-Buly, M. R., Coskie, T., Robinson, L., \& Egawa, K. (2006). Literacy coaching: Coming out of the corner. Voices From the Middle, 13(4), 24-28.

Rose, L. C., E. Gallup, A. M. (2001). Phi Delta Kappa/Gallup poll: Of the public's attitudes toward the public school. Bloomington, IN: Phi Delta Kappa International retrieved June 9, 2009, from http://www.pdkintl.org/kappan/k0109gal.htm

Rose, L. C., E Gallup, A, M. (2002). Phi Delta Kappa/Gallup poll: Of the public's attitudes toward the public school. Bloomington, IN: Phi Delta Kappa International retrieved June 9, 2009, from http://www.pdkintl.org/kappan/k0309pol.htm

Rose, L. C., E Gallup, A, M. (2003). Phi Delta Kappa/Gallup poll: Of the public's attitudes toward the public school. Bloomington, IN: Phi Delta Kappa International retrieved June 9, 2009, from http://www.pdkintl.org/kappan/k0309pol.htm

Rose, L. C., E Gallup, A, M. (2004). Phi Delta Kappa/Gallup poll: Of the public's attitudes toward the public school. Bloomington, IN: Phi Delta Kappa International retrieved June 9, 2009, from http://www.pdkintl.org/kappan/k0409pol.htm

Rose, L. C., E Gallup, A, M. (2005). Phi Delta Kappa/Gallup poll: Of the public 's attitudes toward the public school. Bloomington, IN: Phi Delta Kappa International retrieved June 9, 2009, from http://www.pdkintl.org/kappan/k0509pol.htm 
Rose, L. C., E Gallup, A, M. (2006). Phi Delta Kappa/Gallup poll: Of the public's attitudes toward the public school. Bloomington, IN: Phi Delta Kappa International retrieved June 9, 2009, from http:/www.pdkintl.org/kappan/k0609pol.htm

Rose, L. C., E Gallup, A, M. (2007). Phi Delta Kappa/Gallup poll: Of the public's attitudes toward the public school. Bloomington, IN: Phi Delta Kappa International retrieved June 9, 2009, from http://www.pdkintl.org/kappan/k_v89/k0709pol.htm

Rosenhotz, S. (1989). Teachers' workplaces. New York, NY: Longman.

Slater, L. (2008). Pathways to building leadership capacity. Educational Management Administration \& Leadership 36(1), 55.

Senge, P. (1990). The fifth discipline. New York: Doubleday.

Seven years and counting. (2001, November 28). Education Week, p. 27.

Snow, C., Ippolito, J., \& Schwartz, R. (2006). What we know and what we need to know about literacy coaches in middle and high school: A research synthesis and proposed research agendas. In Standards for Middle and High School Literacy Coaches (pp. 35-49). Newark, DE: International Reading Association.

Steiner, L. (2004). Designing effective professional development experiences; What do we know $\left(2^{\text {nd }}\right.$ ed.). Naperville, IL: Learning Point Associates.

Stiggins, R. (2002). Assessment crisis: The absence of assessment for learning. Phi Delta Kappan, 83. P. 758

The Education Trust. (2004, August 27). The ABCs of "AYP" beyond any doubt: We can do this. Retrieved from http://www.2.edtrust.org/EdTrust/Press+Room/new+ayp+abc.htm

The Education Trust. (2007, October 31). What will happen if a school does not make adequate progress? Washington, DC: Author.

Tiwana, A. (2000). The knowledge management toolkit. Upper Saddle River, NJ: Prentice Hall.

Tiwana, A. (2001). The influence of knowledge integration on project success: An empirical examination of E-Business Teams. Dissertation, Georgia State University. Retrieved June 17, 2009, from http://proquest.umi.com.proxy.lib.ilstu.edu

U.S. Department of Education. (2005, February). A guide to education and No Child Left Behind. Retrieved October 1, 2007, from http://www.ed.gov/print/nclb/overview/intro/guide/guide.html 
U.S. ED (2004). Standards and Assessments Peer Review Guidance: Information and Examples for Meeting Requirements of the No Child Left Behind Act of 2001. Accessed April 21, 2009, from

http://www.ed.gov/admins/lead/account/saa.html\#examples

U.S. ED (n.d.). Decision Letters on Each State's Final Assessment System Under No Child Left Behind (NCLB). Accessed April 21, 2009, from http://www.ed.gov/admins/lead/account/nclbfinalassess/index.html 


\section{APPENDIX}

COOK COUNTY SCHOOL DISTRICTS SAMPLED 


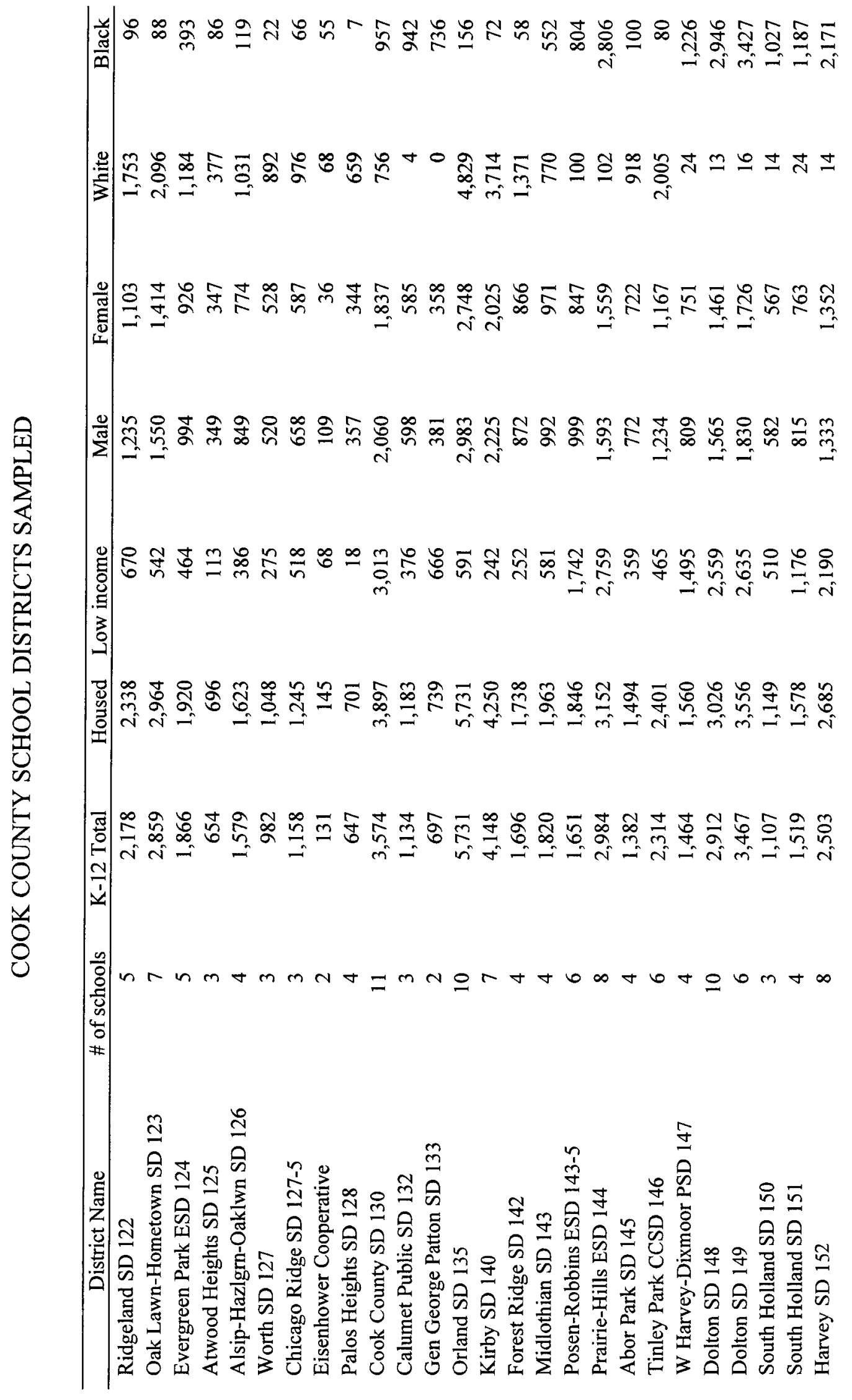




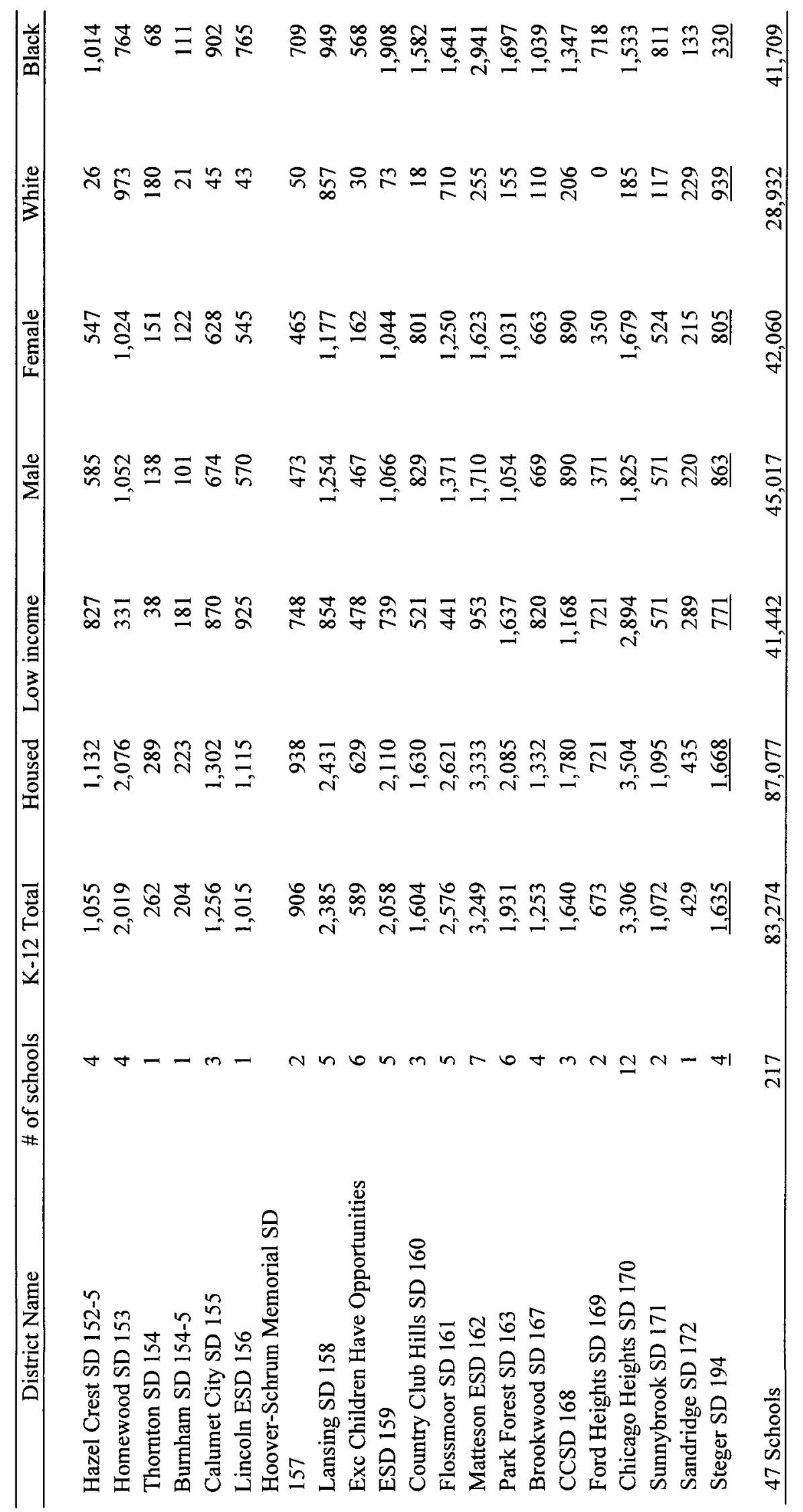

